\title{
Ozone Reductions Using Residential Building Envelopes
}

\author{
Iain Walker, Max Sherman and William W. Nazaroff \\ Environmental Energy Technologies Division \\ Indoor Environment Department \\ Lawrence Berkeley National Laboratory \\ Berkeley, CA 94720
}

February 2009

The research reported here was supported by the California Energy Commission Public Interest Energy Research program award number CEC-500-02-004, and the Assistant Secretary for Energy Efficiency and Renewable Energy, Office of the Building Technologies Program, U.S. Department of Energy under Contract No. DE-AC02-05CH11231. 


\section{Ozone Reductions Using Residential Building Envelopes}

Prepared For:

California Energy Commission Public Interest Energy Research Program

Prepared By:

Lawrence Berkeley National Laboratory

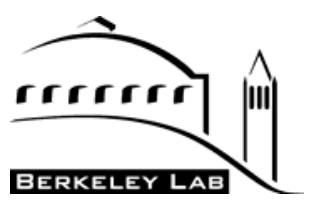

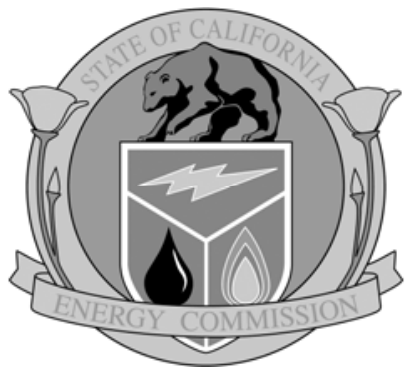

Arnold Schwarzenegger Governor

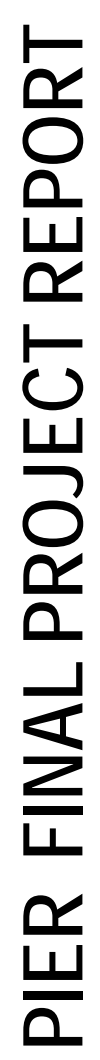




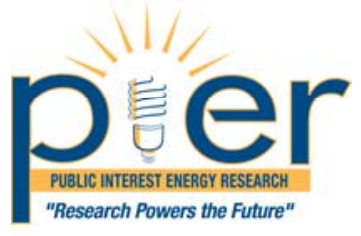

\author{
Prepared By: \\ Lawrence Berkeley National Laboratory \\ Project Manager: lain Walker \\ Authors: Iain Walker, Max Sherman and William W. Nazaroff \\ Berkeley, CA 94720 \\ Commission Contract No. 500-02-004 \\ Commission Work Authorization No: Insert: \#
}

Prepared For:

Public Interest Energy Research (PIER)

California Energy Commission

Ed Vine

Contract Manager

Insert: Program Area Lead Name

Program Area Lead

Insert: Program Area Name

Insert: Office Manager Name

Office Manager

Insert: Office Name

Martha Krebs

PIER Director

Thom Kelly

Deputy Director

ENERGY RESEARCH \& DEVELOPMENT DIVISION

Melissa Jones

Executive Director

\title{
DISCLAIMER
}

This report was prepared as the result of work sponsored by the California Energy Commission. It does not necessarily represent the views of the Energy Commission, its employees or the State of California. The Energy Commission, the State of California, its employees, contractors and subcontractors make no warrant, express or implied, and assume no legal liability for the information in this report; nor does any party represent that the uses of this information will not infringe upon privately owned rights. This report has not been approved or disapproved by the California Energy Commission nor has the California Energy Commission passed upon the accuracy or adequacy of the information in this report.

The research reported here was supported by the California Energy Commission Public Interest Energy Research program award number CEC-500-02-004, and the Assistant Secretary for Energy Efficiency and Renewable Energy, Office of the Building Technologies Program, U.S. Department of Energy under Contract No. DE-AC02-05CH11231. 


\section{Disclaimer}

This document was prepared as an account of work sponsored by the United States Government. While this document is believed to contain correct information, neither the United States Government nor any agency thereof, nor The Regents of the University of California, nor any of their employees, makes any warranty, express or implied, or assumes any legal responsibility for the accuracy, completeness, or usefulness of any information, apparatus, product, or process disclosed, or represents that its use would not infringe privately owned rights. Reference herein to any specific commercial product, process, or service by its trade name, trademark, manufacturer, or otherwise, does not necessarily constitute or imply its endorsement, recommendation, or favoring by the United States Government or any agency thereof, or The Regents of the University of California. The views and opinions of authors expressed herein do not necessarily state or reflect those of the United States Government or any agency thereof, or The Regents of the University of California.

Ernest Orlando Lawrence Berkeley National Laboratory is an equal opportunity employer. 


\section{Table of Contents}

1.0 Abstract ......................................................................................................................... 2

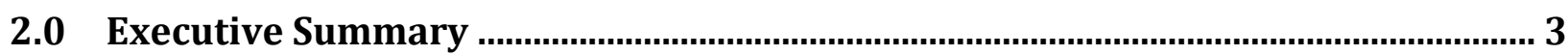

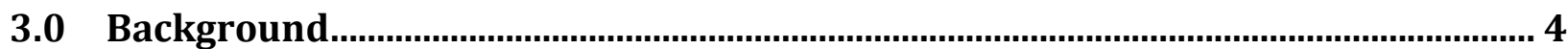

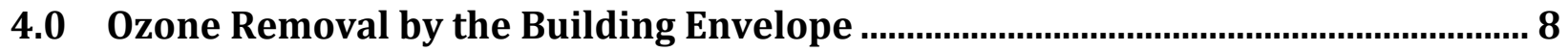

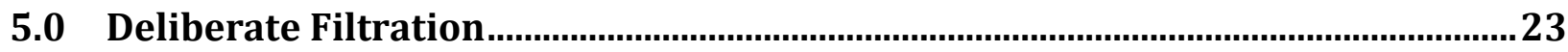

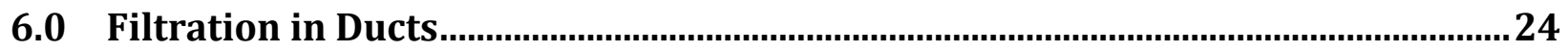

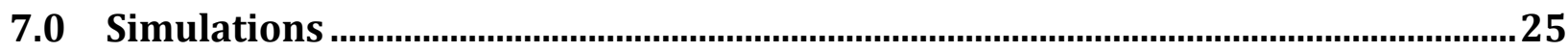

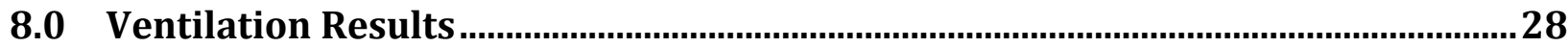

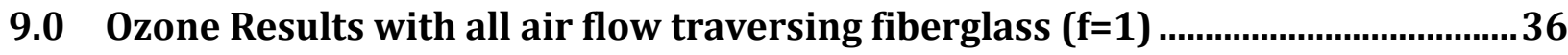

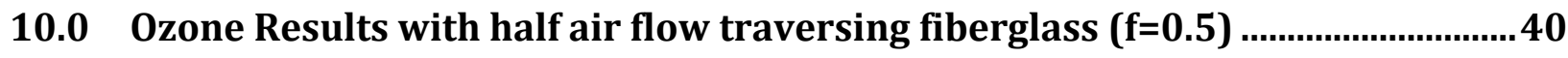

11.0 Results and Discussion............................................................................................48

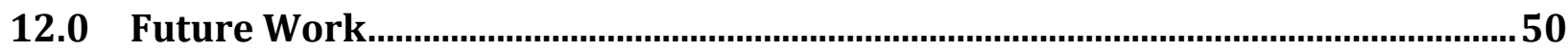

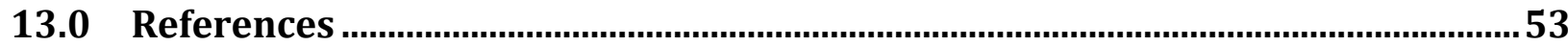

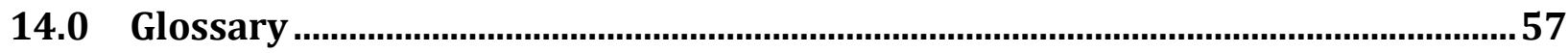

15.0 Ozone reactions with indoor materials: A bibliography ......................................58 


\subsection{Abstract}

Ozone is an air pollutant with that can have significant health effects and a significant source of ozone in some regions of California is outdoor air. Because people spend the vast majority of their time indoors, reduction in indoor levels of ozone could lead to improved health for many California residents. Ozone is removed from indoor air by surface reactions and can also be filtered by building envelopes. The magnitude of the envelope impact depends on the specific building materials that the air flows over and the geometry of the air flow paths through the envelope that can be changed by mechanical ventilation operation. The 2008 Residential Building Standards in California include minimum requirements for mechanical ventilation by referencing ASHRAE Standard 62.2. This study examines the changes in indoor ozone depending on the mechanical ventilation system selected to meet these requirements. This study used detailed simulations of ventilation in a house to examine the impacts of different ventilation systems on indoor ozone concentrations. The simulation results showed that staying indoors reduces exposure to ozone by $80 \%$ to $90 \%$, that exhaust ventilation systems lead to lower indoor ozone concentrations, that opening of windows should be avoided at times of high outdoor ozone, and that changing the time at which mechanical ventilation occurs has the ability to halve exposure to ozone. Future work should focus on the products of ozone reactions in the building envelope and the fate of these products with respect to indoor exposures.

Keywords: Ozone, Title 24, mechanical ventilation, filtration, ASHRAE Standard 62.2, building envelope, infiltration, simulation 


\subsection{Executive Summary}

This report summarizes results of a literature review, development of an ozone deposition model for building envelopes, and ventilation/ozone simulations. The model was used to compare the effects of different mechanical ventilation systems on indoor ozone concentrations.

The following five key conclusions result from the modeling, simulation and analysis:

- Staying indoors significantly (by $80 \%$ to $90 \%$ ) reduces exposure to ozone - even when mechanical ventilation systems are operating (as long as the air exchange is low) due to a combination of envelope filtration and interior deposition.

- Using a continuous supply fan for ventilation air limits envelope filtering and results in the highest indoor concentrations of ozone at about $7 \%$ of the outdoor concentration.

- The higher ventilation rate for a heat recovery ventilator (HRV) results in greater indoor concentrations of ozone

- Reduced ventilation rates during the peak outdoor ozone periods when economizers are used result in lower concentrations of ozone

- Open windows and the resulting unfiltered high ventilation rate significantly reduces the benefits of being indoors.

Recommended future activities are:

- Investigate the use of optimized ventilation strategies and air tightening to mitigate indoor ozone

- A more in-depth analysis of the health benefits and risks of economizers or natural ventilation used to reduce cooling loads in different California climates

- Further examination of the byproducts of ozone reactions with building materials (such as insulation) and simulating the byproduct formation and indoor levels of byproducts from ozone-initiated chemistry

- Evaluation of the deliberate ozone removal using activated carbon

- Studies of airflow through walls and ceilings to discern to what extent air flows through insulation

- Laboratory or field measurement of ozone penetration for typical envelope assemblies to allow better separation of envelope filtration from interior deposition

- Development and testing of construction materials specially developed to reduce ozone entry into residences by envelope filtration with minimal formation of volatile byproducts 


\subsection{Background}

Ozone is an air pollutant with that can have significant health effects and a significant source of ozone in some regions of California is outdoor air (California Air Resources Board (2005)). Because people spend the vast majority of their time indoors, reduction in indoor levels of ozone could lead to improved health for many California residents.

The 2008 Residential Building Standards in California include minimum requirements for mechanical ventilation by referencing ASHRAE Standard 62.2"Ventilation and Acceptable Indoor Air Quality in Low-Rise Residential Buildings". These minimum requirements are based on the dilution of indoor pollutants with outdoor air. In this study, the opposite issue is examined: the contaminants (ozone in particular) are in the outdoor air, and their entry into a building needs to be limited or controlled. ASHRAE stands for American Society for Heating Refrigeration and Air-conditioning Engineers. ASHRAE is an engineering society that writes standards for many aspects of building performance. These standards are approved by ANSI (American National Standards Institute) and are prepared and developed using the best knowledge available to the industry by following ANSI procedures for voluntary consensus standards.

There are three key components to air flow in and out of residences: infiltration, natural ventilation and mechanical ventilation. Most homes experience infiltration - this is air flows through the small cracks in a building envelope (walls, floor, ceiling, around doors and windows, etc.) and is driven by wind and the temperature differences between inside and outside the home (called stack effect). Air flow through a deliberate opening (typically a window) due to wind and stack effects is called natural infiltration. If a fan is used to bring air into a house or exhaust it from a house this is called mechanical ventilation. A device called a Heat Recovery Ventilator (HRV) is designed to both exhaust and supply air to a home. A heat exchanger in the HRV is used to temper the incoming air. This is particularly useful in cold winter months when the outgoing air is used to preheat the incoming air and is a useful energy saving feature. An economizer is used when it is hot during the daytime but cooler at night. The economizer brings in a large quantity of outdoor air (using the furnace fan) into the home and pre-cools it with cool outdoor air. This can save on air conditioning energy and costs. Typical air flows for infiltration are about $100 \mathrm{cfm}$ (cubic feet per minute). The mechanical fan driven air flows required to comply with ASHRAE Standard 62.2 are typically less than this for most homes. The air flows are significantly higher (1000 cfm or more) for economizers and require that deliberate vents are opened in the house for pressure relief.

In addition to deposition and reaction with interior surfaces, ozone can be filtered by building envelopes that depend on particular ventilation system and envelope characteristics.

Laboratory studies have indicated that ozone filtration by building envelopes can occur (Lui and Nazaroff (2001)). The magnitude of this reduction is highly variable and ranges form zero to $90 \%$ and depends on the specific building materials that the air flows over and the geometry of the air flow paths through the envelope. This is linked to the effect that different mechanical ventilation systems have on the air flow paths for entry of air into a building. For example, compare a continuous supply ventilation system to a continuous exhaust ventilation system. 
For the supply system, the outdoor air does not pass through the envelope - instead air enters the building via a fan and its associated ducting. In this case, filtration may occur at dedicated outdoor air filters, or by deposition on the ducting used to deliver the air. For the exhaust system, air enters through leaks in the building envelope and leaves via a fan and its ductwork. In this case, any filtration of air entering the building occurs in the flow paths in the building envelope. Another mechanical ventilation system characteristic is the ability to change the ventilation rate with time. In particular, the ventilation rate could be reduced during times of high outdoor ozone concentration and then increased at other times in order to meet the minimum requirements. The effect of lowering ventilation rates at peak outdoor ozone times can also be examined.

This study quantifies through modeling estimates, the impact on indoor ozone concentration of ozone removal by reaction with building materials that line cracks and other points of entry. This study focuses on residential buildings and the particular envelope air flow paths and ventilation systems used in residences in California. The objectives of this study are to:

- Develop a model combining flows through individual air flow paths with deposition of ozone on different material surfaces and flow paths. The model predictions for indoor ozone will be validated by comparison to measured field data.

- Use this model to examine the changes in indoor ozone concentrations due to the use of different mechanical ventilation systems.

- Based on the simulation results provide recommendations for limiting penetration of outdoor ozone.

- Make suggestions for possible future research on ozone in residences.

There are four key ventilation/filtration parameters for control of ozone entry that will be addressed:

1. Quantity of air flow. Generally, less air flow means less ozone transported into the building. This must be balanced with the requirements of ASHRAE Standard 62.2 minimum ventilation requirements for dealing with indoor pollutants. This must also be balanced by the desire to reduce air conditioning loads (energy use) through increased natural ventilation or use of economizers.

2. Time of operation. ASHRAE Standard 62.2 allows ventilation rates to change with time so long as various criteria are met. This allows for the possibility of reduced ventilation rates at times of high outdoor ozone concentrations, with increased ventilation at other times. Since urban ozone exhibits a strong diurnal profile, this strategy may offer a practical means to improve indoor air quality and reduce energy use.

3. Air flow path. This includes details of the air flow geometry for air flowing through the building envelope (including cracks, ducts, supply air filters, etc.) and relating envelope construction details to air flow path geometry and deposition. This changes the potential for deposition in the various air flow paths. 
4. Flow path materials. Laboratory testing has shown that different materials react with ozone at different rates and generate different reaction products. The different reaction rates lead to changes in filtration potential. This study evaluated the effect of different mechanical ventilation systems on the air flow path and associated envelope materials.

\subsection{Field Measurements of Ozone in Homes}

The ratio of indoor to outdoor ozone concentrations has been measured in several studies. Weschler (2000) reports an extensive summary of indoor-outdoor ozone concentration ratios measured in about 60 studies covering a wide range of buildings. Concentrating on homes, Avol et al. (1998) reported indoor to outdoor concentrations of $0.37 \pm 0.25$ for 136 southern California homes. Romieu et al. (1998) reported ratios of $0.20 \pm 0.18$ in 145 Mexico City homes. A complication in interpreting the indoor to outdoor ozone concentration ratio was that many of the homes had open windows during sampling. Focusing on air-conditioned homes with closed windows (as was done for this study), the resulting indoor-outdoor concentration ratio is about 0.1 due to lower air-exchange rates and possible envelope filtration (there is no filtration for air flow through an open window) (Lee et al. (1999 and 2004) and Stock et al. (2004)). These measured values will be used as a reference for the simulations. Given the large ranges found in these studies, a target range of indoor to outdoor ozone concentration ratios is about 0.05 to 0.4. So long as the ratios are within this reasonable range, this study will then concentrate on the relative changes in indoor concentration depending on the ventilation technique employed.

In rough terms, not accounting for envelope deposition, the indoor:outdoor ratio of the time averaged concentrations is given by $a /(a+k)$, where $a$ is the air-exchange rate and $k$ is the deposition factor. The deposition factor has been determined in many studies (as summarized by Weschler (2000)). The most relevant for houses were the 43 homes evaluated by Lee et al. (1999) that. The mean deposition factor over all the houses was (referred to as surface removal rate) 2.8 per hour - with significant variation from house to house leading to a standard deviation of 1.3 per hour. So, the 0.05 to 0.4 range of indoor:outdoor ozone concentration ratios corresponds to air-exchange rates in the range 0.15 to 2 per hour if envelope deposition is ignored. In the 43 California homes studied by Lee et al. (1999), ozone was deliberately introduced, and the decay rate was monitored. The effect of infiltration was subtracted from the measured decay rate. The houses were very tight - the LBNL infiltration model (Sherman and Grimsrud (1980)) was used on actual blower door data from the houses to estimate a $4 \mathrm{~Pa}$ air exchange at 0.05 Air Changes per Hour $(\mathrm{ACH})$ or less during the testing. The HVAC did not run during the testing ${ }^{1}$.

Overall, these field measurements suggest that interior deposition is a significant contributor to reductions of indoor ozone concentration. This has the effect of lowering the mean values of indoor ozone concentrations. So, although this study focuses on the differences in indoor

${ }^{1}$ The results in Table 3 of Weschler (2000) and the study by Sabersky et al. (1973) showed values of interior deposition coefficient of 2.9 for no forced air and 5.4 with forced air. 
concentration due to envelope deposition, it is important to realize that interior deposition has a significant effect on the indoor ozone concentration.

\subsection{Simulations of indoor ozone concentration}

The simulations used in this study an existing ventilation, heat transfer and Heating, Ventilating and Air Conditioning (HVAC) equipment simulation tool called REGCAP that has been used in several previous studies of HVAC systems (most recently Walker and Sherman (2006), Sherman and Walker (2008) and Lstiburek et al. (2007)). This tool allowed minute-byminute simulations of HVAC systems, so that complex timing algorithms may be simulated. For this study, a timestep of one minute was used. The simulations were performed over a time period of a couple of days to a week coinciding with high outdoor ozone concentrations.

The indoor ozone estimates were based on a mass balance model that depends on air flows in and out of the building, the incidental filtration provided by individual air flow paths, deliberate filtration by the HVAC system, and deposition on interior surfaces. It was assumed that there is no significant internal generation of ozone, and gas-phase reactions with other airborne chemicals were ignored. These assumptions are acceptable given that the purpose of this study is to compare different ventilation techniques and strategies relative to each other. The following differential equation was used to describe the rate of change of indoor ozone concentration with time:

$$
\frac{d C_{O_{3}, \text { in }}}{d t}=\sum_{i} F_{O_{3}, i} Q_{\text {in }, i} C_{O_{3}, \text { out }}-Q_{\text {out }} C_{O_{3}, \text { in }}-k C_{O_{3}, \text { in }}-\eta Q_{h} C_{O_{3}, \text { in }}
$$

Where, Co3,in is the indoor ozone concentration, $\mathrm{Co3}_{\text {,out }}$ is the outdoor ozone concentration, Fo3,i is the penetration factor of ozone for leak path $\mathrm{i}$ (including filtration for supply air), $\mathrm{Q}_{\mathrm{in}, \mathrm{i}}$ is the air flow into the house (in $\mathrm{ACH}$ ) through crack i, Qout is the air flow out of the house (in $\mathrm{ACH}$ ), $\mathrm{Q}_{\mathrm{h}}$ is the air flow through the HAVC system expressed in terms of $\mathrm{ACH}\left(\mathrm{h}^{-1}\right), \mathrm{k}$ is the indoor deposition factor $\left(\mathrm{h}^{-1}\right)$, and $\eta$ is the ozone removal efficiency on HVAC system filters. $\eta$ is set to $5 \%$ (a reasonable value from Hyttinen et al. (2006)) when the HVAC system is on. Some simulations were repeated with $\eta$ set to $10 \%$ to simulate a high performance filter and to $95 \%$ to simulate an activated carbon filter.

The air flows were assumed to be quasi-steady over the short time period of one minute for the simulation steps. Equation 2 was used for the minute-by-minute calculation of indoor ozone.

$$
C_{O_{3}, \text { in }}(t)=C_{O_{3}, \text { in }}(t-1)+\Delta t\left(\sum_{i} F_{O_{3}, i} Q_{\text {in }, i}(t) C_{O_{3}, \text { out }}(t)-C_{O_{3}, \text { in }}(t-1)\left(Q_{\text {out }}(t)+k+\eta Q_{h}\right)\right)
$$

Where $\Delta t$ is the timestep (one minute in these simulations).

The air flows were converted from the mass flows generated in the ventilation simulations using the indoor and outdoor air density and house volume. 


\subsection{Ozone Removal by the Building Envelope}

Ozone is a reactive gas and a strong oxidizer. It interacts with surfaces with which it comes into contact; in the process, ozone is destructively consumed. Surface reactions for ozone are significant in determining the amount of ozone removed from the air. These chemical reactions also give rise to various reaction products, some of which are volatile. The net effect of reducing ozone and increasing byproduct concentrations may, or may not, lead to improved indoor air quality. This would depend on the byproduct yields and on the relative toxicity of the byproducts formed in relation to that of ozone. In this study, specific chemical reactions and the potential health issues relating to the ozone reaction products were not addressed because this is beyond the scope of the current study. Studies of how ventilation systems would influence indoor concentrations of ozone byproducts remain a key research topic for the future. Instead, this work focused on the reduction of ozone entering the home. Section 12 of this report discusses future work in more detail - with a particular focus on the reaction products.

The extent of ozone penetration through building envelopes depends on air flow velocity, crack geometry, and reaction probabilities ${ }^{2}$ on the surface. There are two types of flow path that differ significantly. The first is for air flowing through insulation in wall cavities or ceilings. The second is for flow in cracks.

The ozone deposition calculations for the building envelope were based on previously published work (Morrison et al., (1998) Liu and Nazaroff (2001)). Different performance parameters related to ozone removal were assigned to the different leakage paths in the building envelope depending on their geometry and construction materials.

In future work, it might be possible to consider two additional studies:

(a) simulating byproduct formation and indoor levels of byproducts from ozoneinitiated chemistry; and

(b) deliberate ozone removal using activated carbon.

Study (a) would require the application of knowledge on ozone reactions to the ozone deposition information produced by the simulations. Study (b) would require additional simulations using a $95 \%$ efficient HVAC filter in place of the $5 \%$ filter.

These studies would point to important future directions. First, envelope filtration of ozone is useful if the production of toxic or other undesirable byproducts is minimized, but it would not be useful if these byproducts are substantially formed. Second, activated carbon is an effective control technology. Building-scale (possibly even residential-scale) control of ozone might make sense for modern housing in high-ozone areas.

\footnotetext{
${ }^{2}$ The reaction probability is the likelihood that ozone reaching a surface undergoes a chemical reaction with the surface. If reaction probability is high then any ozone reaching the surface is likely to react with the surface and be removed.
} 


\subsection{Envelope Leakage Flow Paths}

The air flow through the envelope was split among several air flow paths based on the geometry and the materials that form the walls of the crack. The assumed total envelope leakage was based on Title 24 (California's residential building energy code) default with a Specific Leakage Area of 4, corresponding to a flow coefficient (C) of $0.067 \mathrm{~m}^{3} / \mathrm{sPa}^{\mathrm{n}}$ for the Title 24 default house simulated in this study. The envelope pressure exponent was assumed to be 0.67 and was assumed to be the same for all leaks. The envelope leakage distribution was assumed to be $15 \%$ at floor level, $50 \%$ in the walls and $35 \%$ in the ceiling (based on ASHRAE Fundamentals 2005 Ch. 27). The wall and floor level leakage was split into four equal parts one for each face of the building. The wall flow was treated as distributed leakage in the ventilation calculations, so there can be both inflow and outflow for each of the four wall surfaces. For the floor level and ceiling leaks, all the flow was either in or out.

The removal of ozone by the building envelope was separated into two main categories corresponding to different air flow paths: flow through cracks and flow through insulation. The floor level leakage was assumed to flow through cracks, and the wall and ceiling flows are through insulation.

The crack air flow paths have dimensions that can be characterized by the envelope pressure exponent. The pressure exponent for the leaks determines the characteristic dimensions and the flow velocities that are needed in the deposition calculations. This deposition depends on the ozone reactions with the crack surfaces that could be different for each air flow path. The ozone surface reaction probability $(\gamma)$ is about $10^{-6}$ (Cano-Ruiz et al. 1992) for many building envelope materials such as wood and polyvinyl chloride (PVC), but is an order of magnitude (or more) higher for concrete and brick surfaces. This implies that the air flow entering the building should be separated into flow through cracks in the walls and ceiling, and flow through floor levels leaks where one surface is the concrete foundation slab. Because the essential knowledge regarding the split of leaks of different pressure exponents is unknown, it was assumed that they all have the same exponent (Walker et al. (1998) have shown that pressure exponent is relatively constant over the pressure range of interest for filtration air flow).

\section{Crack at floor level around the floor plate.}

This crack was split in to four parts for the air flow model - one for each face of the building. The air flow could be inward or outward for each of the four parts independently, and the flow direction was tracked separately by the air flow model. This flow path has two faces: the wood of the framing and the concrete of the slab/foundation. It is important to look at these two faces because the ozone deposition to the materials is substantially different.

The air flow velocity was determined based on the pressure exponent. The following analysis to determine characteristic dimensions and flow velocities was based on the equations presented by Sherman (1992).

Sherman introduced the "S" factor that non-dimensionalizes the pressure across the leak relative to the critical pressure, $P_{c}$. At the critical pressure, the pressure drop due to fully developed laminar flow is equal to the pressure drop due to entry and exit effects. For the 
assumed exponent of $2 / 3$, the $S$ factor is equal to one. Using a typical crack pressure difference of $2 \mathrm{~Pa}$ as the critical pressure, the following relationship relates the crack length to its area (assuming it is a round section tube).

$$
P_{c} \equiv \frac{512 \pi^{2} \mu^{2} L^{2}}{m \rho A^{2}}
$$

Where $\mu$ is the viscosity of air $\left(1.8 \times 10^{-5} \mathrm{~kg} / \mathrm{ms}^{2}\right.$ for room temperature, sea level air), $\mathrm{L}$ is the crack length $(\mathrm{m}), \mathrm{m}$ is factor that has been measured in laboratory studies to have a value of 2.16 to 2.41 (following Sherman's analysis a value of 2.28 was used), $\rho$ is the air density $\left(1.2 \mathrm{~kg} / \mathrm{m}^{3}\right)$ and A is the crack area $\left(\mathrm{m}^{2}\right)$.

Substituting these values and rearranging Equation 3, results in a relationship relating crack length to area (and critical pressure):

$$
\frac{L}{A}=1293 \sqrt{P_{c}} \text { or } A=\frac{L}{1293 \sqrt{P_{c}}}
$$

With a critical pressure of $2 \mathrm{~Pa}$ and a crack length of $0.15 \mathrm{~m}$ the crack area is $0.000082 \mathrm{~m}^{2}$ corresponding to a crack diameter of $10 \mathrm{~mm}$.

To determine the flow velocity, $Q$, the volumetric air flow was calculated:

$$
Q=\frac{8 \pi v L}{m}(\sqrt{1+8 S}-1)
$$

where $v$ is the kinematic viscosity ${ }^{3}$ of air $\left(1.5 \times 10^{-5} \mathrm{~m}^{2} / \mathrm{s}\right)$.

Substituting the values above for $\mathrm{L}, \mathrm{m}$ and $\mathrm{S}$ (set to 1 ):

$$
Q=0.000331 L
$$

Combining Equations 4 and 6 results in an expression for velocity as a function of characteristic pressure:

$$
U=\frac{Q}{A}=\frac{0.000331 L}{\frac{L}{1293 \sqrt{P_{c}}}}=0.426 \sqrt{P_{c}}
$$

With a critical pressure of $2 \mathrm{~Pa}$, the mean air speed is $0.6 \mathrm{~m} / \mathrm{s}$.

\section{Ozone Penetration for Cracks}

The relationships used to determine ozone penetration in cracks were taken from the analysis given by Liu and Nazaroff (2001). The penetration factor ( $\left.\mathrm{FO}_{3}\right)$ for ozone in cracks was given by:

$$
F_{O 3}=\exp \left(\frac{-2 V_{0} L}{U d}\right)
$$

where $V_{o}$ is the deposition velocity ${ }^{4}$ and $d$ is the crack height $(\mathrm{m})$.

${ }^{3}$ Kinematic viscosity is the absolute viscosity divided by density. 
The deposition velocity is the term that includes the reaction probability. It has two components: the surface-uptake-limited deposition velocity ${ }^{5}, \mathrm{~V}_{\mathrm{s}}$, and the mass-transport-limited deposition velocity ${ }^{6}, \mathrm{~V}_{\mathrm{t}}$. They are related as follows:

$$
V_{0}=\frac{V_{s} V_{t}}{V_{s}+V_{t}}
$$

The surface-uptake-limited deposition velocity is given by:

$$
V_{s}=\frac{\gamma<V>}{4}
$$

where $<\mathrm{V}>$ is the Boltzman velocity ${ }^{7}$, which is about $360 \mathrm{~m} / \mathrm{s}$ at $293 \mathrm{~K}$ for ozone, and $\gamma$ is the reaction probability. The reaction probability depends on the surface properties.

Some values for ozone-surface reaction probability that are useful for these building envelope calculations are:

For glass fibers:

$\gamma=6 \times 10^{-6}$ for freshly exposed glass fibers from Lui and Nazaroff (2001) - with a surface uptake deposition velocity of $5.4 \times^{-4} \mathrm{~m} / \mathrm{s}$.

For concrete:

$\gamma=4.4 \times 10^{-5}$ to $10^{-4}$ for outdoor surfaces and $7.9 \times 10^{-5}$ for a slab from Simmons and Colbeck (1990). Given this range a central value of $5 \times 10^{-5}$ was selected for concrete faced cracks.

For plywood (using the same value for wood surfaces):

$\gamma=4.7 \times 10^{-6}$ to $5.8 \times 10^{-7}$ from Sabersky et al. (1973). A central value of $1 \times 10^{-6}$ was used in the calculations.

More recent work has included more thorough measurements for wood and concrete and gives values of surface uptake deposition velocities directly:

- $0.00080 \mathrm{~m} / \mathrm{s}$ for coarse concrete and $0.00017 \mathrm{~m} / \mathrm{s}$ for fine concrete (Grontoft and Raychaudhuri (2004)) at 50\% RH.

- $0.00022 \mathrm{~m} / \mathrm{s}$ for untreated unfinished wood at 50\% RH (Grontoft and Raychaudhuri (2004)).

${ }^{4}$ Deposition velocity is the velocity at which particles or molecules migrate to a surface and depends on molecular interactions.

${ }^{5}$ Surface uptake velocity depends on the reaction rates at the surface.

${ }^{6}$ The mass transport deposition velocity depends on the fluid mechanics of the boundary layer at the surface and how particles or molecules are transported towards the surface due to fluid motion past or over the surface.

${ }^{7}$ Boltzmann velocity is the average speed of the molecules (in this case ozone) in the gas phase and governs diffusion within gases. This is not the same as the average speed of the bulk flow. 
- Deposition velocity for gypsum wall board is given by Kleno et al. (2001) as $0.0012 \mathrm{~m} / \mathrm{s}$.

Grontoft and Raychaudhuri (2004) showed that the deposition velocities varied over a range of approximately a factor of two for most building materials as relative humidity varied from $0 \%$ to $90 \%$. The variation in deposition velocity with humidity is non-monotonic and can either increase or decrease with humidity. The values used in these simulations were mid-point values at $50 \% \mathrm{RH}$.

Grontoft (2002) discussed the reduction in deposition velocity for successive tests of an individual sample. This implies that the deposition rate will vary depending on the deposition history of the surface. The decrease reported by Grontoft was about $20 \%$ for concrete floor tile. Given the paucity of data on the reduction in deposition velocity, particularly for the materials of interest in this study, this effect was ignored. In addition, there are sure to be variations in deposition velocity with temperature, and, again because of the lack of necessary data, these effects were ignored. The values used in the current study are those at steady state and use the following equations from Liu and Nazaroff (2001).

The mass-transport-limited deposition velocity is given by:

$$
V_{t}=-\ln \left(X_{d}\right) \frac{U d}{2 L}
$$

where $X_{d}$ is determined from an equation linking Brownian diffusion to crack geometry and air flow rate:

$$
\phi=\frac{4 D L}{d^{2} U}
$$

where $\mathrm{D}$ is the molecular diffusion coefficient of ozone in air $\left(1.82 \times 10-5 \mathrm{~m}^{2} / \mathrm{s}\right)$.

$$
X_{d}=0.915 \exp (-1.885 \phi)+0.0592 \exp (-22.3 \phi)+0.026 \exp (-152 \phi)
$$

For all but the largest concrete faced cracks, the air flows and crack geometries of interest in this study result in deposition velocities that are limited by the surface-uptake deposition velocity that is typically and order of magnitude lower than the mass transport velocity. For example, a wood faced crack at $0.1 \mathrm{~m} / \mathrm{s}$ has a surface uptake velocity of $0.00023 \mathrm{~m} / \mathrm{s}$ and a mass transport velocity of $0.007 \mathrm{~m} / \mathrm{s}$.

For a flow path through a wood-faced envelope crack, the ozone penetration for three different crack heights is shown in Figure 1. The results in Figure 1 show that for the larger leak characteristic of $10 \mathrm{~mm}$ (as determined in the "S" factor analysis) the penetration factor is greater than $95 \%$ under typical conditions (air velocity $>0.1 \mathrm{~m} / \mathrm{s}$ ). For concrete, the higher reaction probability results in less ozone penetration, as shown in Figure 2.

Figure 1a shows the ozone penetration factor for different leak velocities for three orders of magnitude to show how it drops off. In practice, however, the lower decades would never be relevant because the quantity of ozone transported at these low velocities is insignificant 
regardless of the penetration factors. Therefore, in Figure 1b, the same data using a linear air velocity scale was shown. 


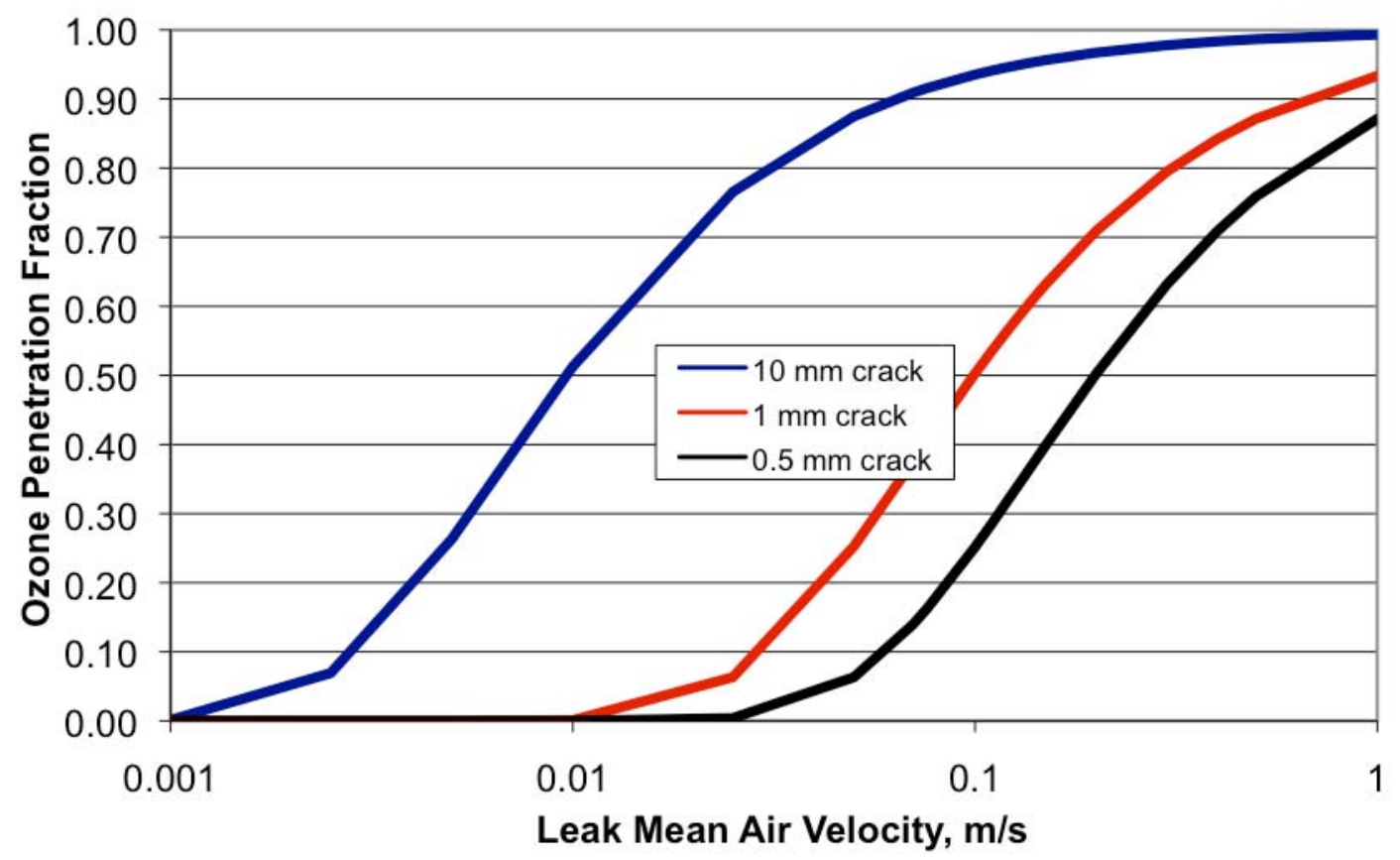

Figure 1a. Ozone penetration in $15 \mathrm{~cm}$ long wood faced cracks.

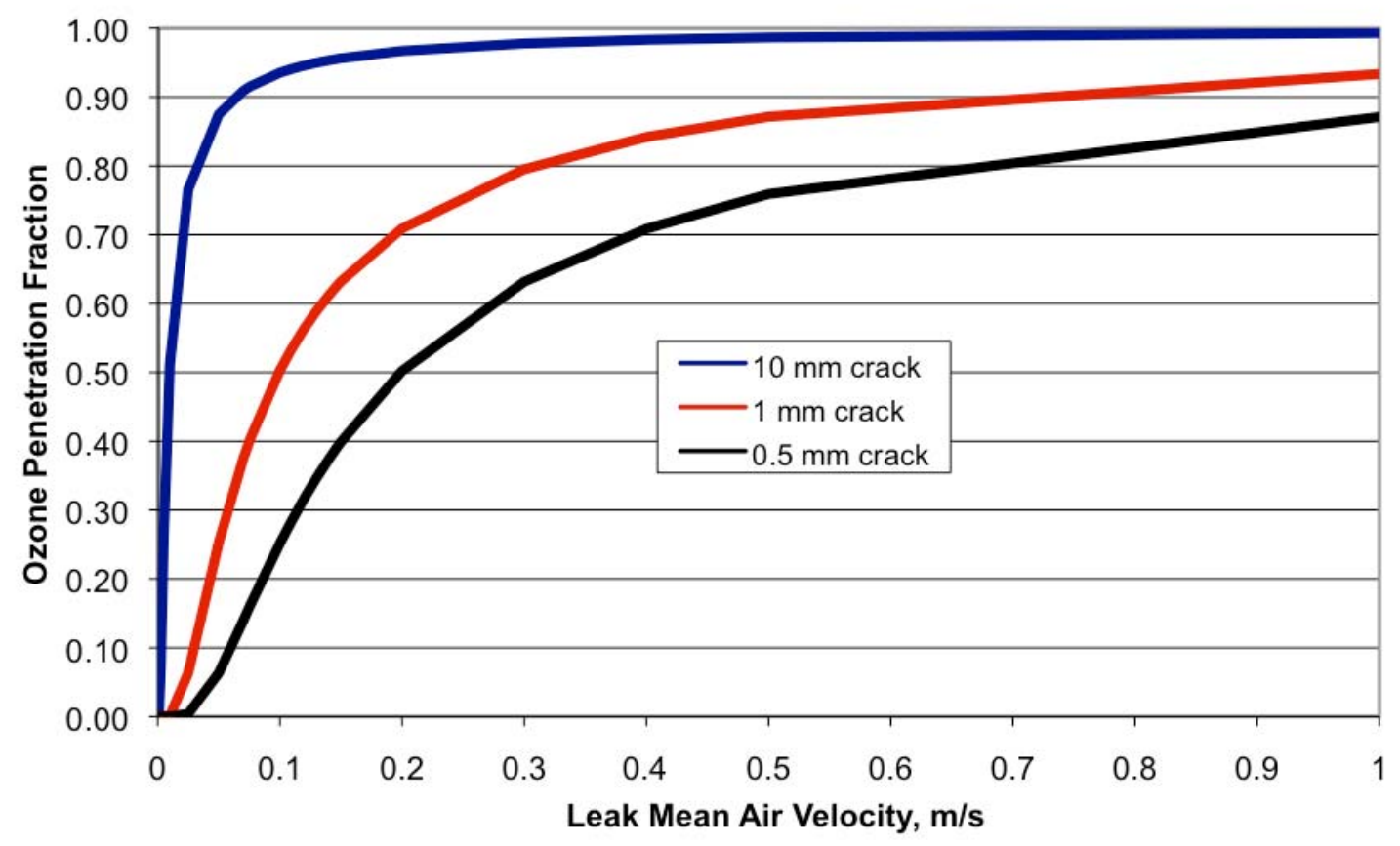

Figure $1 \mathrm{~b}$. Ozone penetration in $15 \mathrm{~cm}$ long wood faced cracks (linear scale). 


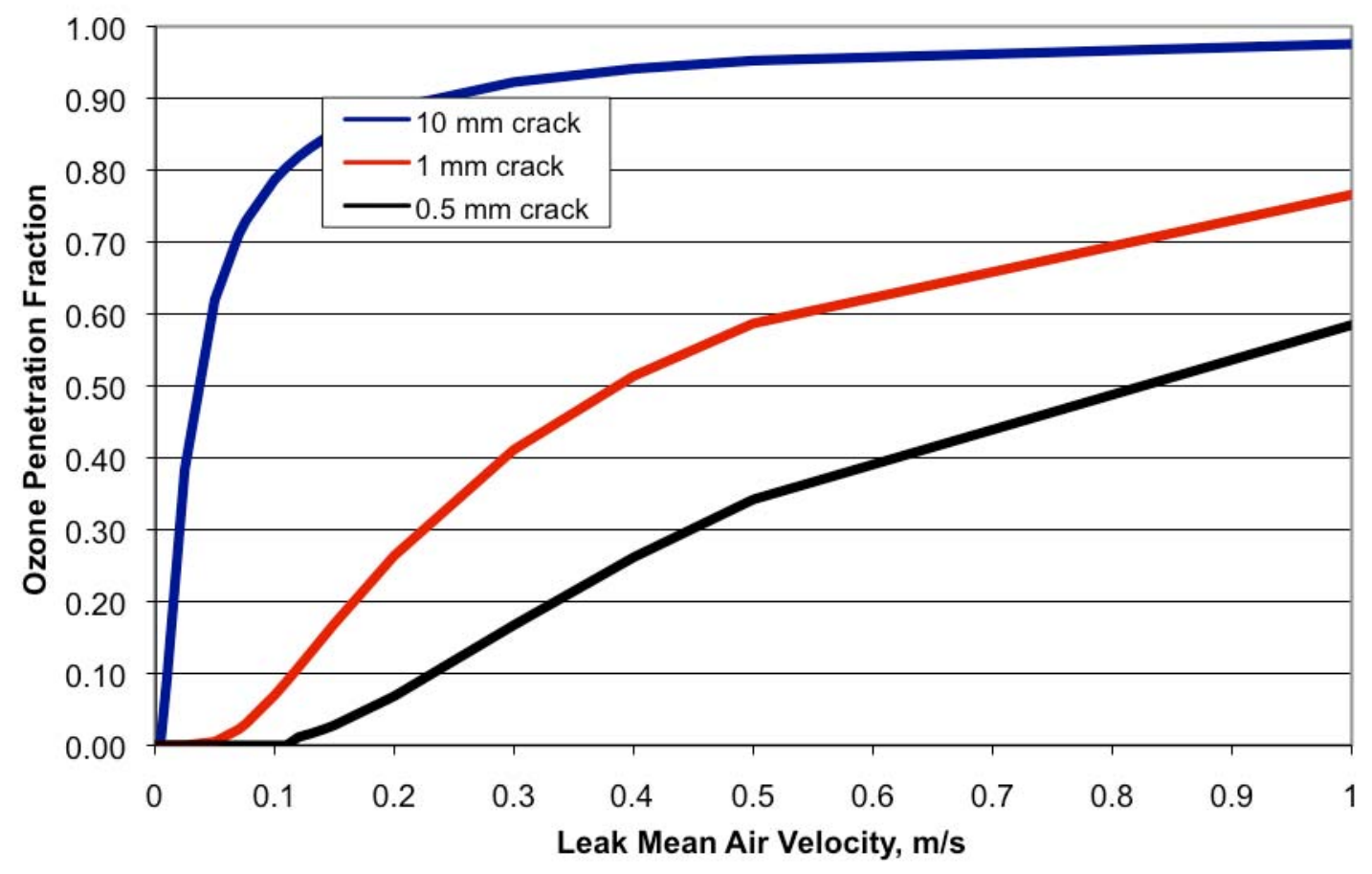

Figure 2. Ozone penetration for a $15 \mathrm{~cm}$ long concrete faced crack.

The results for $15 \mathrm{~cm}$ long paths are appropriate for air flow paths that do not flow through the cavity insulation. For flow through the wall cavity and the ceiling, the air flow path also includes about $1 \mathrm{~cm}$ of gypsum wallboard on the interior surface. For the wall cavity, the air flow also includes about $1 \mathrm{~cm}$ of exterior sheathing - commonly plywood. Applying the same crack deposition relationships to short $1 \mathrm{~cm}$ long wood and gypsum-faced cracks gives the results in Figure 3 and Figure 4. The short crack has essentially total penetration at velocities greater than $0.1 \mathrm{~m} / \mathrm{s}$ for a $10 \mathrm{~cm}$ crack, indicating that the deposition in plywood and gypsum board sheathing can be neglected and the deposition inside wall cavities and ceiling insulation dominates for these flow paths. 


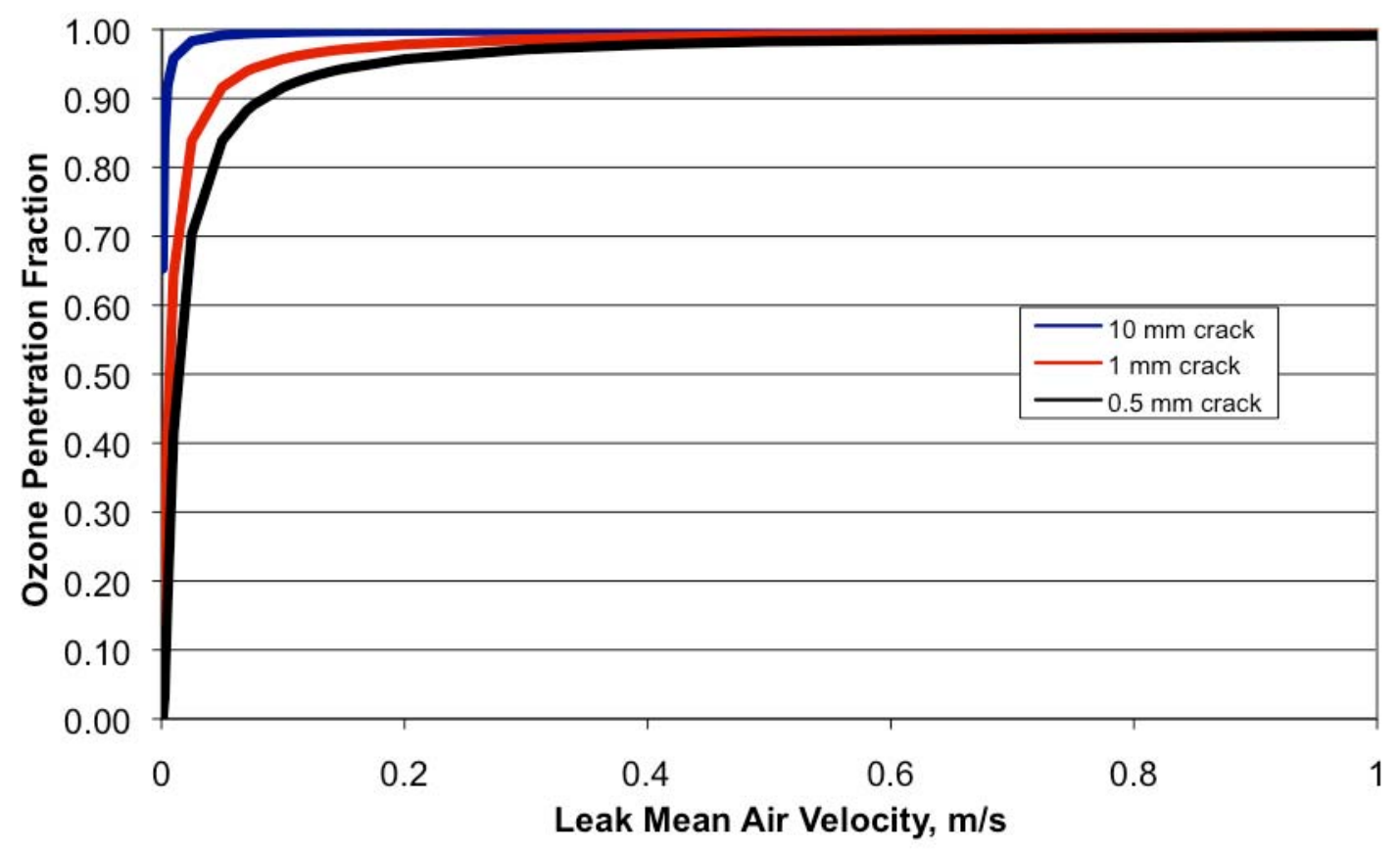

Figure 3. Ozone penetration for a short $1 \mathrm{~cm}$ wood faced crack. 


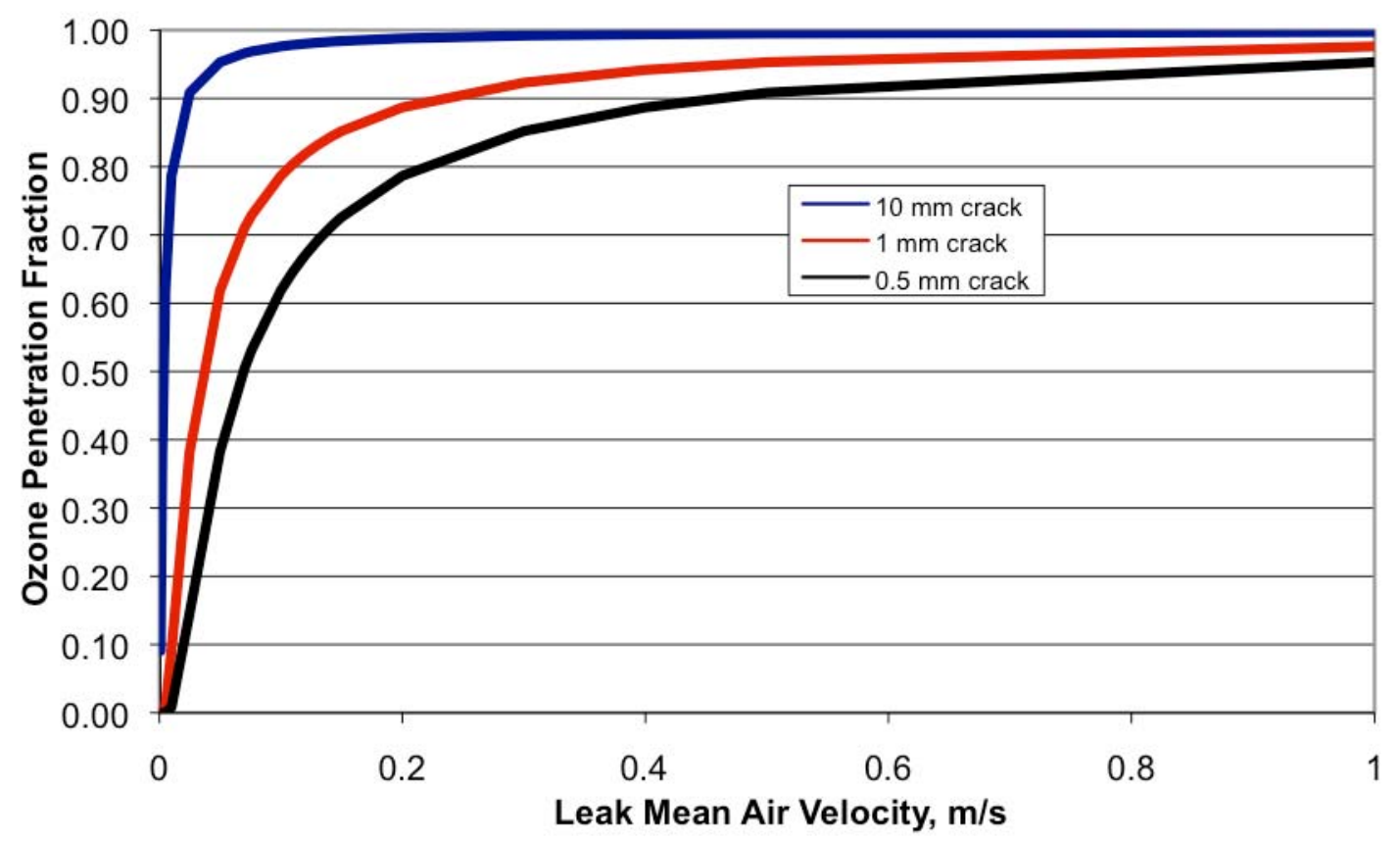

Figure 4. Ozone penetration for a short $1 \mathrm{~cm}$ gypsum faced crack.

\section{Combining the Wood and Concrete Crack for floor level leaks}

The crack at floor level will have one face that is wood and the other that is concrete. Thus, the two faces of the crack have different uptake coefficients. Liu and Nazaroff (2001) reported the basic work on this topic, but limited their analysis to cases in which the crack walls had common reaction rate coefficients. The following analysis determines the relationships for a crack with two different faces. The flow through the crack is represented in two dimensions, with the top and bottom surfaces lining the flow channel. A steady-state material balance equation is written on ozone over an along-stream segment of thickness $\Delta x$. If the rate of deposition uptake is the same on both surfaces, then the material balance would be written as follows:

$$
U d W C\left(x-\frac{\Delta x}{2}\right)=U d W C\left(x+\frac{\Delta x}{2}\right)=2 V_{0} \Delta x W C(x)
$$

Here, the first term on the left represents advective transport ${ }^{8}$ into the control volume. The terms on the right represent, respectively, advective transport out of the control volume and depositional loss on the top and bottom surfaces. The "deposition velocity" model was used for surface loss, where the flux to a surface is equal to $\mathrm{V}_{\mathrm{o}} C$, with $\mathrm{V}_{\mathrm{o}}$ being the deposition velocity.

\footnotetext{
${ }^{8}$ Advective transport is due to the bulk flow of the fluid - in this case the air and ozone mixture.
} 
Rearranging equation (14) and taking the limit as $\Delta x \rightarrow 0$, leads to the following differential equation

$$
\frac{d C}{d x}=-\frac{2 V_{0}}{U d} C
$$

that produces the solution

$$
C(x)=C(0) e^{-\frac{2 V_{0}}{U d} x}
$$

To combine the effects of mass transport and surface reaction, the deposition process was represented using an analogue to an electric circuit using a resistor network. In this concept, the concentration of ozone in the crack air is analogous to a voltage, the flux to a surface is analogous to a current, and the deposition velocity is analogous to conductance, the reciprocal of resistance. The overall flux to either surface is $2 v_{o} C$, and, as noted by Liu and Nazaroff (2001, equation 7), the resistors-in-series treatment produces this relationship:

$$
2 V_{0}=2\left(\frac{V_{s} V_{t}}{V_{s}+V_{t}}\right)=2\left(\frac{1}{V_{s}}+\frac{1}{V_{t}}\right)^{-1}
$$

This relationship corresponds to expectations for resistors in series, with $r_{s}=1 / V_{s}$ and $r_{t}=1 / V_{t}$ :

$$
V_{0}=\left(r_{s}+r_{t}\right)^{-1}
$$

Allowing for different surface reaction rates, two surface resistances are defined as $r_{s 1}$ and $r_{\mathrm{s} 2}$. Using the resistor model, the expression for the overall deposition to either surface can be represented as follows

$$
2 V_{0}=\left(r_{s 1}+r_{t}\right)^{-1}+\left(r_{s 2}+r_{t}\right)^{-1}
$$

Substituting $\mathrm{V}_{\mathrm{s} 1}=1 / \mathrm{r}_{\mathrm{s} 1}$ and $\mathrm{V}_{\mathrm{s} 2}=1 / \mathrm{r}_{\mathrm{s} 2}$, and rearranging, results in this combined expression for the dependence of the overall deposition velocity on the surface uptake limited deposition velocities and the transport-limited deposition velocity.

$$
V_{0}=\frac{V_{t}\left(V_{s 1} V_{t}+2 V_{s 1} V_{s 2}+V_{s 2} V_{t}\right)}{2\left(V_{s 1}+V_{t}\right)\left(V_{s 2}+V_{t}\right)}
$$

To apply this expression, the transport-limited deposition velocity is given by Equation 11 . The surface uptake-limited deposition velocities are estimated knowing the total deposition velocities $(0.00022 \mathrm{~m} / \mathrm{s}$ for wood and $0.00080 \mathrm{~m} / \mathrm{s}$ for concrete) at particular transport deposition velocities (from data in Grontoft and Raychaudhuri (2004)). For wood, $\mathrm{V}_{\mathrm{s}}=0.00022 \mathrm{~m} / \mathrm{s}$ (the same as $\mathrm{V}_{0}$ ) and for concrete, $\mathrm{V}_{\mathrm{s}}=0.0009 \mathrm{~m} / \mathrm{s}$. These values of $\mathrm{V}_{\mathrm{s}}$ were used together with $\mathrm{V}_{\mathrm{t}}$ calculated for each time step in the simulations in order to obtain Vo for each time step, and thereby determine ozone penetration using Equation 8.

Figure 5 shows the ozone penetration calculated using Equation 20 for deposition velocity for a two faced crack, with one face of wood and the other of concrete. 


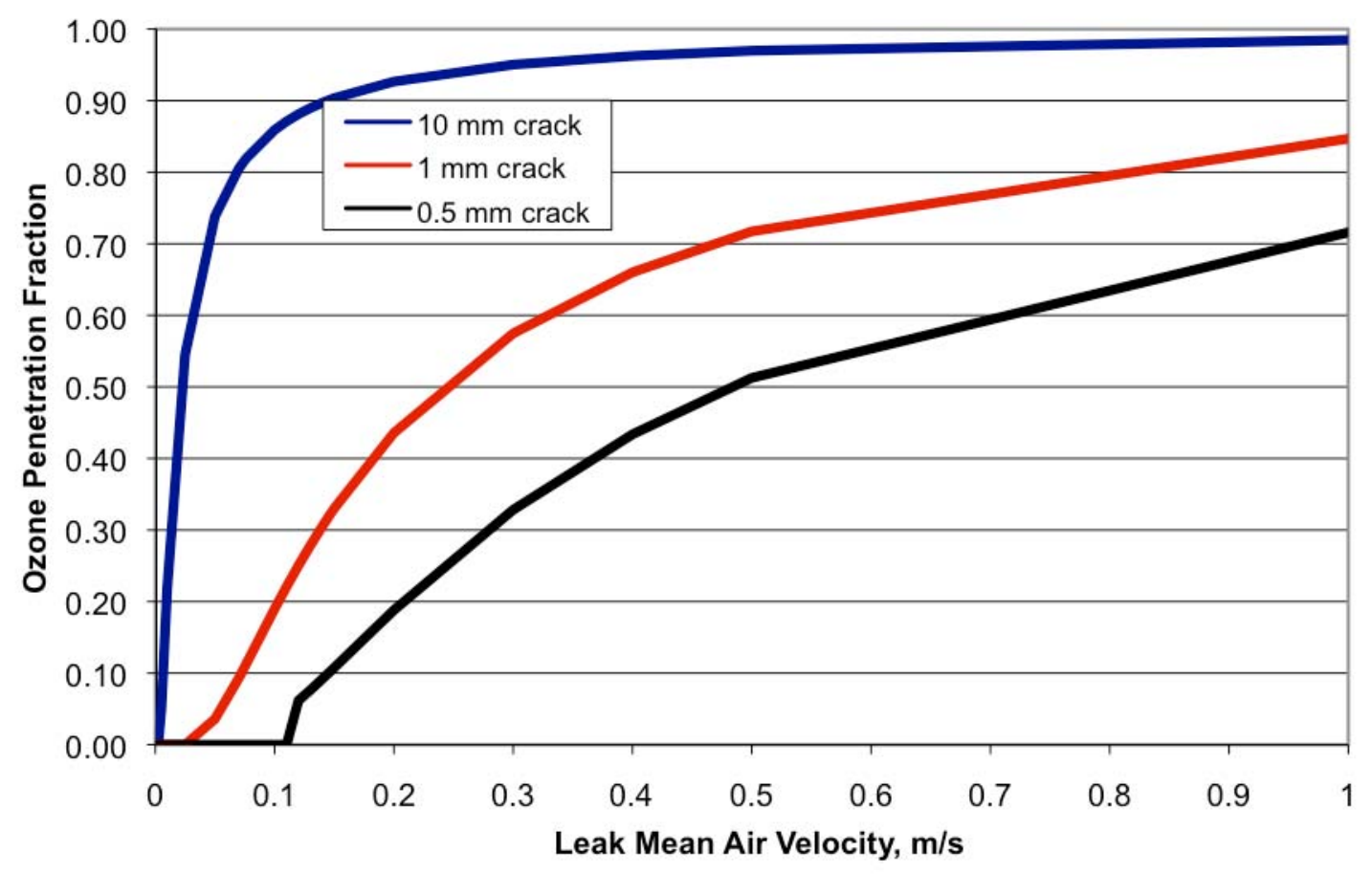

Figure 5. Ozone penetration for a 2 faced crack - one face is wood, the other concrete.

\subsection{Wall and Ceiling leaks}

The wall and ceiling leaks both have air flows through glass fiber insulation in addition to having leaks through or around the solid components. For the walls, the insulation is in a cavity where the inner cavity face is gypsum wallboard and the exterior face is plywood sheathing. The ozone filtration in insulation is different from that through cracks and depends on the glass fiber diameter, fiber packing density (solidity), mean air velocity and flow path (Liu and Nazaroff 2001). For glass fiber insulation, the fiber diameter is well known and is assumed to be the same for all the insulated cavity air flow paths. The ozone removal is then determined by the pattern of air flow through the insulation. The fraction of air flow through insulation for wall and ceiling leaks is given by the parameter " $f$ ".

For wall cavities, there are two extremes of cavity flow. One is flow that is straight through the wall (horizontal flow) and has a path length of the wall thickness $(0.15 \mathrm{~m})$. The second is vertical flow through the cavity, where the path length is the full cavity height: $2.5 \mathrm{~m}$. The vertical flow in wall cavities has a much greater path length and will have almost total ozone removal; however, this flowpath has a high air flow resistance and only a small fraction of the total envelope air flow will take this path, therefore, limiting the potential for ozone removal. In other words, this vertical flow path will have a lot of ozone removal from only a small fraction of the air entering the building , resulting in little change in overall envelope ozone removal

${ }^{9}$ The air flow through the insulation is D'Arcy flow where, for a given pressure difference, the air flow is inversely proportional to the air flow resistance. The vertical flow path is 17 times the 
efficiency. Therefore, the calculations in this study only include the horizontal flow and are taken from Liu and Nazaroff 2001.

The ozone penetration through a wall section with fiberglass insulation is given by:

$$
F_{O_{3}}=f \exp \left(\frac{-4 V_{o} \alpha L}{U d_{f}}\right)
$$

where: $\alpha$ is the solidity of the insulation (about 0.003 for glass fiber) and $d_{f}$ is the fiber diameter (about $10 \times 10^{-6} \mathrm{~m}$ or $10 \mu \mathrm{m}$ ). L changes for wall and ceiling air flow paths.

The deposition velocity, $V_{0}$, was determined using equation 10 with the same surface-reactionlimited deposition velocity given by Equation 9, but with a different mass transport deposition velocity given by:

$$
V_{t}=\frac{\eta_{d}}{\pi} U
$$

where $\eta_{\mathrm{d}}$ is the single fiber filtration efficiency and is related to the Peclet number $(\mathrm{Pe})$ :

$$
\eta_{d}=2 P e^{-\frac{2}{3}}=2\left(\frac{U d_{f}}{D}\right)^{-\frac{2}{3}}
$$

where $\mathrm{D}$ is the molecular diffusivity of ozone $\left(1.82 \times 10^{-5} \mathrm{~m}^{2} / \mathrm{s}\right)$.

Figure 6 shows the ozone penetration fraction for the three different glass fiber filled air flow paths with $\mathrm{f}=1$ (i.e., all flow goes trough the insulation).

length of the horizontal flow path, with 17 times the flow resistance. For the same pressure difference there will be 17 times more flow through the horizontal flow path than the vertical flow path. Liu and Nazaroff (2001) showed that even if every building cavity had vertical flow through the glass fiber insulation, the resulting air flows would be on the order of $10 \%$ of the total building infiltration. 


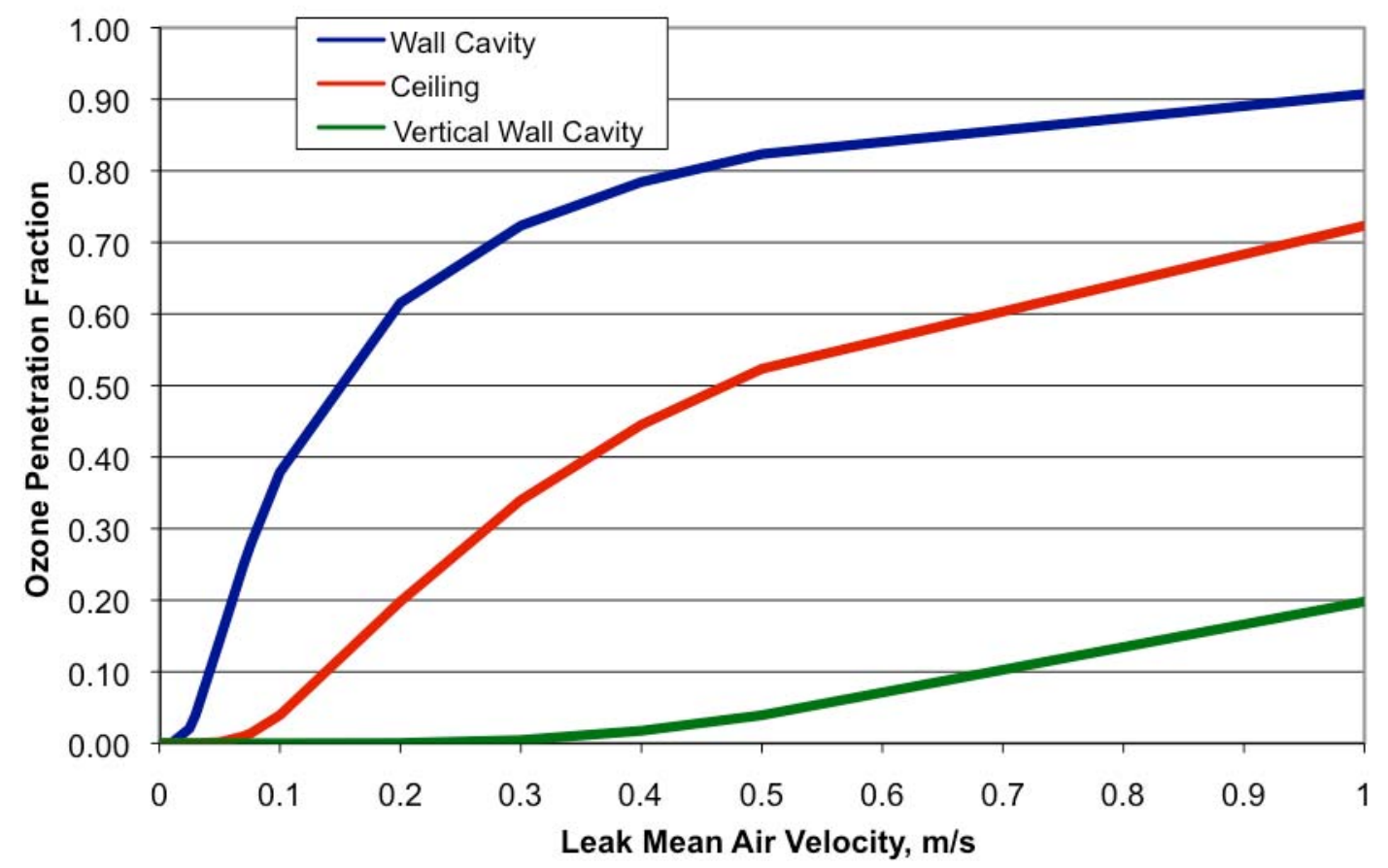

Figure 6. Ozone penetration factors through glass fiber insulation for a $0.15 \mathrm{~m}$ (6 in.) wall cavity, a $0.5 \mathrm{~m}$ (1.5 ft.) thick ceiling insulation blanket, and a $2.5 \mathrm{~m}$ tall vertical wall cavity flow path.

To determine the ozone penetration, the air velocity through the insulation is required. The mean air velocity for air flowing through the insulation depends on the geometry of the air flow. Mean air velocity is given by:

$$
U=\frac{Q}{A}
$$

where $\mathrm{Q}$ is the volumetric air flow rate and $\mathrm{A}$ is the cross-sectional area of the flow path. $\mathrm{Q}$ is determined by the air flow calculations in the simulation tool. The cross sectional area appropriate for velocity estimates is different for flow in wall cavities or through ceiling insulation.

The velocity of air flow through the insulation can be estimated based on the diffusive Darcy air flow through the insulation:

$$
Q=\frac{B_{o}}{L} \frac{1}{v} A \triangle P
$$

where $B_{o}$ is the permeability. The permeability depends on the density of the insulation. For a typical insulation density of $28 \mathrm{~kg} / \mathrm{m}^{3}\left(1.6 \mathrm{lb} / \mathrm{ft}^{3}\right)$, Lecompte (1987) reports a permeability of $2.5 \times 10^{-9} \mathrm{~m}^{2}$. Equation 18 can be rewritten in terms of mean velocity:

$$
U=\frac{B_{o}}{L} \frac{1}{v} \Delta P
$$


Substituting the above value for permeability and assuming a 1 Pa pressure difference, the mean velocity can be determined for three different air flow paths:

1. The $0.15 \mathrm{~m}$ straight through wall gives a mean velocity of $0.0009 \mathrm{~m} / \mathrm{s}$,

2. the $0.5 \mathrm{~m}$ of ceiling insulation has a mean velocity of $0.00027 \mathrm{~m} / \mathrm{s}$, and

3. the $2.5 \mathrm{~m}$ vertical flow path through a wall cavity has a mean velocity of $0.0005 \mathrm{~m} / \mathrm{s}$.

At these low velocities, there is no penetration of ozone.

At higher pressure differences of $5 \mathrm{~Pa}$, the air flows increase to $0.0046 \mathrm{~m} / \mathrm{s}, 0.00138 \mathrm{~m} / \mathrm{s}$ and $0.00028 \mathrm{~m} / \mathrm{s}$ for the same three air flow paths, but these air velocities are still not high enough for there to be any ozone penetration. These calculations imply that penetration will be zero all the time for air flow through the glass fiber insulation in the ceiling, so ceiling air flows will not transport any ozone into the building.

\subsection{Summary of Envelope Ozone Removal Four floor level leaks:}

These leaks have two faces, and the expression for deposition velocity $\left(\mathrm{V}_{0}\right)$ for a two-faced crack given by Equation 20 was used, with fixed values of $V_{s}=0.00022 \mathrm{~m} / \mathrm{s}$ for wood and $0.0009 \mathrm{~m} / \mathrm{s}$

for concrete. $V_{0}$ was used in Equation 8, together with crack geometry $(10 \mathrm{~mm}$ height and $15 \mathrm{~cm}$ length) and air velocity (from Equation 7) to estimate the ozone penetration. Each of the four floor level leaks has its own air flow, air velocity and ozone penetration factor because the air flow through each of the four floor level leaks is different - and may not even be in the same direction.

\section{Four Wall Leaks}

The walls can have leaks with either inflow or outflow and, in general, both will be present. The ozone removal used to determine indoor concentrations will only apply to inflow. The calculations above shows that there is no ozone penetration for these air flow paths.

\section{Ceiling Leak}

Like the wall leaks, the ceiling leak also has no ozone penetration. After initial simulations showed excess envelope filtration compared to measured field data, the simulations were repeated with half of the inflowing ceiling air flows bypassing the insulation.

If the envelope filtration is too high, then the full amount of air must not be going through the insulation materials either because of bypasses or because of the occasional use of operable openings. To examine the impact of this effect, two cases were examined - one case with all the air flow traveling through the insulation $(f=1)$ and a second case where half the air flow travels through the insulation $(f=0.5)$. 


\subsection{Deliberate Filtration}

Ozone can be deliberately filtered for non-residential buildings using several approaches. Shair (1981) used activated carbon filters that were used only when outdoor concentrations rose above 0.08 ppm and reported a filter life of three years. Shaver et al. (1983) showed that ozone concentrations in a museum (where high levels of ozone could potentially damage exhibits) could be kept below $0.01 \mathrm{ppm}$ using activated carbon. These studies provide examples of deliberate filtration for specific building applications. In residences, however, there has been little or no deliberate filtration of ozone.

Research at LBNL (Gundel et al. 2002) has shown that commercially available filters that have a layer of activated carbon can reduce ozone concentrations by up to $96 \%$ initially and $50 \%$ in the long term. Activated carbon filters are commercially available for residential HVAC applications but are not commonly used and would require continuous operation of the central forced air system. These filters could also be used for supply air systems.

Aside from the deliberate filtration of ozone, there is some filtration provided by existing HVAC system filters. Zhao et al. (2007) showed that clean filters removed 0 to $9 \%$ of ozone flowing through them. Dirty filters were more effective, with $10 \%$ removal for dirty residential filters and over $40 \%$ for dirty commercial filters (with the greatest filtration provided by higher MERV $^{10}$ filters). The experiments of Zhao et al. (2007) were performed at air velocities two orders of magnitude below those found in HVAC systems (this was due to the limited flows available in their experimental apparatus). Therefore, there is some uncertainty associated with extending their experimental results to real systems because high air flows would reduce the time available for the chemical reactions that deposit the ozone on the filter. Hytttinen et al. (2006) examined the effect of dirt and dust on filtration of ozone from building HVAC filters. The results varied widely from filter to filter, but generally the filters with a sooty coating removed the most ozone, and the ozone filtration decreased with time of exposure, as explained below. These laboratory studies found that ozone removal rates were much higher at the beginning of experiments and that they decayed to a steady non-zero value as ozone reaction sites were used up in the ozone removal. In the current study, it was assumed that the filters are dirty (as these are the most likely to be in place in residences), meaning that the steady-state (post initial decay of filtration efficiency) results for dirty filters are most appropriate. The dirty filters in Hyttinen et al. (2006) removed 3 to $20 \%$ of the ozone. A typical value of $5 \%$ of ozone removal was used for central forced air system filter and for the filters on the supply side of HRV and continuous supply systems.

${ }^{10}$ Minimum Efficiency Reporting Value - a measure of how well a filter performs under standardized testing conditions. Higher MERV implies more filtration. 


\subsection{Filtration in Ducts}

Morrison et al. (1998) found that an internally lined duct would initially remove approximately $9 \%$ of the ozone, but over a period of 10 days of ozone removal efficiency, the filtration rate would diminish to less than $4 \%$. In an unlined duct, in which only galvanized sheet metal is exposed to the air-stream, the removal efficiency was lower, approximately $0.02 \%$. Most residential ducts are a combination of unlined sheet metal plenums and connectors together with plastic flexible ducting with no exposed duct liner. The interior core of flexible duct is a non-porous PVC surface and is more like sheet metal than duct liner. The reaction probability for sheet metal and PVC are the same (within experimental measurement uncertainty estimated at $\pm 30 \%$ by Morrison et al. (1998)) at $1 \times 10^{-6}$. Therefore, ducts in ventilation systems are unlikely to be a major sink for ozone. Consequently, in the simulations below, there will be no ozone removal in the ducts of supply ventilation systems: the HRV, continuous supply and the Central Fan Integrated Supply. In addition, ozone removal from air flows through heating and cooling coils is also likely to be negligible and will not be included in the modeling. 


\subsection{Simulations}

A house was simulated, and the simulation was based on a California Residential Building Energy Code (2005) compliant home that had been used in a previous simulation study (Walker and Sherman 2006).

The REGCAP model combines a ventilation model, a heat transfer model and a simple moisture model. The ventilation model is a two zone model, in which the two zones are the attic and the house below it and they interact through the ceiling flow. Both zones use the same type of flow equations and solution method. The total building and attic leakage is separated into components (such as 4 walls, ceiling, floor, flue, etc.). The flow at each leakage site is determined by a power-law pressure - flow relationship. This relationship has a flow coefficient, $\mathrm{C}$, that determines the magnitude of the flow and an exponent for pressure difference, $\mathrm{n}$, that determines how the flow through the leak varies with pressure difference. For each zone the total leakage is divided into distributed leakage that consists of the small cracks inherent in the building construction and intentional openings (e.g. furnace flues and open windows).

Following the work of Sherman and Grimsrud (1980) the distributed envelope leakage is further divided into specific locations based on the height of the leak (i.e. floor, ceiling and walls). The building is assumed to have a rectangular planform with a user specified length, width and height. The attic has the same floor plan as the house and a pitched roof with soffits and gable ends.

In addition to the envelope leakage, the air flows in and out of attic ducts are included in the mass balances. The ducts are modelled differently depending on if the air handler is on or off. When the air handler is off, the duct leaks are assumed to experience the same pressure difference as the ceiling. Air then flows between the house and the attic via these leaks. When the air handler is on, supply leaks enter the attic and return leak flows are form the attic to the return duct and there are register flows between the ducts and the house.

The ventilation rate of the house and the attic is found by determining the internal pressures for the house and attic that balances the mass flows in and out. Because the relationship between mass flow and pressure is non-linear, the solution is found by iteration.

The attic heat transfer model determines the temperature of the attic air and the other components (e.g., pitched roof surfaces and ducts). A lumped heat capacity method is used to divide the attic into several nodes, and an energy balance is performed at each node to determine the temperatures. The attic air temperature is used to find the attic air density used in the ventilation calculations. The attic ventilation rate changes the energy balance for the attic air and the surface heat transfer coefficients. Fortunately this coupling of the attic ventilation model and the heat transfer model is weak because attic ventilation rates are not a strong function of attic air temperature.

A simple building load model is used to determine indoor air temperature. It uses the total heat transmission for the building together with solar loads (including window orientation - i.e., the area of windows in facing north, south, east and west). A critical part of the house model is the 
coupling of the house air to the thermal mass of the structure and furnishings. The model uses a combination of thermal mass and surface area together with natural convection heat transfer coefficients.

An equipment model is used to determine heating and cooling system capacities, efficiencies and energy consumption. For gas or electric furnace heating the capacity is fixed for all conditions. For air conditioning, the indoor and outdoor air conditions, together with air handler flow and refrigerant charge are used to determine the cooling system performance.

The simulation uses minute-by-minute time steps to account for cycling of HVAC equipment.

In addition to the ventilation systems outlined in Section 3, the house had a bathroom exhaust that operated from 7:30 to 8:00 a.m. (two $50 \mathrm{cfm}$ fans) and a kitchen exhaust that operated from 5:00 p.m. to $6: 00$ p.m. (a $160 \mathrm{cfm}$ fan).

\subsection{House Characteristics}

Houses were simulated for two climate zones that had high outdoor ozone levels: Livermore (Climate Zone 12) and Riverside (Climate zone 10). The outdoor ozone profiles were taken from California Air Resources Board (CARB) data (and published on the CARB website). The particular days chosen were the peak ozone days for 2007: for Climate Zone ten this was August $12^{\text {th }}$ and for Climate Zone 12 this was July $22^{\text {nd }}$. The houses were based on the slab-ongrade, two-story, $1761 \mathrm{ft}^{2}$ Title 24 prototype. The envelope thermal load was based on the envelope insulation and window properties specified in Title 24. For the energy load calculations, the standard Title 24 insulation and degradation factors were used as shown in Table 2. The wall surface area was estimated from measured data from several thousand new homes ${ }^{11}$ : the wall area was typically 1.54 times the floor area for a two-story home. Window area was $20 \%$ of floor area with windows equally distributed on the four exterior walls. The window shading coefficient for glazing complied with Title 24 's $50 \%$ shading requirement.

Table 2. House Insulation Levels.

\begin{tabular}{|c|c|c|c|c|c|c|c|}
\hline \multicolumn{2}{|l|}{ Climate Zone } & \multicolumn{3}{|c|}{ Ceiling } & \multicolumn{2}{|c|}{ Wall } & \multirow{2}{*}{$\begin{array}{l}\text { Ducts outside } \\
\text { conditioned } \\
\text { space }\end{array}$} \\
\hline & & & $\begin{array}{l}\text { Heating } \\
\text { Degraded }\end{array}$ & $\begin{array}{l}\text { Cooling } \\
\text { Degraded }\end{array}$ & & Degraded & \\
\hline \multirow[t]{2}{*}{$\begin{array}{l}\text { New } \\
\text { Construction }\end{array}$} & $\begin{array}{l}12- \\
\text { Livermore }\end{array}$ & R38 & $\mathrm{R} 21.6$ & R31.9 & R19 & R16 & R6 \\
\hline & $\begin{array}{l}10 \text { - } \\
\text { Riverside }\end{array}$ & R30 & R18.8 & R26.1 & R13 & R10.9 & R6 \\
\hline
\end{tabular}

${ }^{11}$ Based on Building Science Corporation/Building America data - personal correspondence with Armin Rudd of BSC (2005). 


\subsection{Ventilation Systems}

The simulations evaluated the following ventilation systems that are all ASHRAE Standard 62.2 compliant and commonly available for use in residences:

2. Continuous exhaust. This continuously depressurized the house, and the incoming air enters through the building envelope. Depending on envelope leakage and weather conditions, the exact flow path could change, and with it the ozone removal.

3. Intermittent exhaust. In addition to the characteristics of the continuous exhaust, this system had the capability to be turned off at times of high outdoor ozone levels. This can be done by simple timers, in response to an alert, or, conceivably, through internetbased information linked to real-time local ozone reporting. In the simulations, a timer was used to turn off the exhaust system for four hours at a time. In summer, the off period was from 3:00 p.m. to 7:00 p.m. (coincident with the electrical system peak load and also avoiding some periods of high ambient ozone). In winter, the off period was from 1:00 a.m. to 5:00 a.m. The intermittent exhaust was sized to meet ASHRAE 62.2 and, therefore, had $20 \%$ more air flow than the continuous exhaust.

4. Heat Recovery Ventilator (HRV). The HRV had balanced air flow which meant that the envelope flows were generally unchanged during operation. The supply air was filtered with a particle-laden filter.

5. Central Fan Integrated Supply (CFIS) with continuous exhaust. This system utilized both supply and exhaust, with the supply operating for 20 minutes out of each hour in conjunction with the central furnace or air conditioning blower. The supply air was filtered with a used filter.

6. Continuous supply. This system continually pressurized the house and incoming air enters mostly through the fan and exits through the building envelope. Depending on envelope leakage and weather conditions, the exact flow path could change, and with it the ozone removal. The supply air was filtered with a used filter in the simulations.

7. Economizer. An economizer acted as a big supply fan with a flow set equal to the HVAC central system blower at cooling speed. The economizer air flow passed through the HVAC system's dirty air filter.

8. Open Windows. In previous studies (Avol et al. (1998) and Weschler (2000)), it has been shown that open windows significantly increase indoor ozone levels when outdoor ozone levels are high. This outcome is understood to be due to a combination of significantly (at least by factors of two) increased ventilation rates and zero filtration of entering air. 


\subsection{Ventilation Results}

The analysis focused on four key issues:

- Ventilation rates. Comparing the air flow rates into the building where more air flow results in more ozone introduced into the building.

- Ventilation times. Ventilation rates change with time depending on the ambient weather and on mechanical ventilation system operation. Changing times of higher or lower ventilation enables the use of lower ventilation rates when outdoor ozone concentrations are high and higher rates when ozone is low, thus reducing the amount of ozone entering the home.

- Air flow path. The geometry of different entering air flow paths changes the deposition/filtration of ozone and, therefore, changes the quantity of ozone entering the home. The flow path taken by the entering air can be changed by mechanical ventilation systems and ambient weather. In this study, the ventilation model determined how flow paths change depending on the ventilation system used.

- Flow path materials. Often, the materials exposed to infiltrating air change with each flow path. For example, air flow through the building envelope may encounter surfaces made of wood and glass fiber, whereas ducted supply air will pass through filters and sheet metal or plastic ducting.

\subsection{Individual Air Flow Paths}

The following plots show the flow through the ceiling (a positive number is inflow) and inflows only through wall and floor leaks (each of the four wall and floor leaks were summed to get the building total). These air flows are in $\mathrm{kg} / \mathrm{s}$. To convert to air changes per hour (ACH), one must multiply by 6.8: e.g., the highest air flows in Figure 7 (when the kitchen exhaust is on) correspond to about $0.95 \mathrm{ACH}$. 
Case 1 - Continuous Exhaust. The effect of the morning/evening bathroom and afternoon kitchen exhaust stand out in these results. From 2:00 p.m. to 6:00 p.m. (7:30 p.m. in CZ12) the duct leakage increases the ventilation rate by about $0.02 \mathrm{~kg} / \mathrm{s}(0.14 \mathrm{ACH})$. The cooler indoor temperatures during the daytime result in inflows through the ceiling and outflows through the floor (resulting in no inflow through the floor).

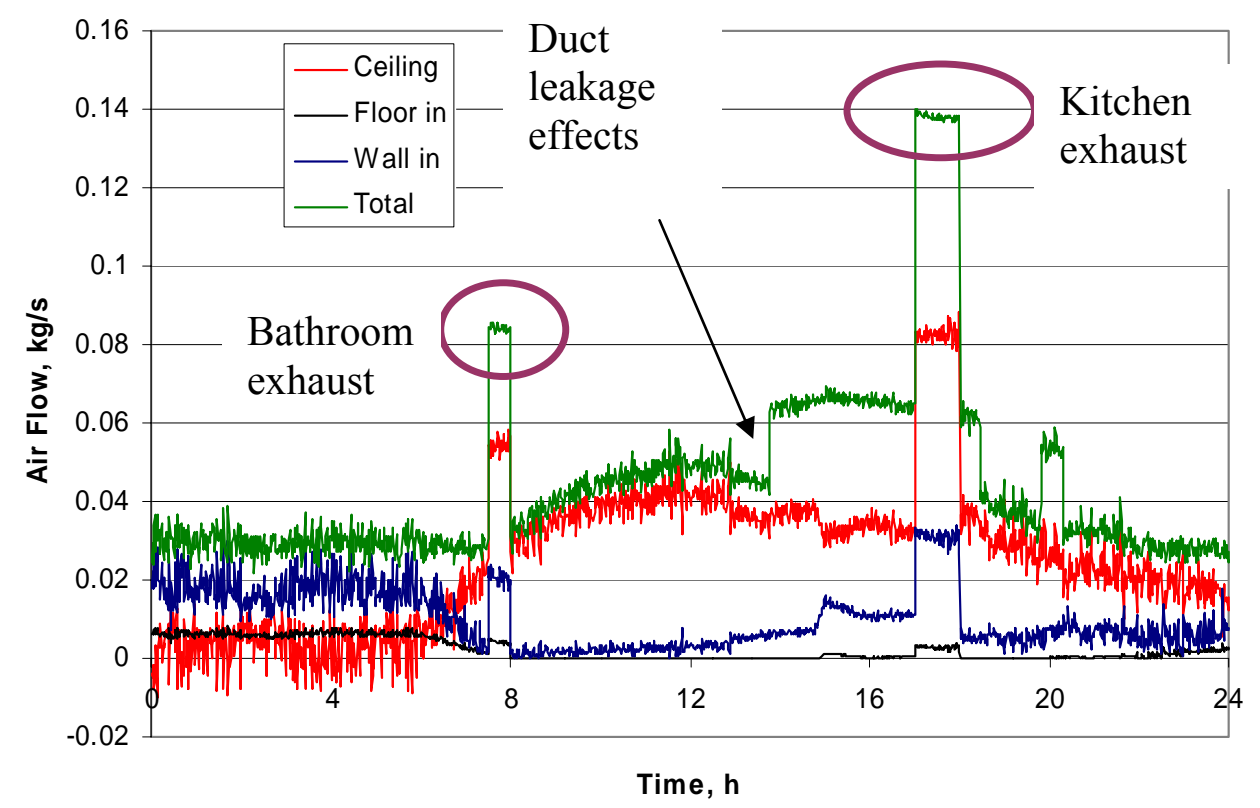

Figure 7. Envelope air flows for continuous exhaust in CZ10.

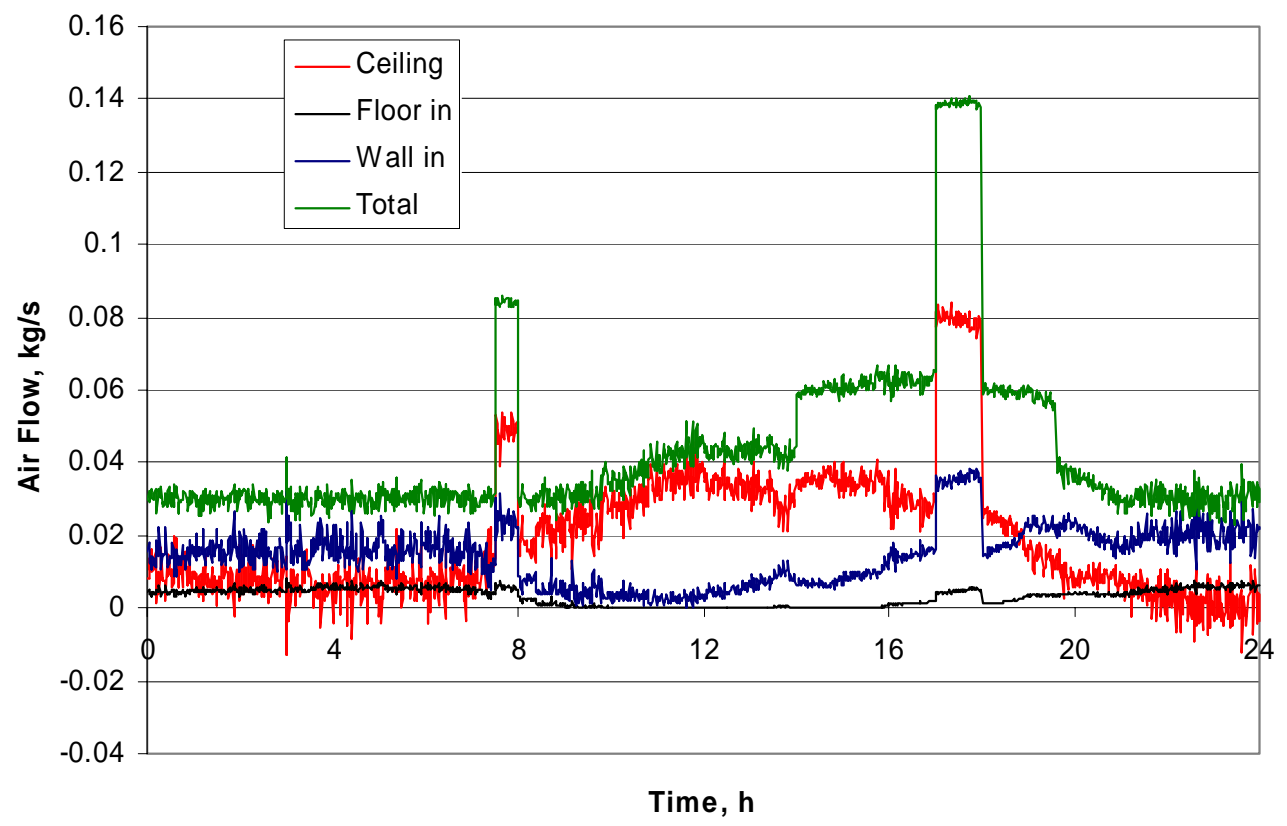

Figure 8. Envelope air flows for continuous exhaust in CZ12. 
Case 2 - Intermittent Exhaust: The intermittent exhaust reduces inflow rates during the afternoon and induces higher envelope inflow while operating compared to the continuous exhaust.

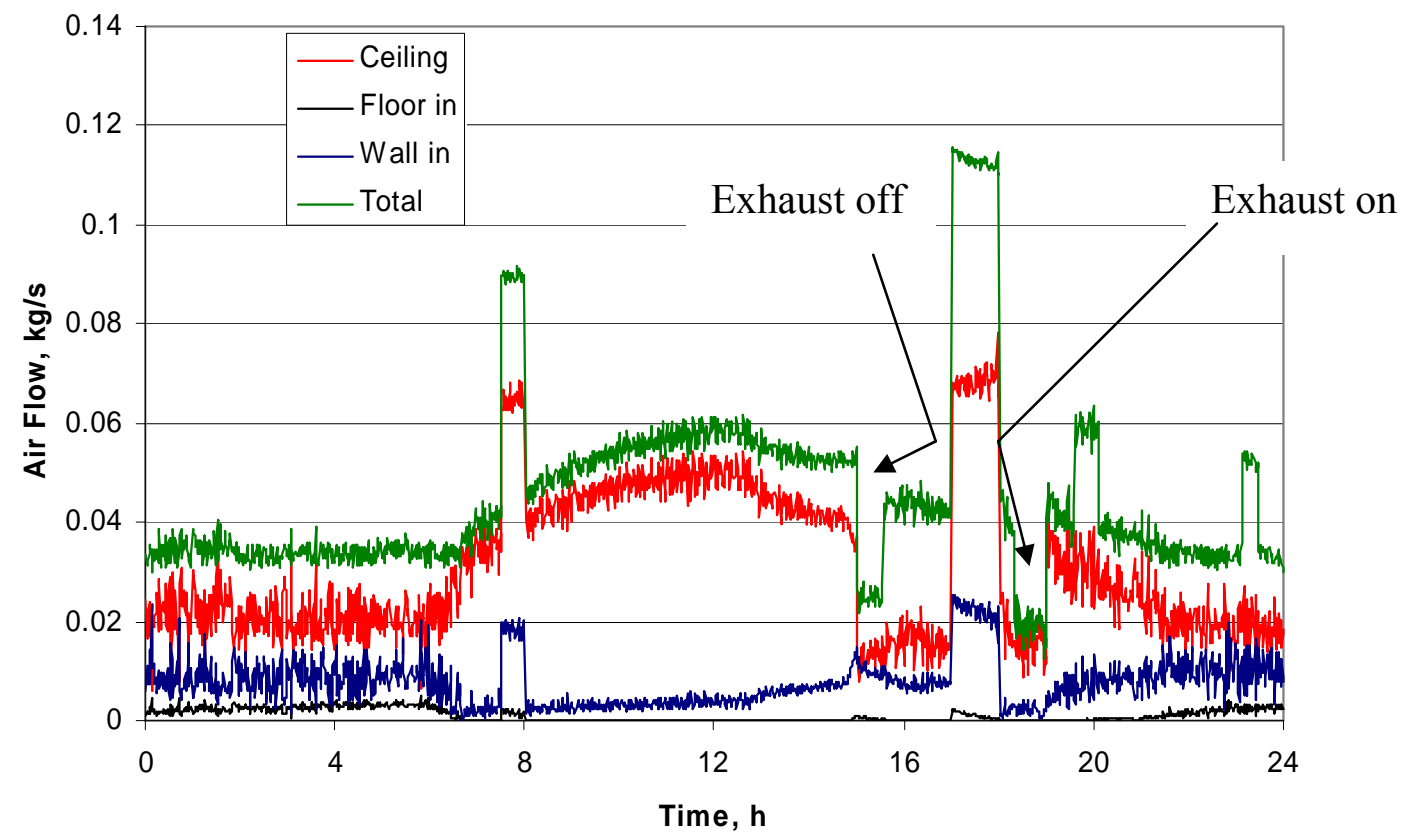

Figure 9. Envelope air flows for intermittent exhaust in CZ10.

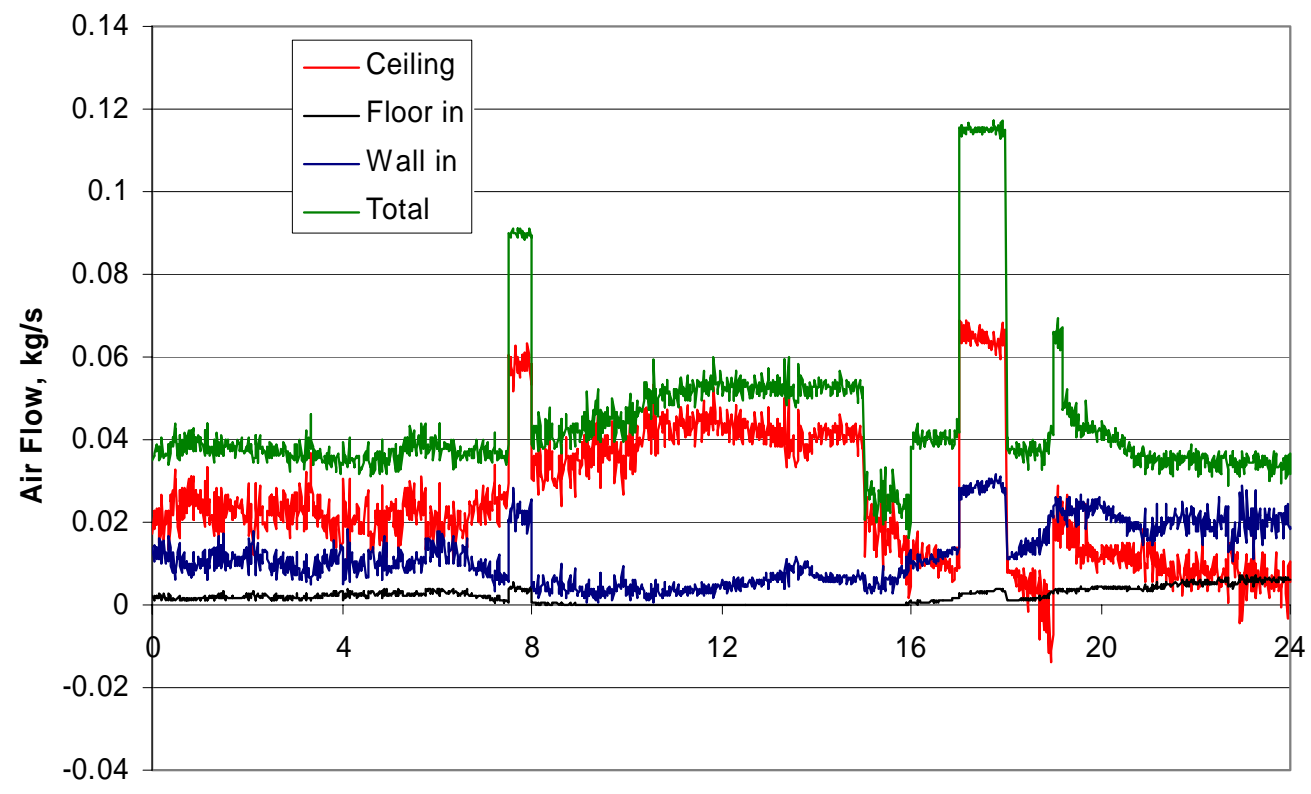

Time, $\mathbf{h}$

Figure 10. Envelope air flows for intermittent exhaust in CZ12. 
Case 3 - HRV: The HRV cycles on and off resulting in large changes in the total air flow in and out. However, it does not depressurize the house, so the other leaks have less inflow than in the exhaust cases.

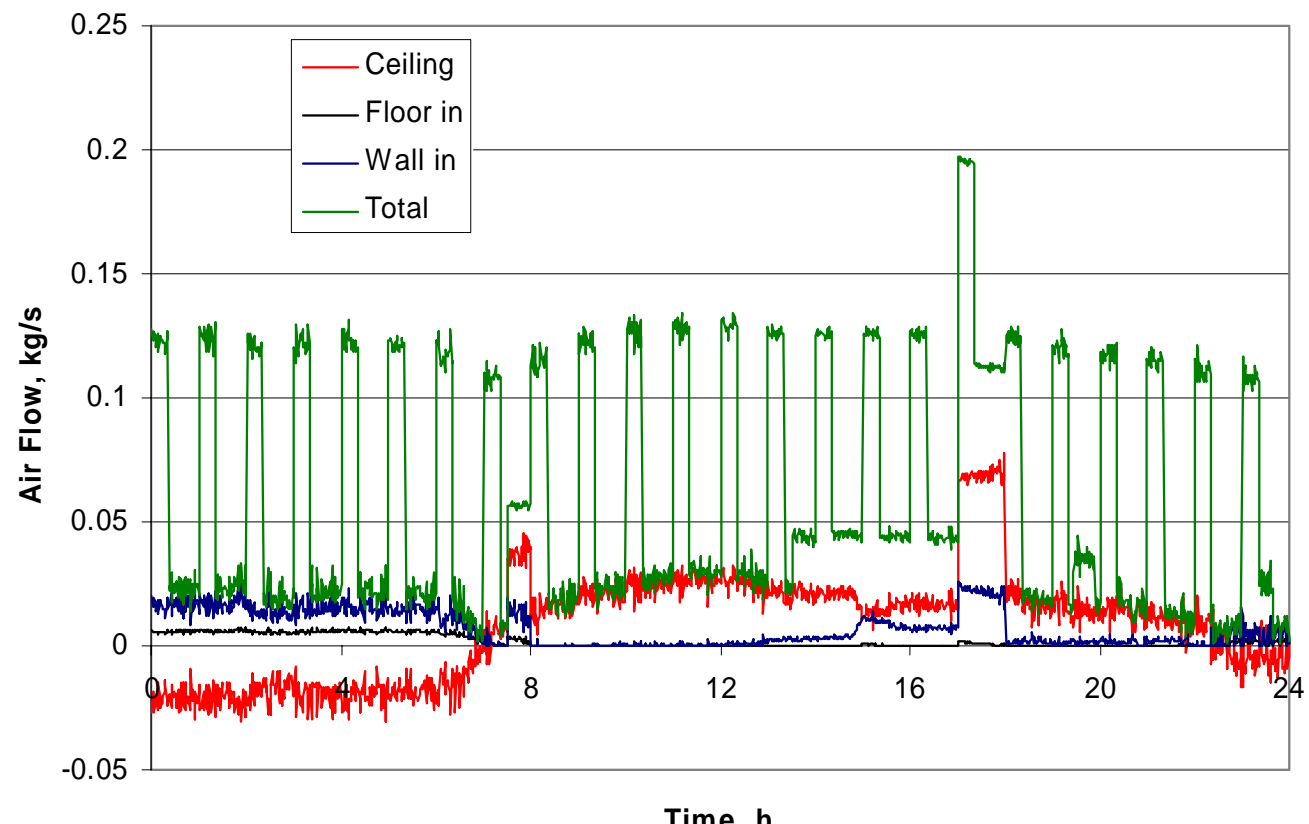

Figure 11. Envelope air flows for a Heat Recovery Ventilator in CZ10.

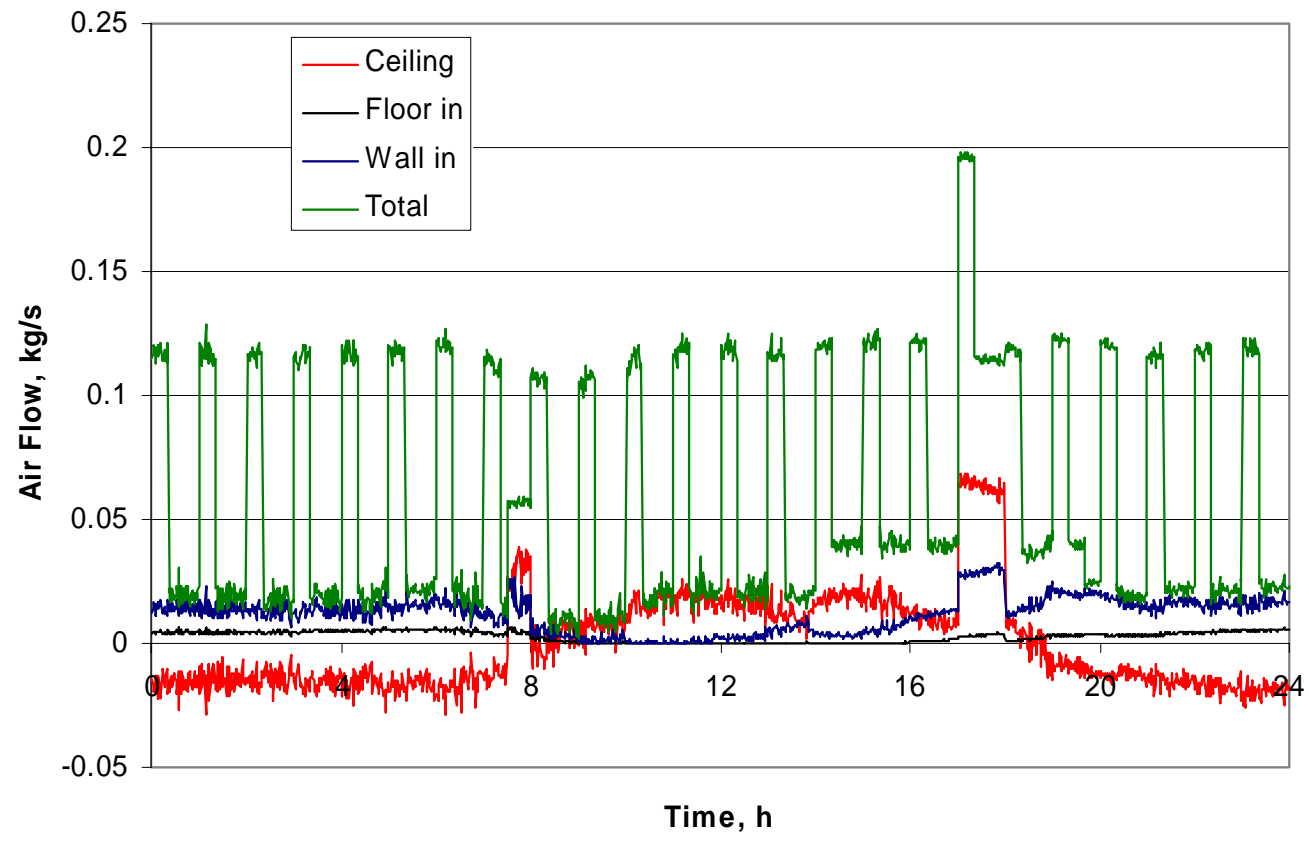

Figure 12. Envelope air flows for a Heat Recovery Ventilator in CZ12. 
Case 4 - Central Fan Integrated Supply and Continuous Exhaust: As with the HRV, the cycling of this system is clear from the changes in total air flow. This system alternates between exhaust only (that leads to increased inflow for other building leaks) and balanced operation and therefore cycling is seen in the other inflows.

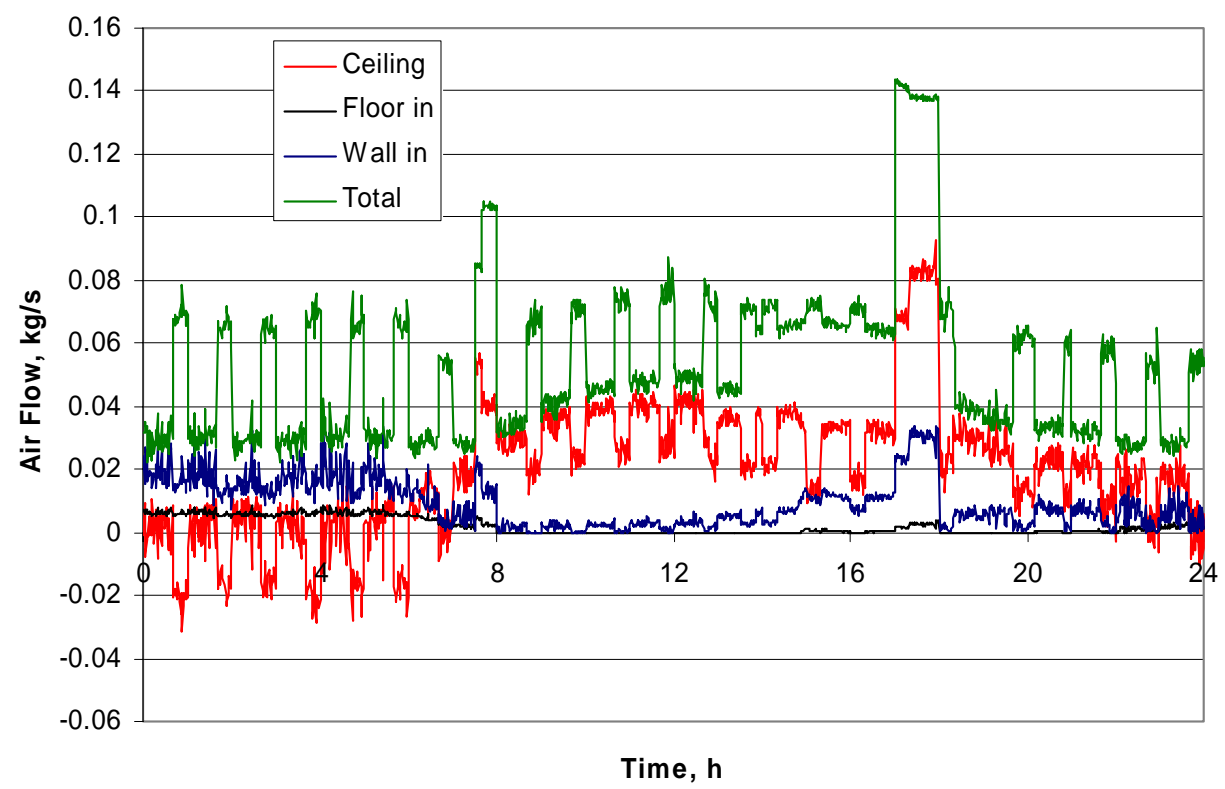

Figure 13. Envelope air flows for Central Fan Integrated Supply and Continuous Exhaust in CZ 10.

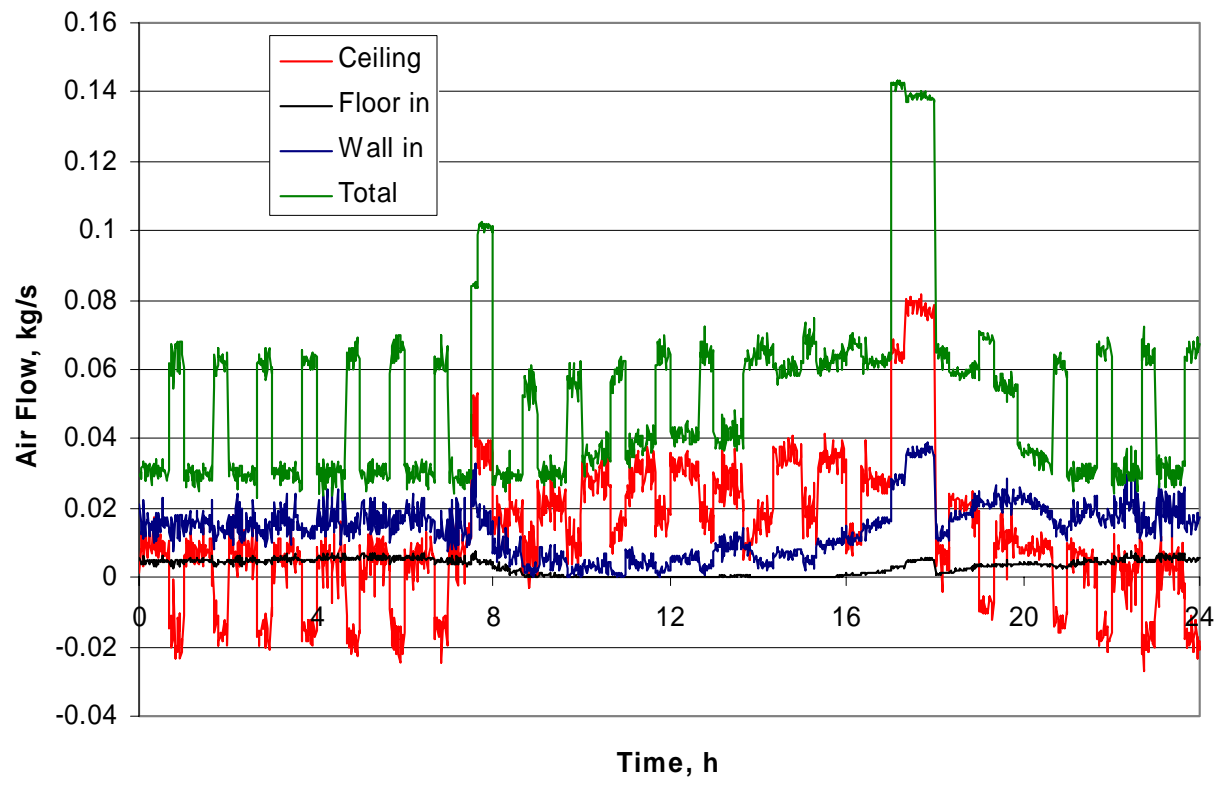

Figure 14. Envelope air flows for Central Fan Integrated Supply and Continuous Exhaust in CZ 12. 
Case 5 - Continuous Supply: The continuous supply pressurizes the house resulting in less inflow for other envelope flow paths. In this case, the ceiling rarely has any inflow.

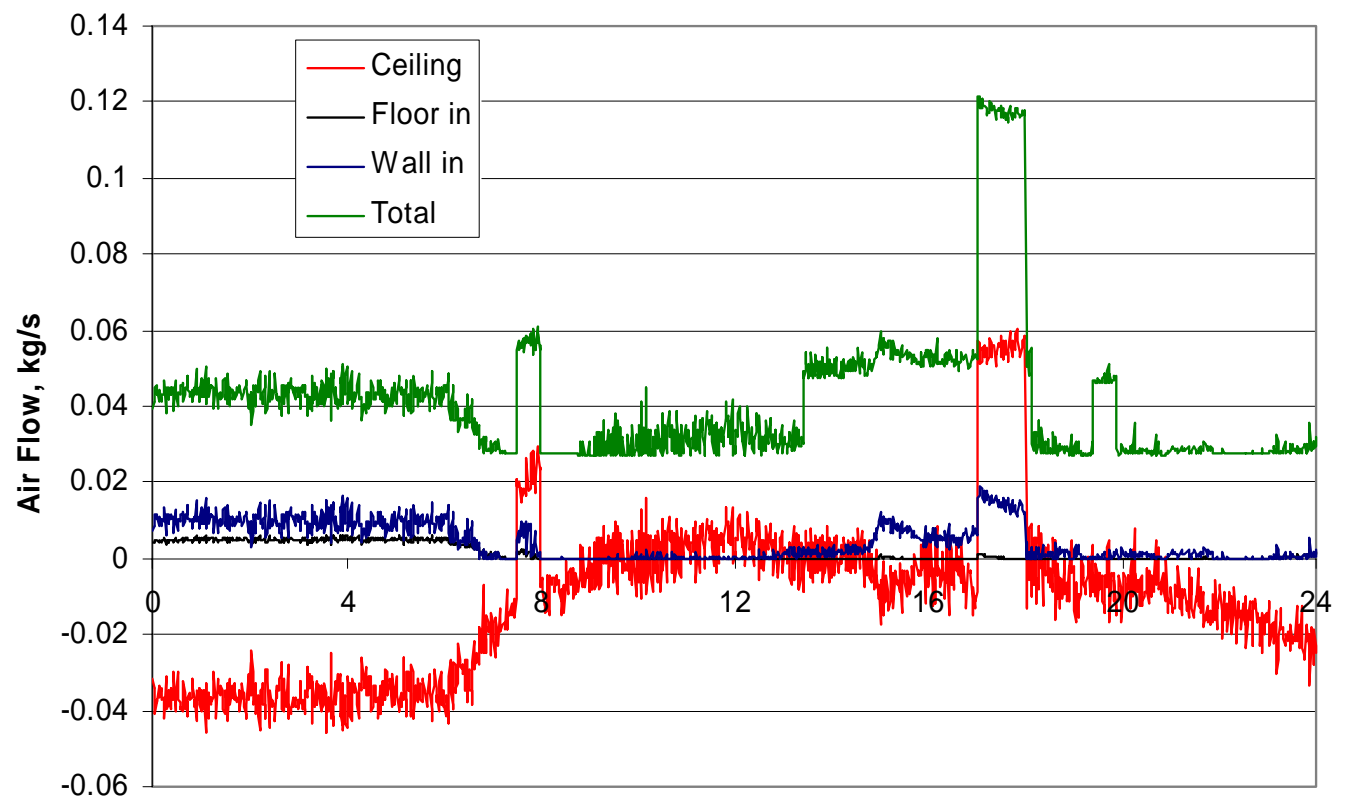

Time, $\mathbf{h}$

Figure 15. Envelope air flows for Continuous Supply in CZ 10.

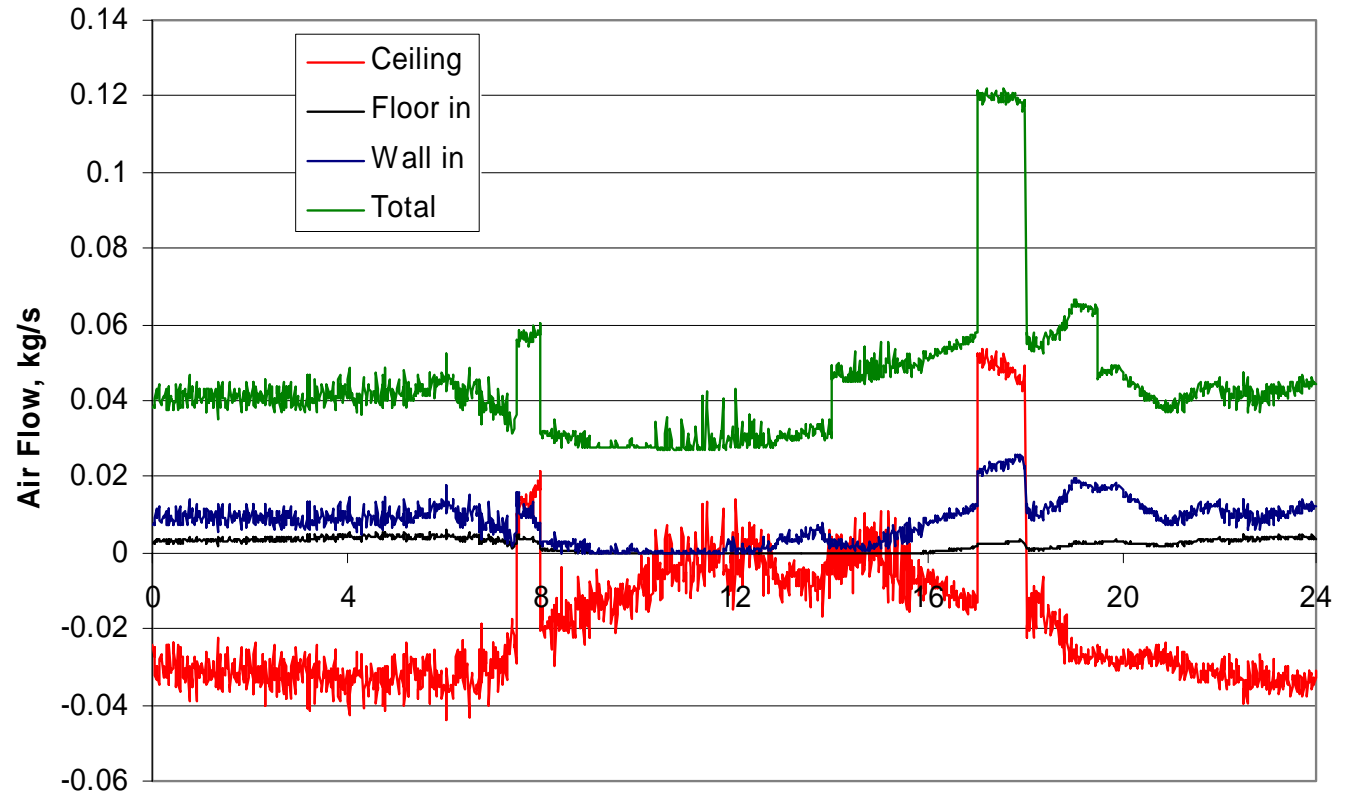

Time, $\mathbf{h}$

Figure 16. Envelope air flows for Continuous Supply in CZ 12. 
Case 6 - Economizer: Economizer airflows at night are larger than other ventilation flows. The magnitude of ventilation flows when the economizer is operating are more than an order of magnitude greater than other air flows. In this case, there is no mechanical ventilation when the economizer is off other than the kitchen and bathroom fan operation.

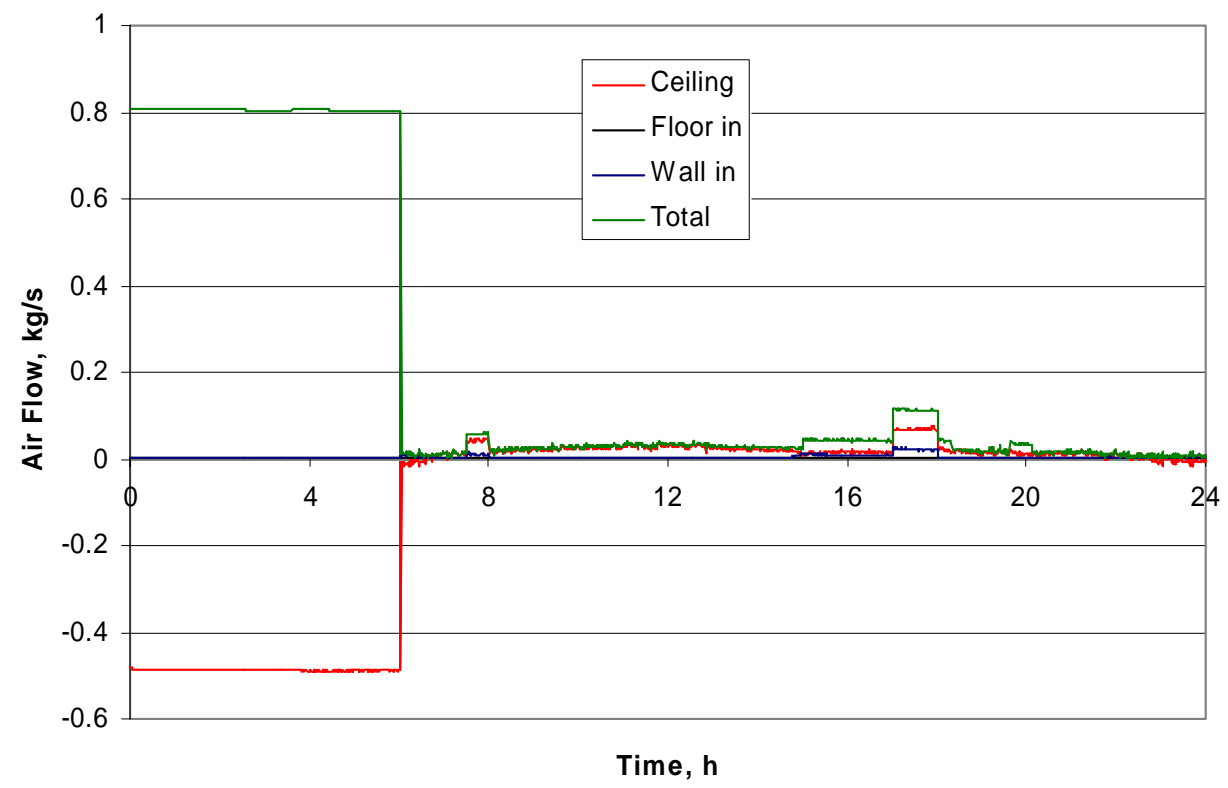

Figure 17. Envelope Air Flows for Economizer in CZ10.

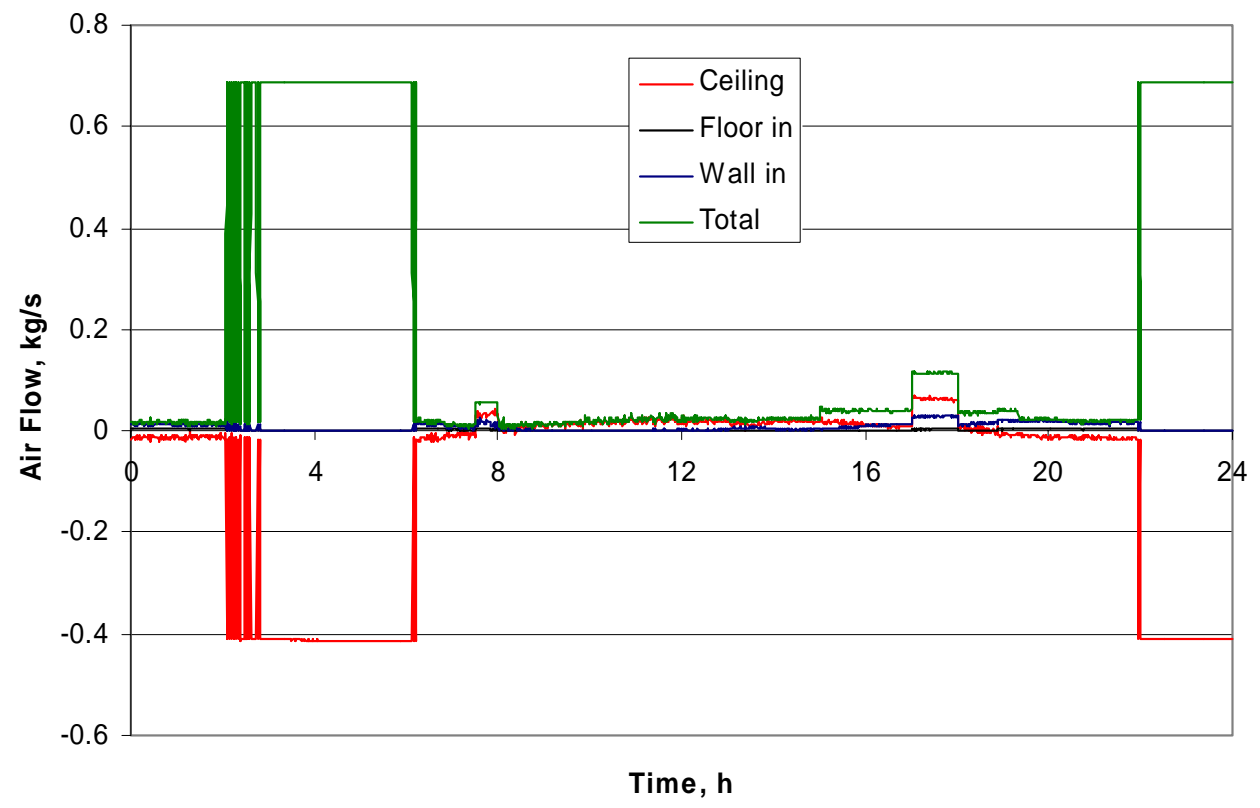

Figure 18. Envelope Air Flows for Economizer in CZ12. 
Although the economizer has very high airflows, the long off times mean that it is not possible to be ASHRAE 62.2 compliant with the economizer alone. Sherman (2006) discussed this issue of intermittent ventilation and the relationship between high and low ventilation rates and their respective operating times. The relationships in Sherman (2006) indicate that for the long (16 hours for CZ10) off times there is no economizer air flow rate that would allow this system to meet ASHRAE 62.2 over a 24 hour period. However, it is possible to take credit for this overventilation. Walker and Sherman (2006) showed how much credit (i.e., time during which no mechanical ventilation is required) one can take for overventilation/economizer operation. In this case of roughly 6 hours of economizer operation there is 10 hours of credit available. To minimize ozone entry, it makes sense to take this credit between the hours of 10:00 a.m. and 8:00 p.m. This means that that additional mechanical ventilation occurs when the economizer is off before 10:00 a.m. and after 8:00 p.m. During these times, the outdoor ozone concentrations are low and will not significantly contribute to the indoor ozone concentration. 


\subsection{Ozone Results with all air flow traversing fiberglass $(f=1)$}

The ventilation flows shown above for each air flow pathway had the ozone removal calculated, then a mass balance on ozone in the house was performed. To better understand the results, the removal mechanisms were examined individually at first, for the single case of CZ10 with continuous exhaust.

The result shown in Figure 19 for the continuous exhaust case is for modeling interior surface loss only (i.e., no envelope or HVAC filtration). In this case, the average $\mathrm{ACH}$ is $0.33 \mathrm{~h}^{-1}$ and with the assumed interior surface deposition coefficient (ISDC) of $2.8 \mathrm{~h}^{-1}$, the expected indoor/outdoor ozone concentration ratio is 0.10 (i.e., $0.33 \mathrm{~h}^{-1} /\left(0.33 \mathrm{~h}^{-1}+2.8 \mathrm{~h}^{-1}\right)$. The simulation results shown in Figure 19 have an average indoor/outdoor ratio of 0.10 , thus confirming that the simulation is performing correctly for surface deposition. This result shows that internal deposition alone brings down the indoor ozone concentrations by about $80 \%$.

\section{Surface Loss only}

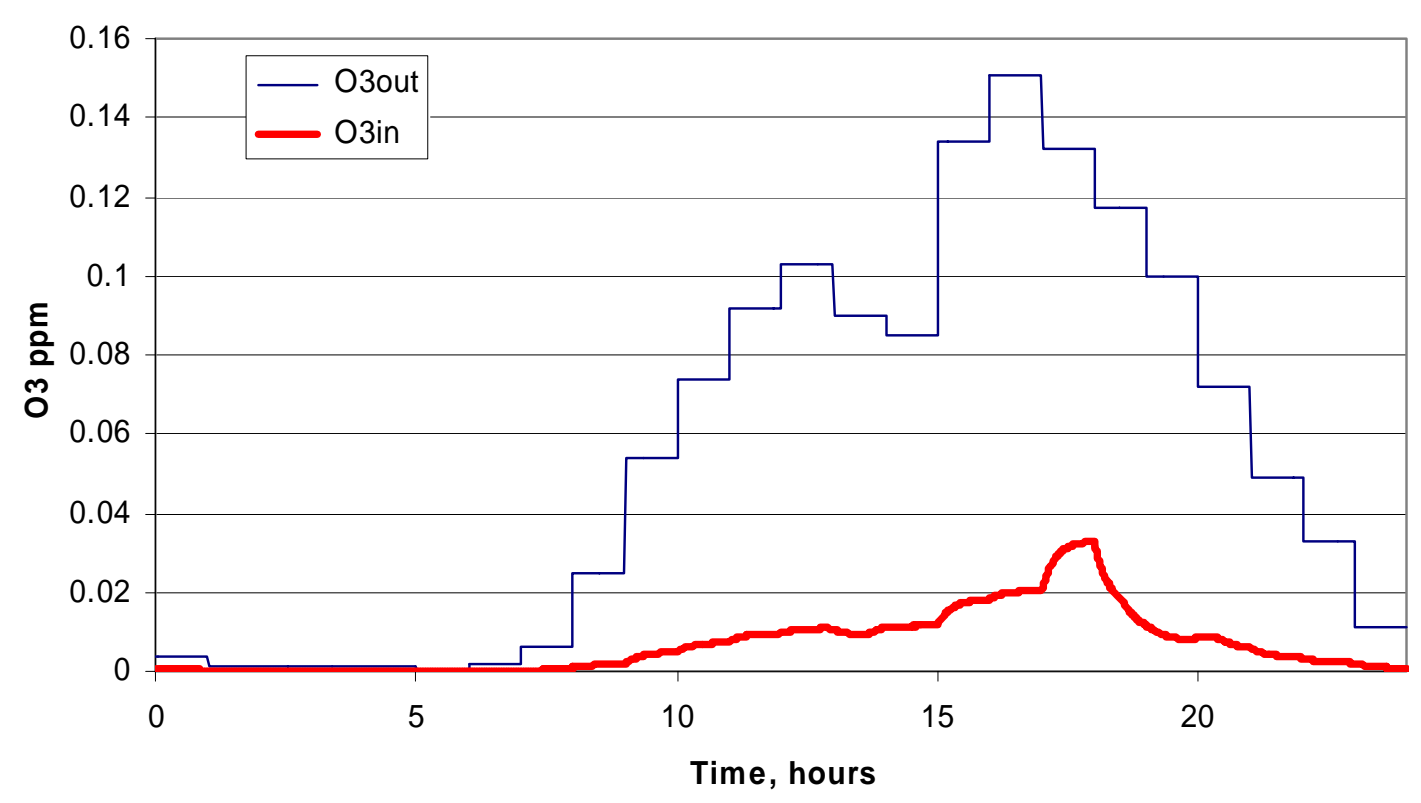

Figure 19. Indoor ozone concentration for surface loss only in CZ10 with continuous exhaust.

Simulations for interior deposition combined with HVAC filtration (but still no envelope filtration) gave the results shown in Figure 20. 


\section{Surface Loss \& 5\% HVAC filter}

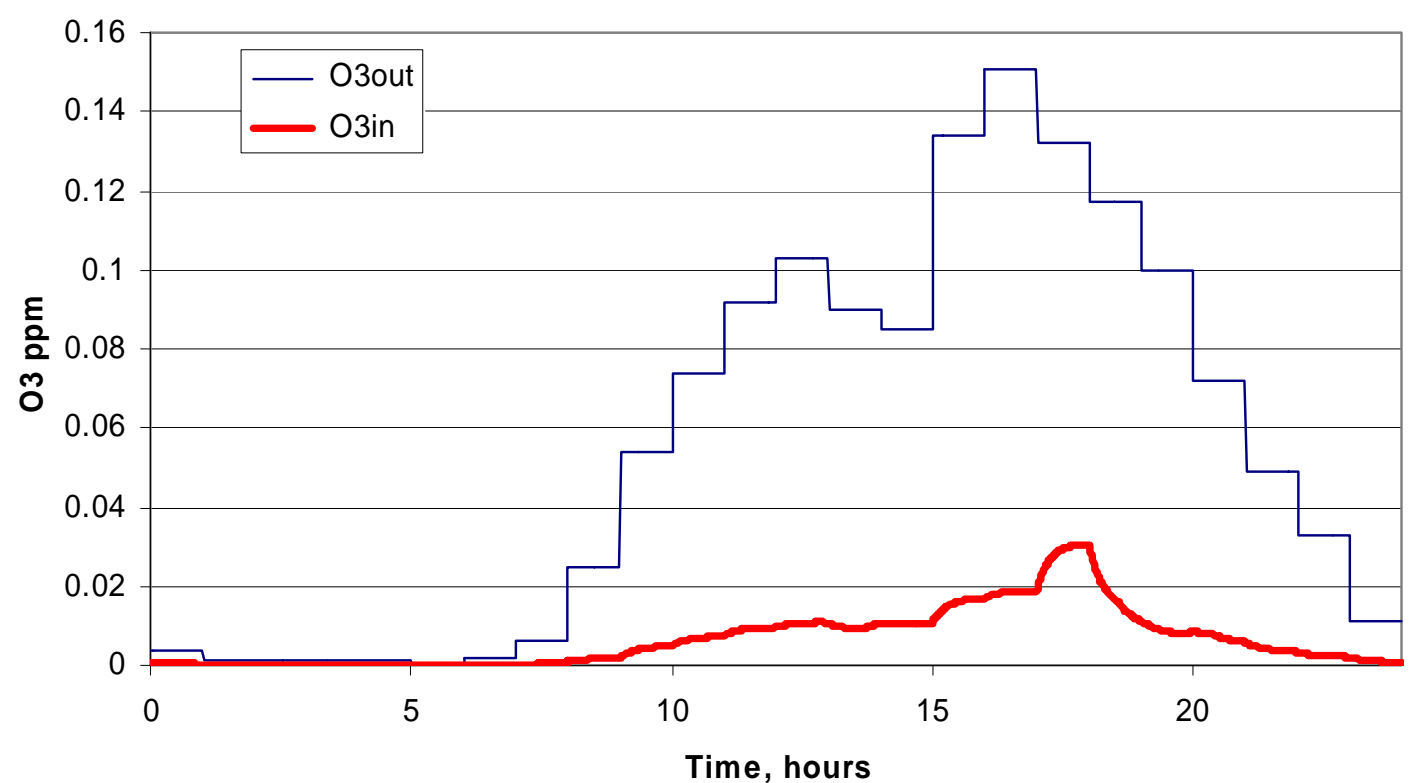

Figure 20. Indoor ozone concentration for surface loss and HVAC filtration in CZ10 with continuous exhaust.

The HVAC filter made very little difference to the ozone concentrations in this case. Just to make sure the calculations were including the HVAC filtration correctly, a simulation was performed with no envelope filtration or interior deposition: i.e., 5\% HVAC filter only. Figure 21 clearly shows the reductions in the afternoon when the cooling system operates, thus confirming that the HVAC filtration calculations are working. 


\section{No Deposition, No envelope}

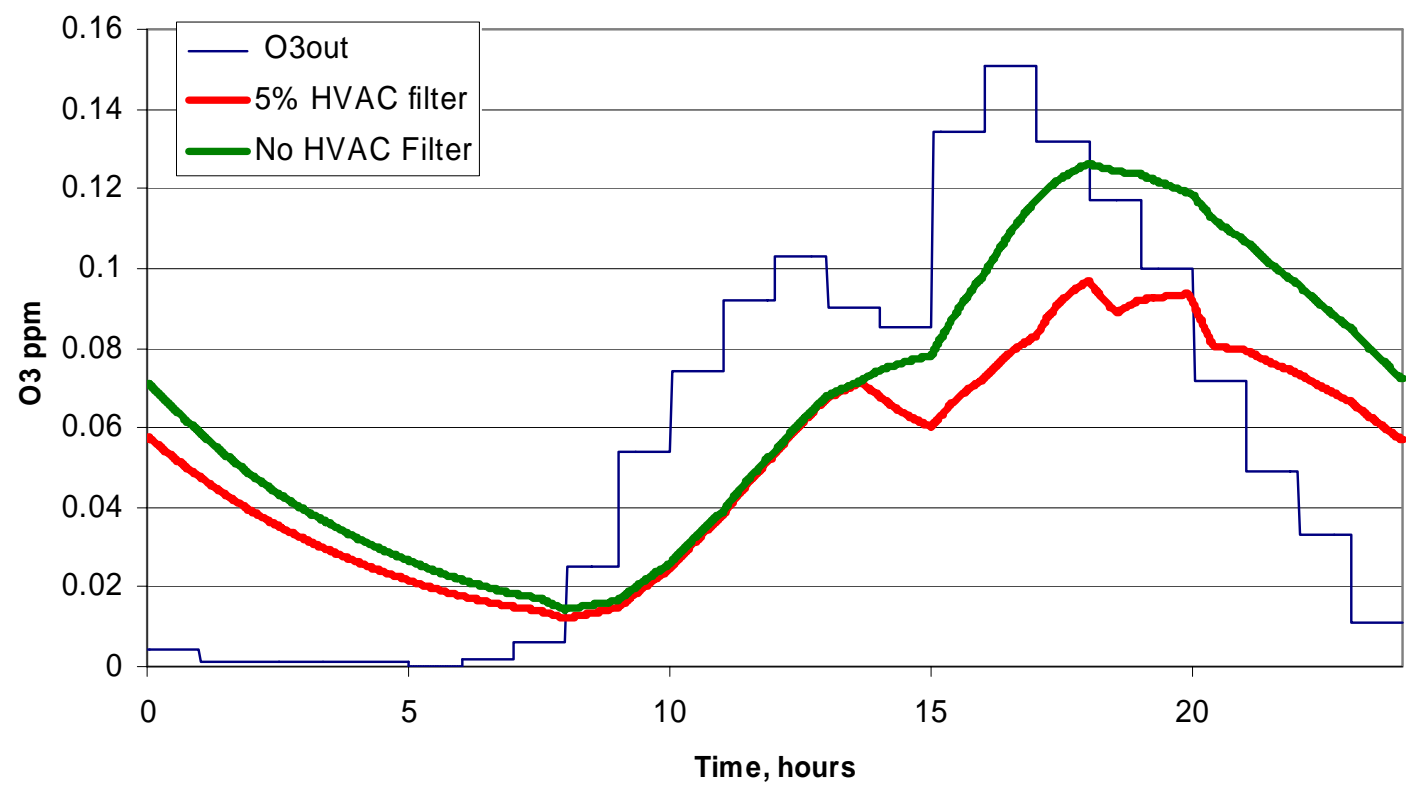

Figure 21. Indoor ozone concentration for HVAC filtration only in CZ10 with continuous exhaust. 
The last independent test was to use the envelope filtration only (i.e., no ISDC or HVAC filtration and no open windows). The results are shown in Figure 22. The indoor concentration averaged $1.3 \%$ of outdoor concentrations. This is too low compared to field measured data discussed earlier. This implies that the envelope filtration is too high if it is assumed that all the air flow in through the walls or ceiling.

\section{Envelope Filtration}

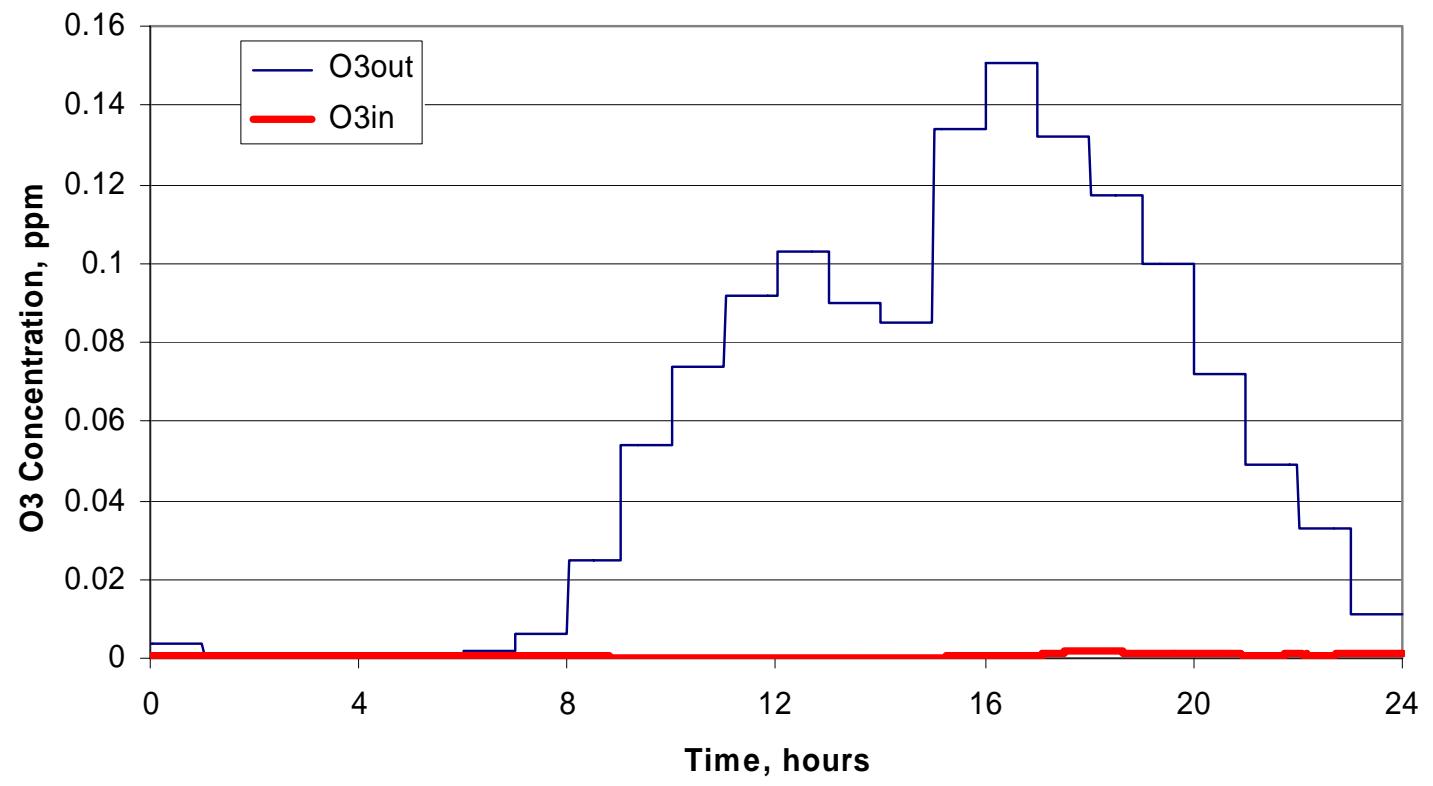

Figure 22. Indoor ozone concentration for envelope filtration only in CZ10. 


\subsection{Ozone Results with half air flow traversing fiberglass $(\mathrm{f}=0.5)$}

The indoor ozone concentrations for the case of half the air flow bypassing the filtration are shown in Figures 23 through 34. As a check on the validity of the results, the concentrations shown in Figure 23 for CZ10 with continuous exhaust can be compared with the field measurements of Lee (1999). For the case shown in Figure 23, the average indoor/outdoor concentration ratio is 5.3\%. For comparison, the three houses in Lee (1999) had windows closed with air conditioning operating and had $\mathrm{I} / \mathrm{O}$ ratios of $0.07,0.09$ and 0.11 . Therefore, the results in the current study are at the low-end of the field data. 


\section{Case 1 - Continuous Exhaust}

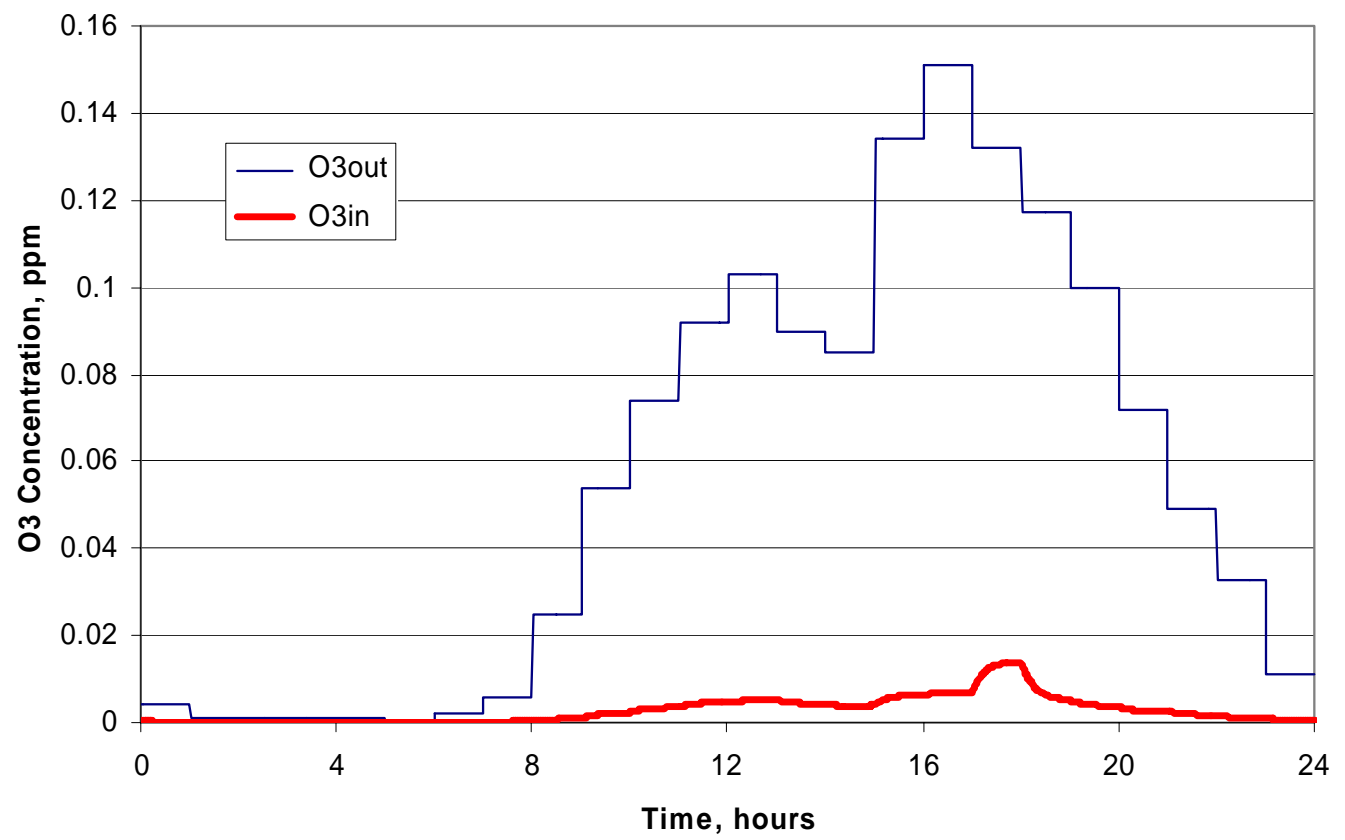

Figure 23. Indoor ozone concentration with half of envelope air flows unfiltered in CZ10 for continuous exhaust.

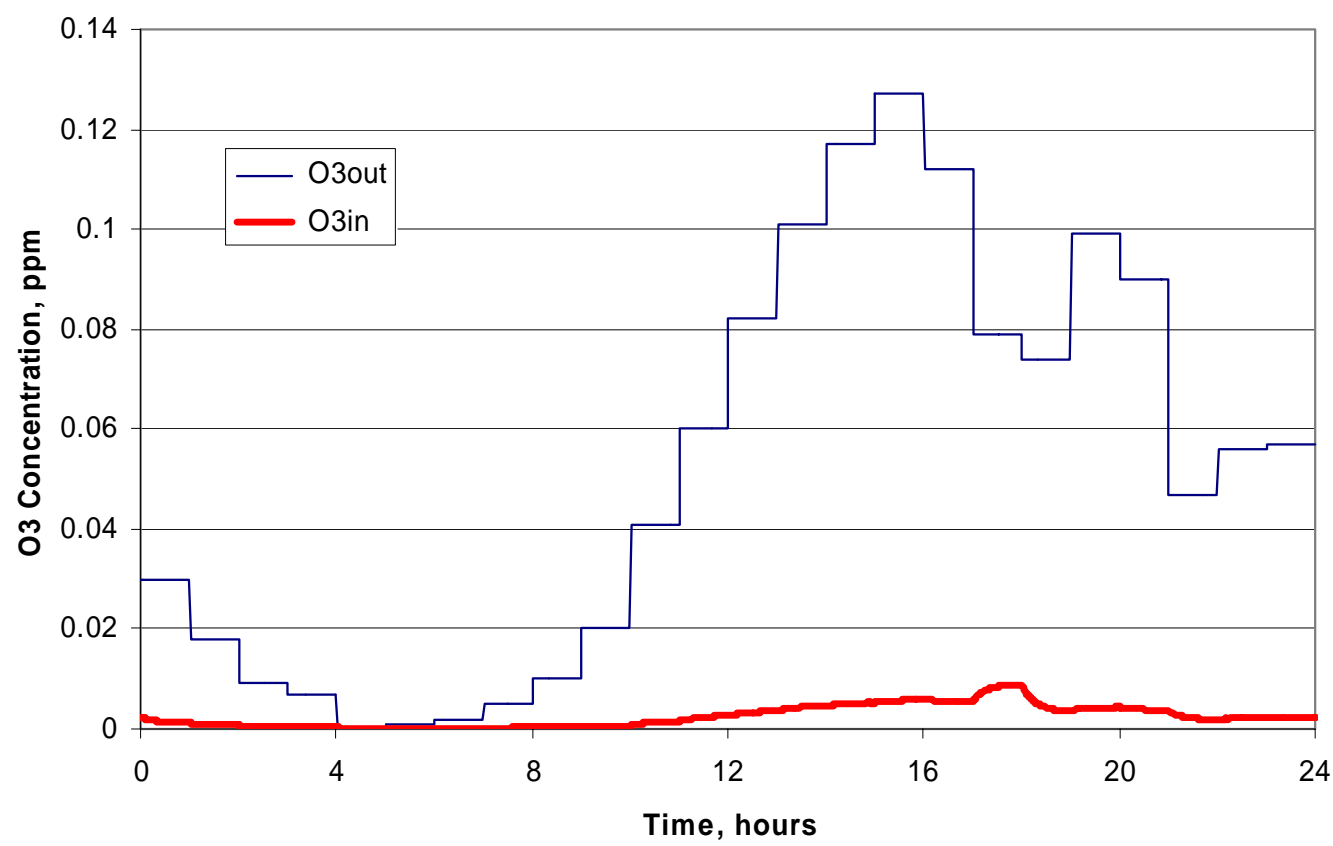

Figure 24. Indoor ozone concentration with half of envelope air flows unfiltered in CZ12 for continuous exhaust. 


\section{Case 2 - Intermittent Exhaust}

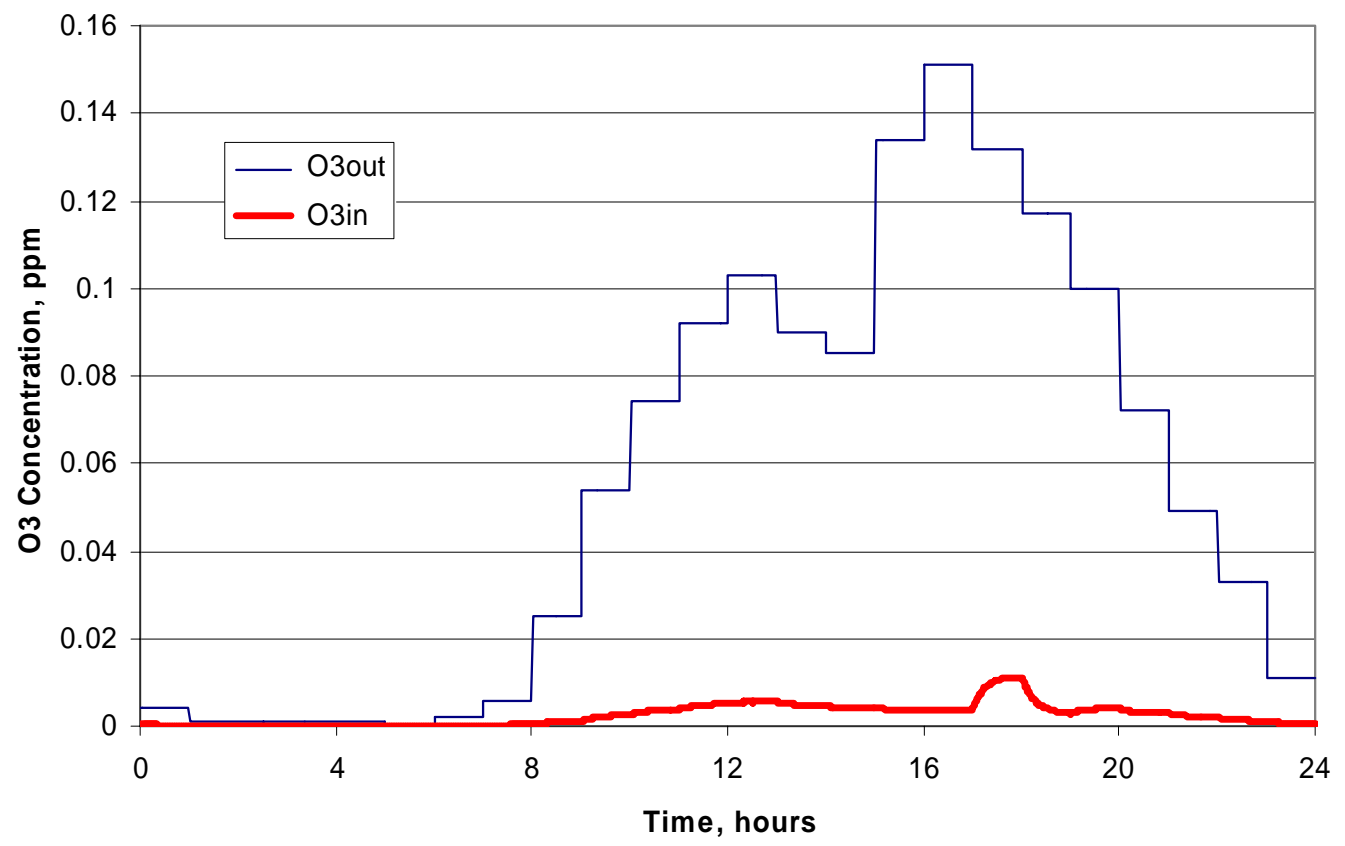

Figure 25. Indoor ozone concentration with half of envelope air flows unfiltered in CZ10 for intermittent exhaust.

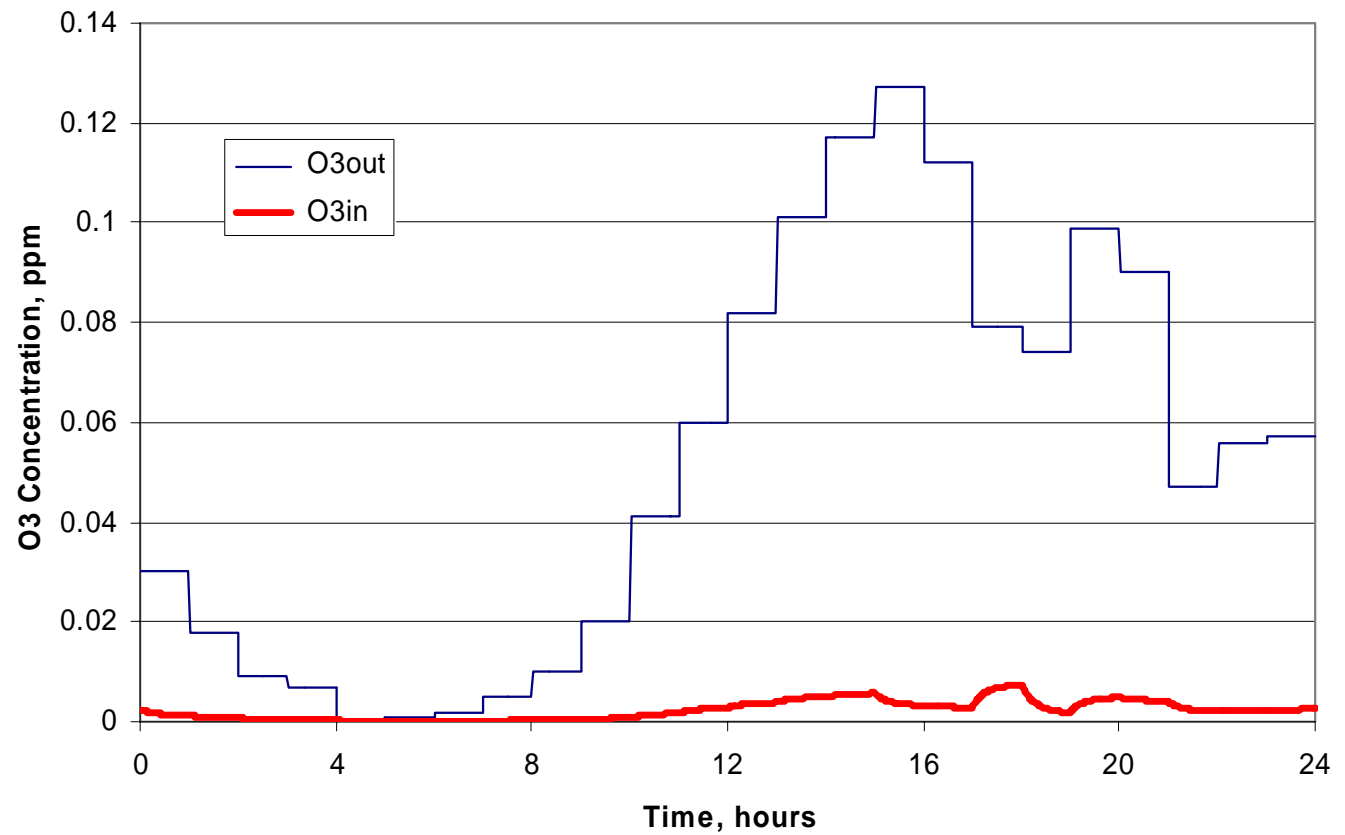

Figure 26. Indoor ozone concentration with half of envelope air flows unfiltered in CZ12 for intermittent exhaust. 


\section{Case 3 - HRV}

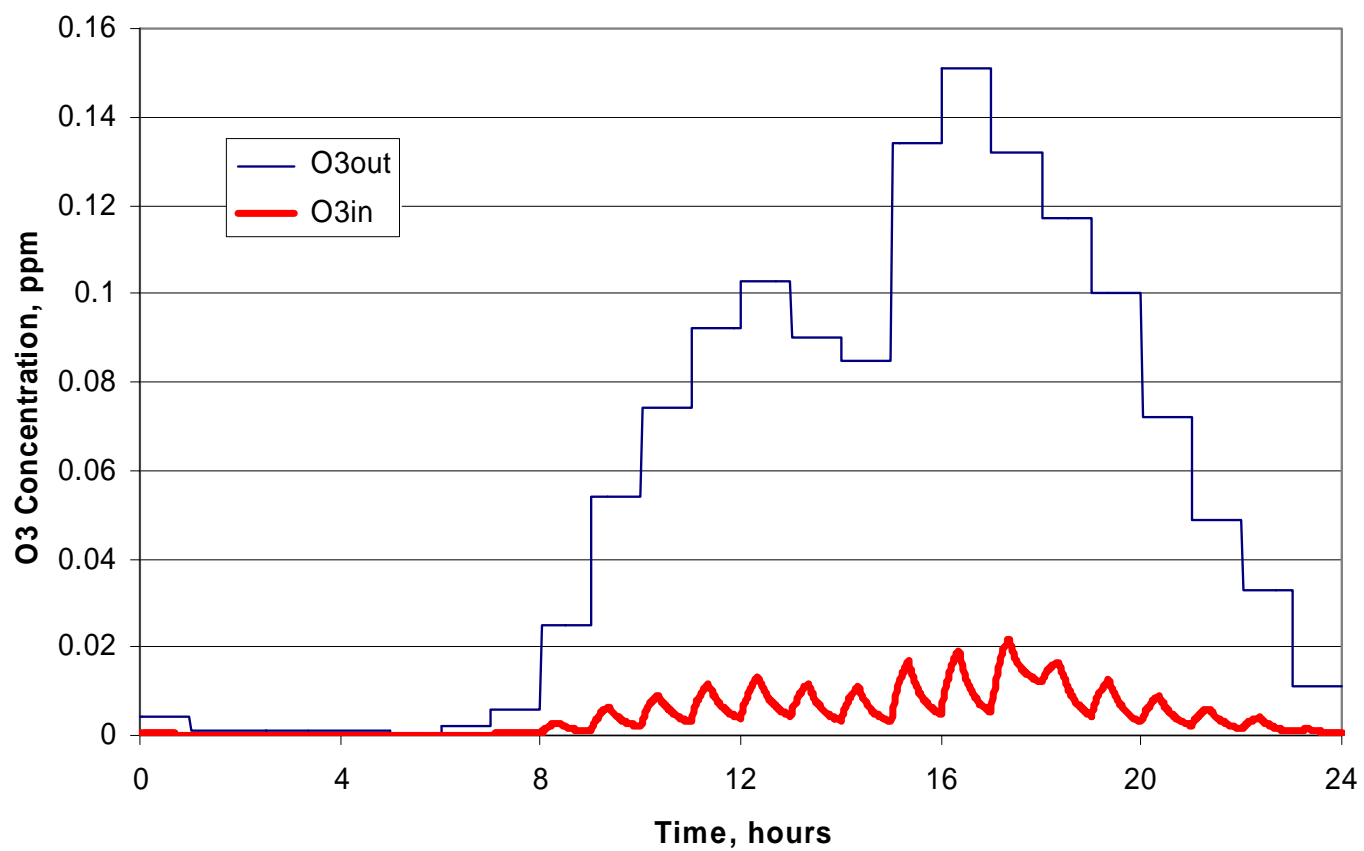

Figure 27. Indoor ozone concentration with half of envelope air flows unfiltered in CZ10 for a Heat Recovery Ventilator.

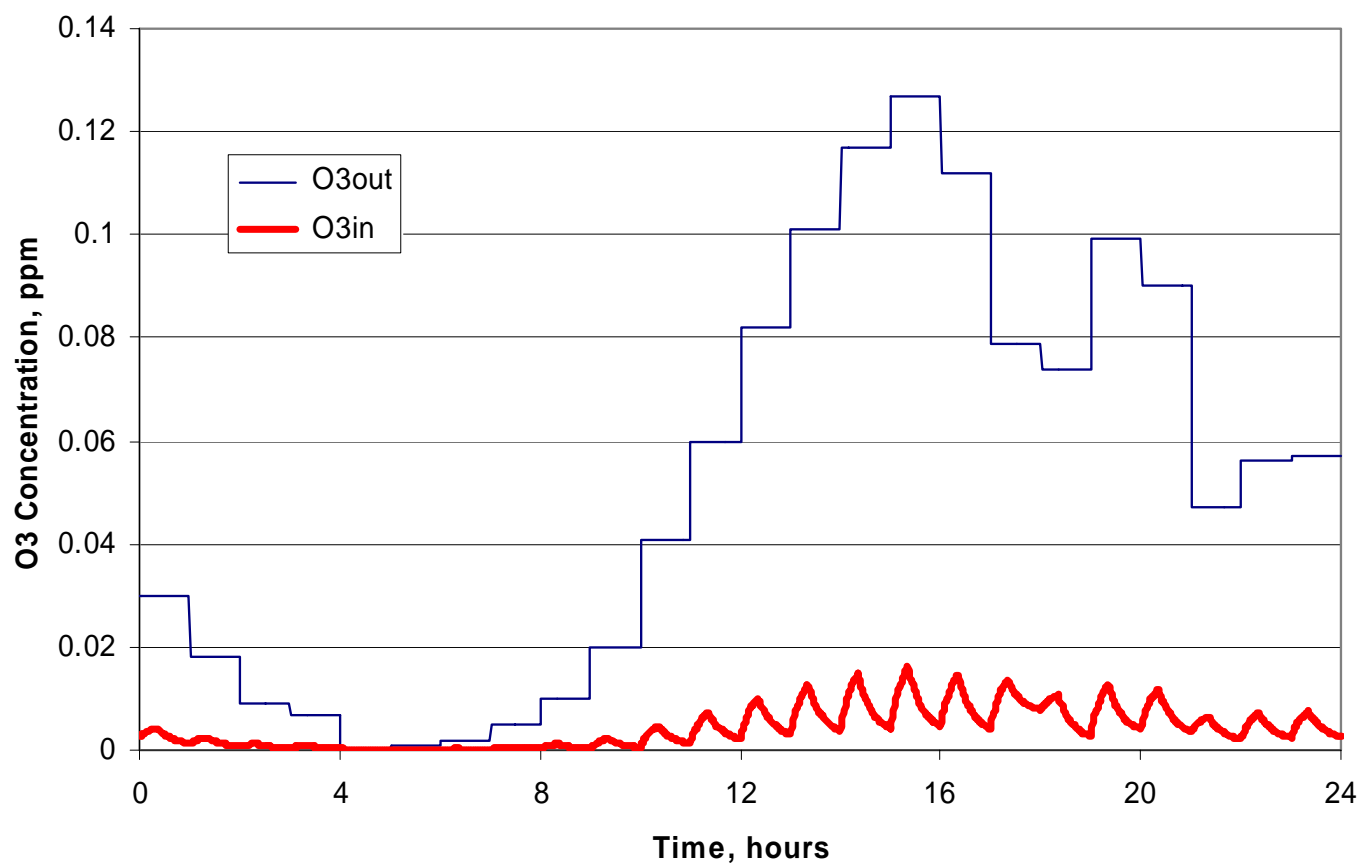

Figure 28. Indoor ozone concentration with half of envelope air flows unfiltered in CZ12 for a Heat Recovery Ventilator. 


\section{Case 4 - CFIS+Continuous Exhaust}

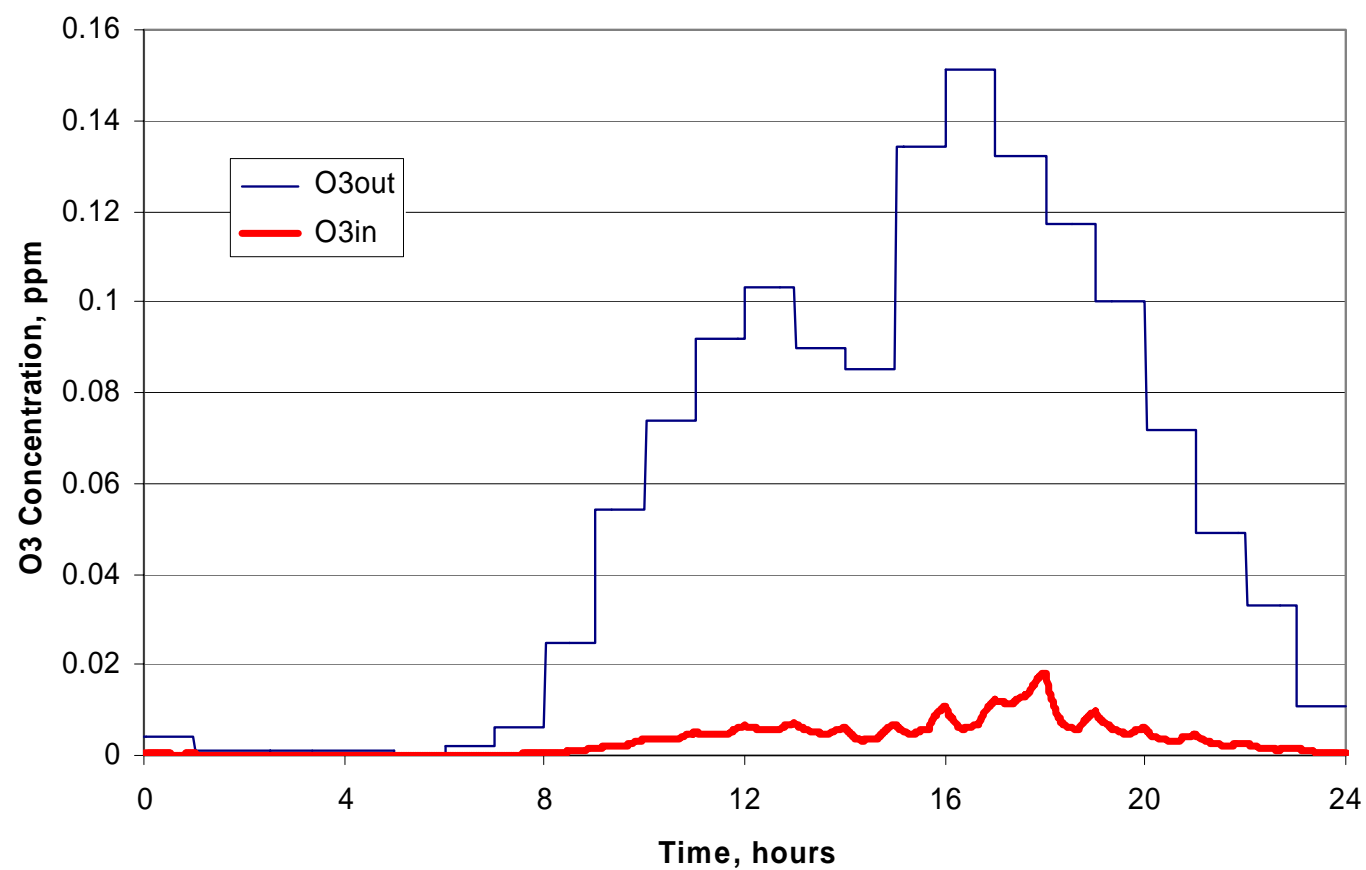

Figure 29. Indoor ozone concentration with half of envelope air flows unfiltered in CZ10 for Central Fan Integrated Supply and Continuous Exhaust.

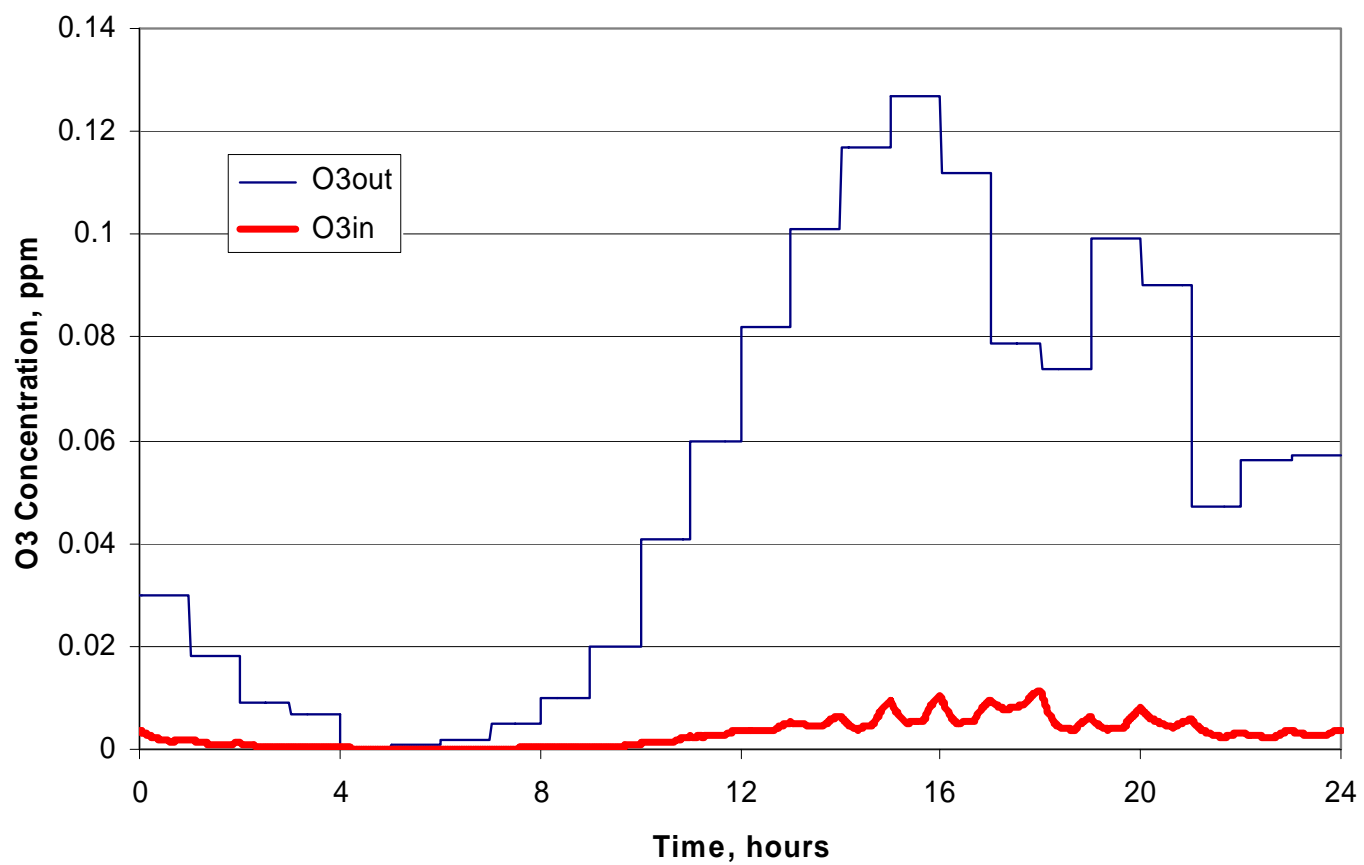

Figure 30. Indoor ozone concentration with half of envelope air flows unfiltered in CZ12 for Central Fan Integrated Supply and Continuous Exhaust. 
Case 5 - Continuous Supply (5\% filtration of supply air)

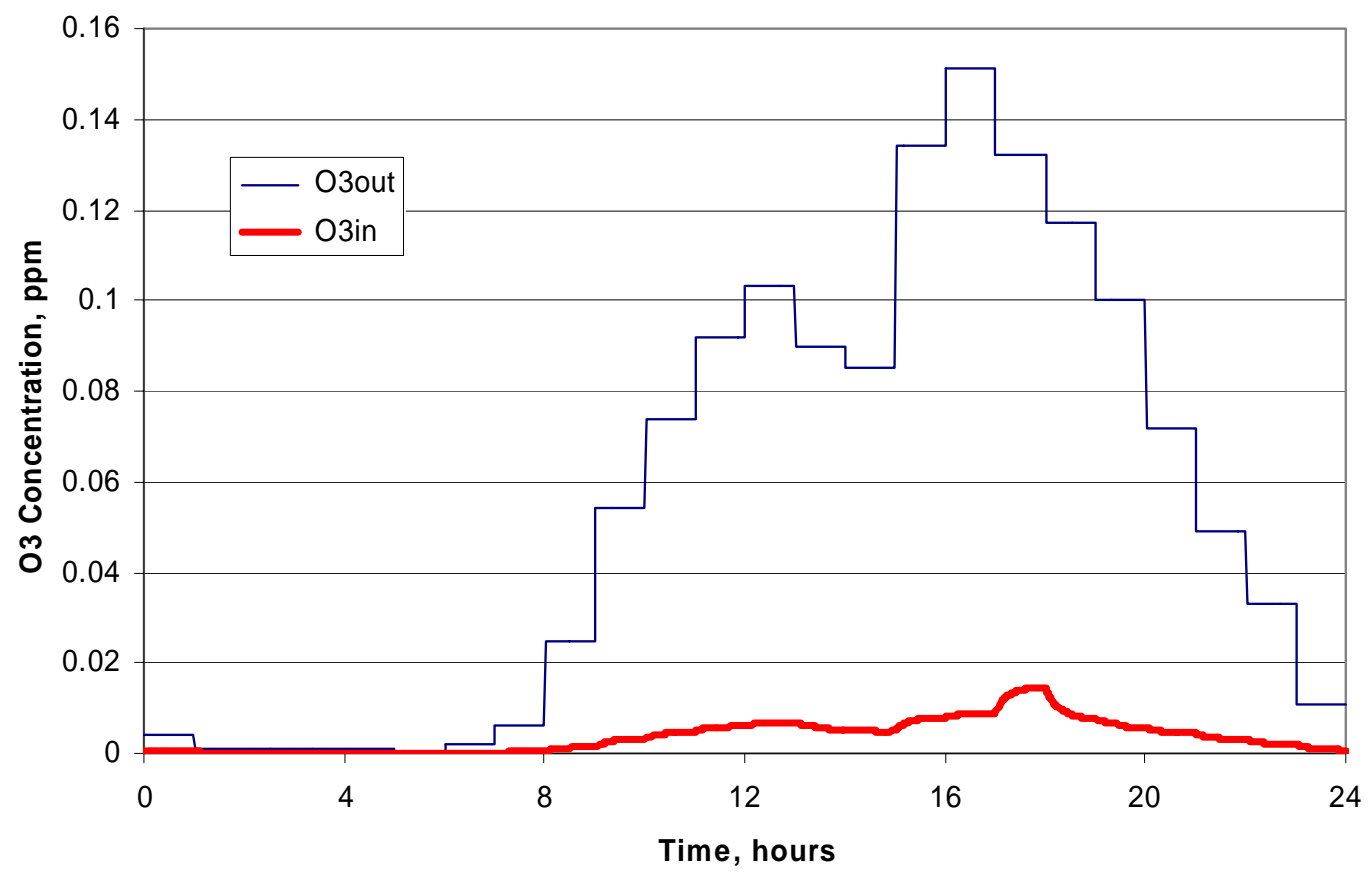

Figure 31. Indoor ozone concentration with half of envelope air flows unfiltered in CZ10 for Continuous Supply.

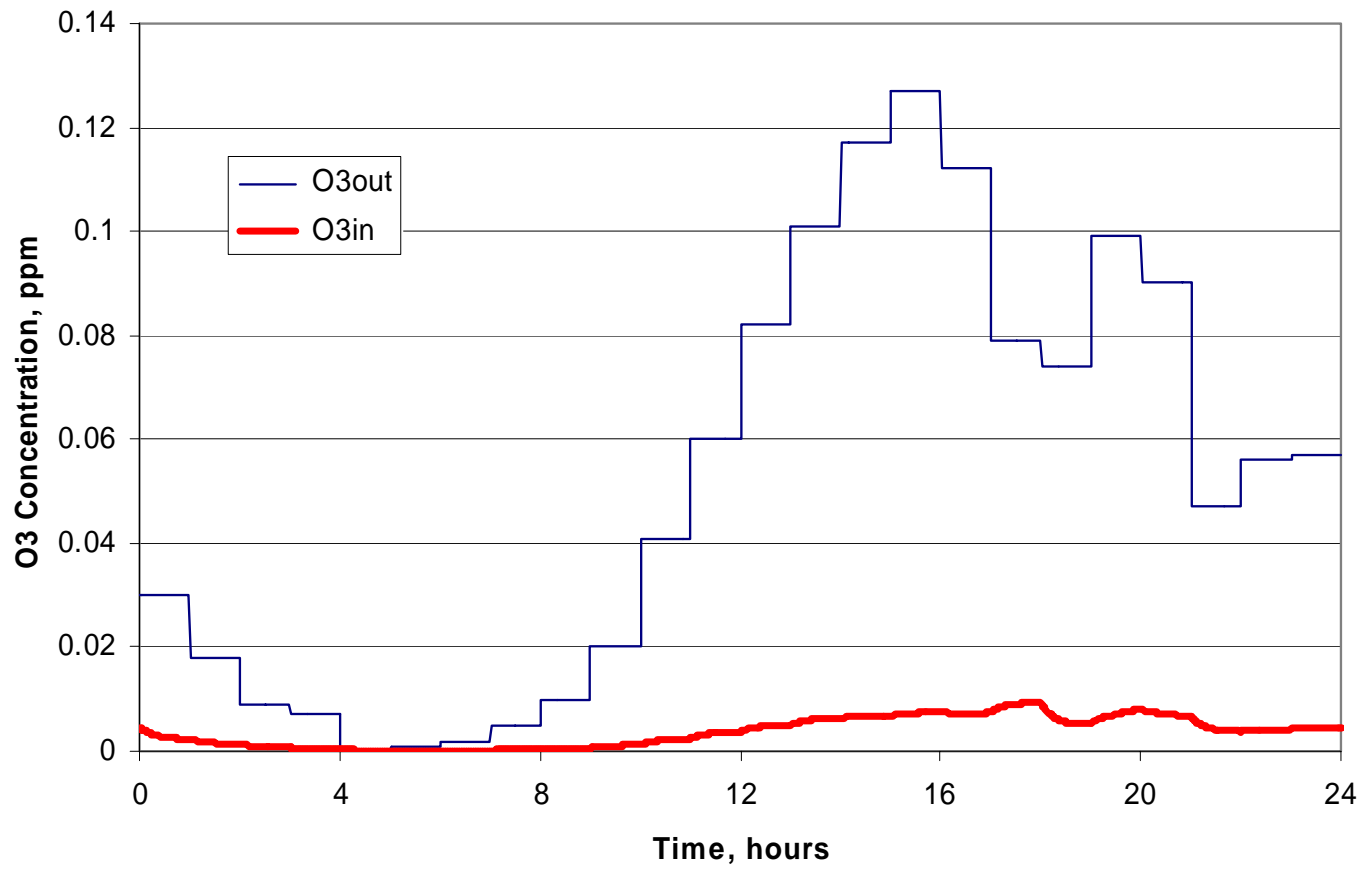

Figure 32. Indoor ozone concentration with half of envelope air flows unfiltered in CZ12 for Continuous Supply. 


\section{Case 6 - Economizer}

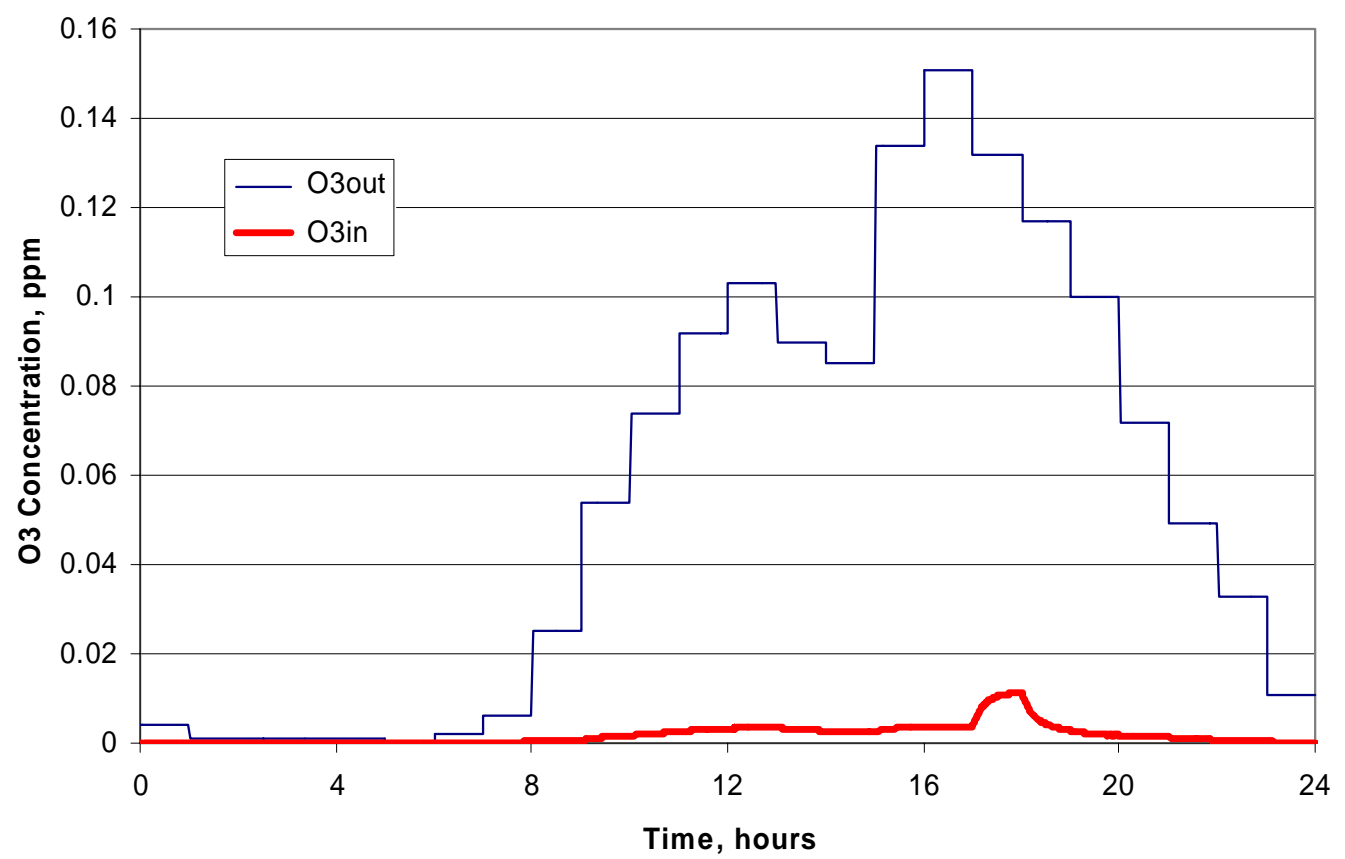

Figure 33. Indoor ozone concentration with half of envelope air flows unfiltered in CZ10 for an Economizer.

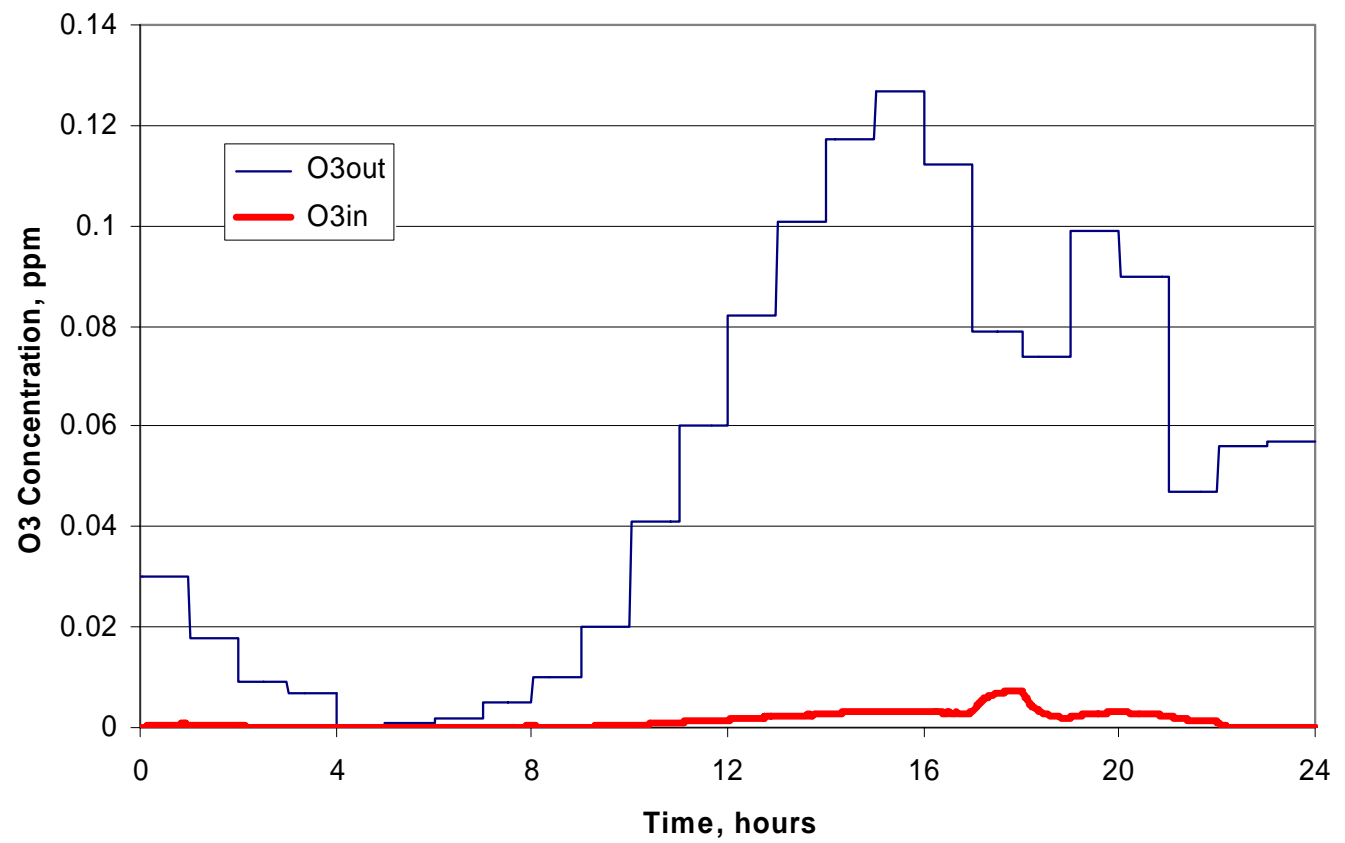

Figure 34. Indoor ozone concentration with half of envelope air flows unfiltered in CZ12 for an Economizer. 


\section{Open Windows}

Measured field data (Lee (1999)) for houses with normally open widows had indoor/outdoor (I/O) concentration ratios averaging $0.68 \pm 0.18$. To see if the simulations can replicate this result, a simulation was run for CZ 10 using open windows - one on the first floor and one on the second floor. Each window had a $1 \mathrm{~m}$ high by $0.5 \mathrm{~m}$ wide opening. The results (including ISDC, $5 \%$ HVAC filter and half filtered ceiling and wall flows) are shown in Figure 35. The ratio of average $\mathrm{I} / \mathrm{O}$ concentration is 0.47 (the average of the ratios is 0.40 and ratio of peaks is 0.58 ). The big increase in ventilation results, as expected, in large increases in interior ozone. Without knowing more about the weather or window opening details in the measured field data, the results are reasonable.

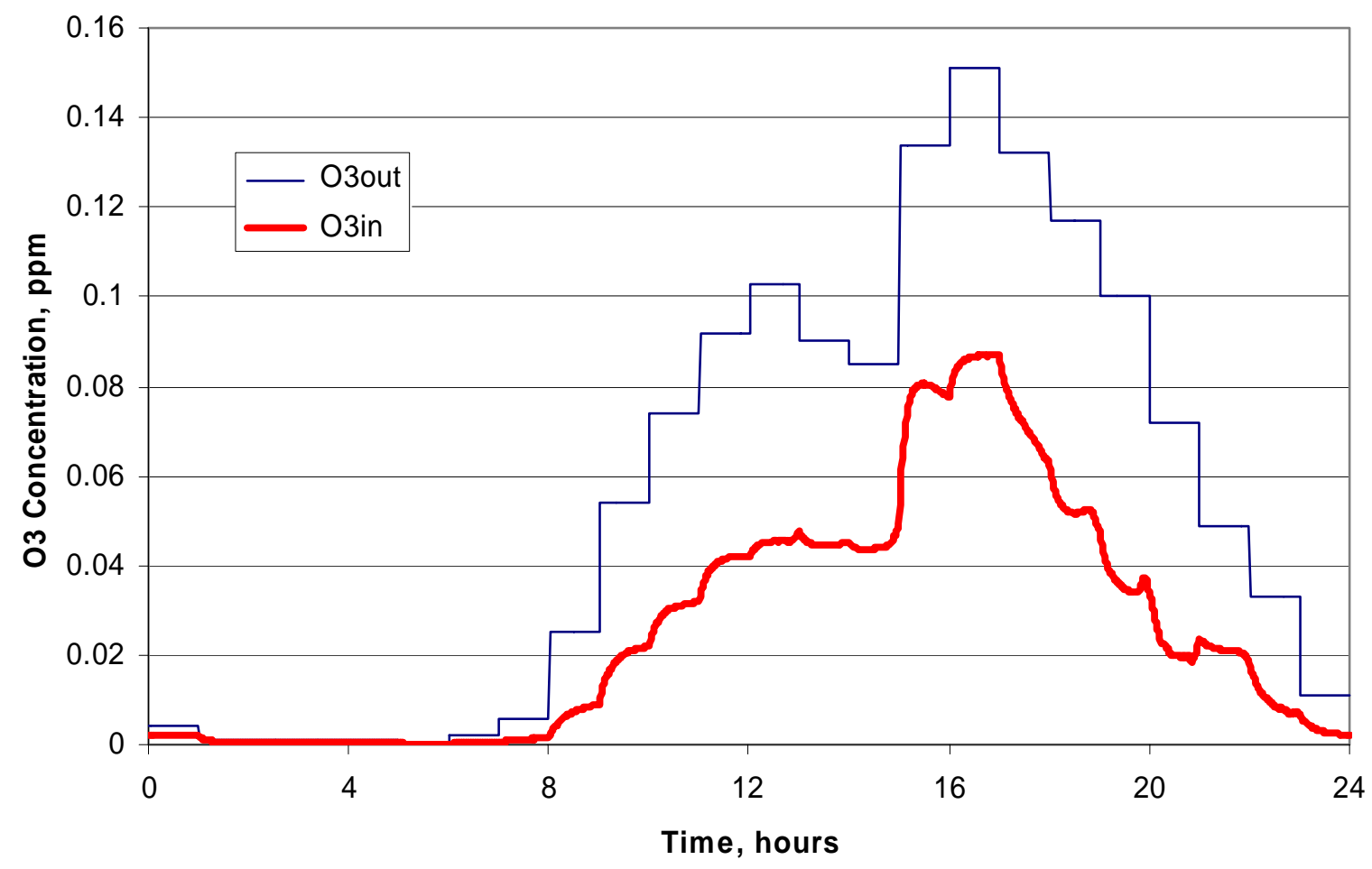

Figure 35. Indoor ozone concentration for open windows in CZ10. 


\subsection{Results and Discussion}

For each case, the average air change rate was calculated, together with the average indoor ozone concentration, the average indoor/outdoor concentration ratio (all over a 24 hour period) and the indoor peak. Table 3 summarizes all these results. For comparison purposes, the outdoor peak and average concentrations are: 0.056 and 0.151 ppm for CZ10 and 0.052 and 0.127 ppm for CZ12.

Table 3. Summary of Air Change Rates and Ozone Concentrations

\begin{tabular}{|c|c|c|c|c|c|}
\hline $\begin{array}{l}\text { Climate } \\
\text { Zone }\end{array}$ & Case & $\begin{array}{l}\text { Average Air } \\
\text { Change Rate, } \\
\text { ACH }\end{array}$ & $\begin{array}{l}\text { Average } \\
\text { Indoor Ozone } \\
\text { Concentration } \\
(\mathrm{ppm})\end{array}$ & $\begin{array}{l}\text { Average } \\
\text { Indoor/Outdoor } \\
\text { Ratio }(\%)\end{array}$ & $\begin{array}{l}\text { Indoor Peak } \\
\text { Concentration } \\
(\mathrm{ppm})\end{array}$ \\
\hline \multirow[t]{7}{*}{10} & $\begin{array}{l}\text { Continuous } \\
\text { Exhaust }\end{array}$ & 0.330 & 0.0028 & $5.3 \%$ & 0.0139 \\
\hline & $\begin{array}{l}\text { Intermittent } \\
\text { Exhaust }\end{array}$ & 0.330 & 0.0025 & $4.7 \%$ & 0.011 \\
\hline & HRV & 0.451 & 0.0045 & $8.3 \%$ & 0.0218 \\
\hline & HRV $50 \%$ filter & 0.451 & 0.0016 & $2.8 \%$ & 0.0082 \\
\hline & $\begin{array}{l}\text { CFIS }+ \text { continuous } \\
\text { exhaust }\end{array}$ & 0.386 & 0.0034 & $6.2 \%$ & 0.0183 \\
\hline & $\begin{array}{l}\text { Continuous } \\
\text { Supply }\end{array}$ & 0.304 & 0.0037 & $6.8 \%$ & 0.0145 \\
\hline & Economizer & 1.645 & 0.0018 & $3.3 \%$ & 0.011 \\
\hline 10 & Open Windows & 2.489 & 0.026 & $46.7 \%$ & 0.087 \\
\hline \multirow[t]{7}{*}{12} & $\begin{array}{l}\text { Continuous } \\
\text { Exhaust }\end{array}$ & 0.320 & 0.0025 & $5.0 \%$ & 0.0088 \\
\hline & $\begin{array}{l}\text { Intermittent } \\
\text { Exhaust }\end{array}$ & 0.320 & 0.0023 & $4.6 \%$ & 0.0073 \\
\hline & HRV & 0.441 & 0.0042 & $8.3 \%$ & 0.0162 \\
\hline & HRV 50\% Filter & 0.441 & 0.0016 & $3.1 \%$ & 0.0070 \\
\hline & $\begin{array}{l}\text { CFIS+continuous } \\
\text { exhaust }\end{array}$ & 0.378 & 0.0030 & $5.9 \%$ & 0.0114 \\
\hline & $\begin{array}{l}\text { Continuous } \\
\text { Supply }\end{array}$ & 0.325 & 0.0037 & $7.1 \%$ & 0.0093 \\
\hline & Economizer & 1.417 & 0.0014 & $2.9 \%$ & 0.0073 \\
\hline
\end{tabular}

The results show that in each case the indoor ozone concentrations are much lower than those outside, typically about $5 \%$ of outdoor concentration on average. In general, the envelope is a better ozone filter than typical HVAC filters, so systems that depressurize the house lead to lower indoor ozone levels. The peak levels follow the same trends.

The following five key conclusions can be drawn from these results: 
1. Staying indoors reduces exposure by $80 \%$ to $90 \%$ even with mechanical ventilation systems operating.

2. Continuous Supply limits envelope filtering and results in highest indoor concentrations.

3. The higher ventilation rate for HRV results in greater indoor concentrations

4. The reduced ventilation rates during the peak outdoor ozone periods for the economizer result in lower concentrations (about 10 hours of no mechanical ventilation credit can be taken for 6 hours of economizer operation)

5. Open windows and resulting unfiltered high ventilation rate significantly reduces benefit of being indoors. 


\subsection{Future Work}

This study has shown that there is significant potential for ozone removal by building envelopes. This removal is due to the reactions between ozone and surfaces within the building envelope. These reactions may produce byproducts that pose health risks themselves. A key aspect of future work should be to examine these byproducts of filtration. The following sections describe some background for these future activities.

\section{Byproducts of ozone-initiated chemistry}

Ozone reactions on materials not only cause the removal of ozone from indoor air, but also the formation of reaction byproducts. Depending on the chemical nature of the byproducts formed, the net effect of ozone-surface chemistry can range from improved indoor air quality (ozone destroyed and byproducts are either not volatile or are innocuous) to potentially worsened indoor air quality (ozone destruction accompanied by significant formation of volatile and more potent pollutants). This range of possible outcomes presents both a challenge and an opportunity. The challenge is that to properly and completely assess the impact of ozone-surface reactions on indoor air quality, one must account for the formation of volatile byproducts. The opportunity is that, with sufficient understanding, it may be possible to deliberately engineer materials either for the building envelope or for indoor surfaces that effectively scavenge ozone while minimizing the production of harmful, volatile byproducts. However, the present understanding of the formation of volatile byproducts from ozone-initiated chemistry is far from complete (Morrison 2008) and that constrains the ability even to properly assess the risks.

To elaborate, consider a simple model for predicting the level of ozone and its byproducts in indoor air. Assume that ozone loss in the building envelope is negligible and instead ozone decomposes on indoor surfaces at a first-order rate, with rate constant $k$ (units $=\mathrm{h}^{-1}$ ). Assume that the decomposition process leads to the formation of volatile byproducts with a certain yield, $Y$, which represents the moles of volatile byproduct generated per mole of ozone consumed. Let $a$ represent the air-exchange rate $\left(\mathrm{h}^{-1}\right)$. For the sake of simplicity, assume that the outdoor concentration of ozone is time invariant at a level $C_{\text {out }}$. Then, the steady-state indoor concentrations of ozone $\left(C_{o}\right)$ and volatile byproducts $\left(C_{p}\right)$ are as follows:

$$
\begin{aligned}
& C_{\text {o }}=\frac{a}{a+k} C_{\text {out }} \\
& C_{p}=\frac{k}{k+a} Y \times C_{\text {out }}
\end{aligned}
$$

With typical values of $k=3 \mathrm{~h}^{-1}$ and $a=0.5 \mathrm{~h}^{-1}$, the expected indoor-outdoor ozone ratio would be $C_{o} / C_{\text {out }} \sim 0.14$. The byproduct to outdoor ozone ratio would be $C_{p} / C_{\text {out }} \sim 0.86 \mathrm{Y}$. From this simple example, depending on the yield, the concentration of volatile byproducts can exceed the indoor concentration of ozone and can also rise to a sizeable fraction of the outdoor ozone level.

Table 4 summarizes the published literature reporting measurements of byproduct yields from ozone-initiated chemistry in indoor environments. The byproducts that have received the greatest attention are oxygenated organics, including aldehydes, ketones, and organic acids. 
Recently, characterization efforts have included the oxidation products of squalene ${ }^{12}$ in human skin oil, such as 4-oxopentanal (4-OPA) and 6-methyl-5-hepten-2-one (6-MHO). Although limited in scope, the evidence suggests an overall yield in the range 0.1-0.5. Studies are lacking on byproduct formation from ozone reaction with common materials in the building envelope, such as fiberglass insulation. Health effects data with which to assess risks from exposure to the byproducts of ozone-initiated chemistry are also limited.

Table 4. Summary of experiments reporting byproduct yields from ozone-initiated chemistry in indoor environments or on indoor materials.

\begin{tabular}{|c|c|c|c|c|}
\hline Materials tested & Byproducts studied & Yields & Reference & Remarks \\
\hline $\begin{array}{l}\text { New and used carpet, } \\
\text { seat fabric, and plastic } \\
\text { from aircraft cabins; } \\
\text { laundered \& soiled } \\
\text { clothing fabrics }\end{array}$ & $\begin{array}{l}\mathrm{C}_{1}-\mathrm{C}_{10} \text { saturated } \\
\text { aldehydes, acetone, 6- } \\
\mathrm{MHO}\end{array}$ & $0.08-0.22$ & Coleman et al., 2008 & $\begin{array}{l}\text { Chamber study; low RH } \\
(10 \%) \text { and short } \\
\text { residence times to } \\
\text { simulate aircraft cabins }\end{array}$ \\
\hline $\begin{array}{l}\text { Carpet (stored, and } \\
\text { aired) }\end{array}$ & $\begin{array}{lr}\mathrm{C}_{1}-\mathrm{C}_{13} & \mathrm{n} \text {-aldehydes; } \\
\text { several } & \text { unsaturated } \\
\text { aldehydes } & \end{array}$ & $\begin{array}{l}\text { Stored }-0.37-0.74 \\
\text { (median }=0.52) ; \text { Aired } \\
-0.13-0.67 \text { (median }= \\
0.19 \text { ) }\end{array}$ & $\begin{array}{l}\text { Morrison and Nazaroff, } \\
2002\end{array}$ & Chamber study \\
\hline Latex paint & $\begin{array}{l}\text { Organic } \\
\text { aldehydes, ketones }\end{array}$ & $\begin{array}{lr}\text { Formaldehyde } & 0.0-0.28 \\
\text { (median = } & 0.03 \text { ); } \\
\text { acetaldehyde } & 0.0-0.13 \\
\text { (median = } & 0.01 \text { ); } \\
\text { acetone } & 0.0-0.77 \\
\text { (median = 0) } & \\
\end{array}$ & Reiss et al., 1995 & Chamber study \\
\hline $\begin{array}{l}\text { Kitchen countertops } \\
\text { and floors; living-room } \\
\text { carpets and walls }\end{array}$ & $\begin{array}{ll}\mathrm{C}_{1}-\mathrm{C}_{10} & \text { saturated } \\
\text { aldehydes, } & \text { 2-nonenal }\end{array}$ & $\begin{array}{l}0.00-0.51 \quad \text { (median }= \\
0.18 ; \text { mean }=0.23 \text { ) }\end{array}$ & $\begin{array}{l}\text { Wang and Morrison, } \\
2006\end{array}$ & Field study \\
\hline $\begin{array}{l}\text { Simulated, } \\
\text { aircraft cabin }\end{array}$ & $\begin{array}{l}\text { Organic acids, } \\
\text { aldehydes, ketones, 6- } \\
\text { MHO, 4-OPA }\end{array}$ & $0.25-0.30$ & Weschler et al., 2007 & $\begin{array}{l}\text { Only study to date to } \\
\text { investigate ozone- } \\
\text { initiated chemistry with } \\
\text { human occupants }\end{array}$ \\
\hline
\end{tabular}

\section{Time dependence of surface reactivity: Aging and recovery}

When ozone reactions with indoor materials are studied in laboratory chambers, it is consistently observed that the rate of reaction tends to decline as the duration of the exposure period increases. This phenomenon is known as "aging." It is thought to result from the consumption of ozone-reactive molecules (e.g., organic molecules with unsaturated $\mathrm{C}=\mathrm{C}$ bonds) on material surfaces. Many papers have been published investigating this phenomenon empirically, as summarized in Table 5. There has been little effort to date that systematically investigates the aging phenomenon in a way that reveals underlying causal mechanisms or that allows reliable extrapolation from the empirical evidence to predict outcomes for conditions not tested.

It is also observed that, after an ozone exposure episode, if the material is kept in an ozonefree environment for a period of hours to days, its capacity to react with ozone can be partially or completely restored (Klenø et al., 2001; Zhao et al., 2007). Recovery might occur because gaseous ozone-reactive organics deposit onto surfaces during the ozone-free period. Or, it might occur because ozone-reactive organics migrate from within the bulk of the material to the surface to restore reactive sites. Although the aging phenomenon is an important feature of laboratory

${ }^{12}$ Squalene is a naturally occurring organic compound that can be oxidized by ozone to form other compounds. 
investigations of ozone-material reactions, it is not clear how it applies to ozone loss indoors. In the study by (Lee et al., 1999) aging did not appear to play an important role however, in ozone loss indoors Wang and Morrison (2006) observed that older residences have lower surface reaction probabilities. This suggests that in future work, the penetration analysis should include a wider range of reaction probabilities. One possible explanation for these different observations is that the reactive capacity of materials in real indoor environments for ozone is not substantially consumed on a daily basis by the indoor ozone load. In addition, the ozone level typically is low overnight, which might allow for restoration of any degradation in the ozone-scavenging capacity of indoor surfaces.

Table 5. Papers reporting experimental investigations of aging in the reaction of ozone with indoor materials.

\begin{tabular}{|l|l|}
\hline Materials studied & Reference \\
\hline Aluminum chamber, stainless steel chamber & Mueller et al., 1973 \\
\hline $\begin{array}{l}\text { Cotton muslin, lamb's wool, neoprene, plywood, nylon, polyethylene sheet, linen, Lucite, } \\
\text { aluminum, plate glass }\end{array}$ & Sabersky et al., 1973 \\
\hline Latex paint & Reiss et al., 1994 \\
\hline Galvanized sheet steel (HVAC), new and used duct liners & Morrison et al., 1998 \\
\hline Carpet, nylon and olefin & Morrison et al., 2000 \\
\hline $\begin{array}{l}\text { Carpet, linoleum, oiled beech parquet, oiled ash, untreated ash, lacquered ash, gypsum } \\
\text { board (painted and unpainted), melamine-coated particle board, stainless steel, paper }\end{array}$ & Klenø et al., 2001 \\
\hline Fiberglass & Liu and Nazaroff, 2001 \\
\hline Concrete tiles, glass, activated carbon cloth & Grøntoft, 2002 \\
\hline HVAC filters (new, used, sooty) & Hyttinen et al., 2006 \\
\hline HVAC filters (clean, loaded) & Zhao et al., 2007 \\
\hline $\begin{array}{l}\text { Carpet (new and used), plastic (new and used), seat fabric (new and used); polyester,, } \\
\text { wool, and cotton clothing fabrics (laundered and soiled) }\end{array}$ & Coleman et al., 2008 \\
\hline
\end{tabular}




\subsection{References}

ASHRAE Standard 62.2. 2004. "Ventilation and Acceptable Indoor Air Quality in Low-Rise Residential Buildings," American Society of Heating, Refrigerating and Air Conditioning Engineers, Atlanta, GA.

ASHRAE Fundamentals Handbook. 2005. American Society of Heating, Refrigerating and Air Conditioning Engineers, Atlanta, GA.

Avol EL, Navidi WC, Colome SD, 1998. Modeling ozone levels in and around southern California homes, Environmental Science \& Technology 32, 463-468.

Bates, D.V. 2005. Ambient Ozone and Mortality. Epidemiology, Vol. 16, No. 4, July 2005. Lippincott Williams and Wilkins.

California Air Resources Board. 2005. Review of the California Ambient Air Quality Standard for Ozone. California Air resources Board, Sacramento, CA.

California Energy Commission. 2005. Title 24, Part 6, of the California Code of Regulations:

California's Energy Efficiency Standards for Residential and Nonresidential Buildings.

California Energy Commission, Sacramento, CA.

Cano-Ruiz, J.A., Modera, M.P. and Nazaroff, W.W. 1992. Indoor Ozone Concentrations:

Ventilation Rate Impacts and Mechanisms of Outdoor Concentration Attenuation. Proc. $13^{\text {th }}$ AIVC Conference, Air Infiltration and Ventilation Center, Coventry, UK.

Coleman, B.K., Destaillats, H., Hodgson, A.T., Nazaroff, W.W., 2008. Ozone consumption and volatile byproduct formation from surface reactions with aircraft cabin materials and clothing fabrics, Atmospheric Environment 42, 642-654.

Grøntoft, T, 2002. Dry deposition of ozone on building materials. Chamber measurements and modeling of the time-dependent deposition, Atmospheric Environment 36, 5661-5670.

Grøntoft, T. and Raychaudhuri, M.R. 2004. Compilation of tables of deposition velocities for $\mathrm{O}_{3}$, $\mathrm{NO}_{2}$ and $\mathrm{SO}_{2}$ to a range of indoor surfaces, Atmospheric Environment 38, 533-544.

Gundel, L., Sullivan, D., Katsapov, G., and Fisk, W. 2002. A Pilot Study of Energy Efficient Air Cleaning for Ozone. LBNL 51836. Lawrence Berkeley National Laboratory, Berkeley, CA.

Hyttinen M, Pasanen N, Kalllokoski P, 2006. Removal of ozone on clean, dusty and sooty supply air filters. Atmospheric Environment 40, 315-325.

Kleno, J.G., Clausen, P.A., Weschler, C.J., and Wolkoff, P. 2001. Determination of ozone removal rates by selected building products using the FLEC emission cell. Environmental Science and Technology, Vol. 35, No. 12, pp. 2548-2553.

Lecompte, J.G.N. 1987. The Influence of Natural Convection in an Insulated Cavity on the Thermal Performance of a Wall. Insulation Materials testing and Applications, ASTM. 
Lee, K., Vallarino, J., Dumyahn, T., Ozkaynak, H., and SPengler, J.D. 1999. Ozone Decay rates in residences. Journal of Air Waste Management Association 49(10):1238-1244.

Lee, K., Parkhurst, W.J., Xue, J.P., Ozkaynak, A.H., Neuberg, D. and Spengler, J.D. 2004. “Outdoor/Indoor/personal ozone exposures of children in Nashville, Tenessee. J. Air Waste Management. 54(3):352-359.

Liu, D. and Nazaroff, W.W. 2001. Modeling Pollutant Penetration across Building Envelopes. Atmospheric Environment, Vol. 35, pp. 4451-4462. Elsevier.

Lstiburek, J., Petit, B. and Rudd, A. 2007. Whole House Ventilation System Options - Phase 1 Simulation Study. ARTI Report No. 30090-01. Air Conditioning and Refrigeration Technology Institute, Arlington, VA.

Morrison, G.C., W.W. Nazaroff, J. Alejandro Cano-Ruiz, A.T. Hodgson and M.P. Modera, 1998. Indoor air quality impacts of ventilation ducts: Ozone removal and emissions of volatile organic compounds, J. Air and Waste Manage. Assoc., 48, 941-952.

Morrison, G.C., Nazaroff, W.W., 2000. The rate of ozone uptake on carpets: Experimental studies, Environmental Science \& Technology 34, 4963-4968.

Morrison, G.C., Nazaroff, W.W., 2002. Ozone interactions with carpet: Secondary emissions of aldehydes, Environmental Science \& Technology 36, 2185-2192.

Morrison, G.C., 2008. Interfacial chemistry in indoor environments. Environmental Science $\mathcal{E}$ Technology 42, 3495-3499.

Mueller, F.X., Loeb, L., Mapes, W.H., 1973. Decomposition rates of ozone in living areas, Environmental Science \& Technology 7, 342-346.

Reiss, R., Ryan, P.B., Koutrakis, P., 1994. Modeling ozone deposition onto indoor residential surfaces, Environmental Science \& Technology 28, 504-513.

Reiss, R., Ryan, P.B., Koutrakis, P. Tibbetts, S.J., 1995. Ozone reactive chemistry in interior latex paint, Environmental Science \& Technology 29, 1906-1912.

Romieu, I., M.C. Lugo, S. Colome, A.M. Garcia, M.H. Avila, A. Geyh, et al., Evaluation of indoor ozone concentration and predictors of indoor-outdoor ratio in Mexico City, J. Air and Waste Manage. Assoc. 48, 327-335, 1998.

Sabersky, R.H., Sinema, D.A., and Shair, F.H. 1973. Concentrations, decay rates, and removal of ozone and their relation to establishing clean indoor air. Environmental Science and Technology, Vol. 7, pp. 347-353.

Shair, F.H. 1981. Relating indoor pollutant concentrations of ozone and sulfur dioxide to those outside: Economic reduction of indoor ozone through selective filtration of the make-up air. ASHRAE Transactions, Vol. 87, part 1, pp. 116-139, ASHRAE, Atlanta, GA. 
Shaver, C.L., Cass, G.R., Druzik, J.R. 1983. Ozone and the deterioration of works of art. Environmental Science \& Technology, Vol. 17, pp. 748-752, American Chemical Society, Washington, DC.

Sherman M.H. and Grimsrud, D.T. 1980. Infiltration-Pressurization correlation: Simplified Physical Modeling. ASHRAE Transactions, Vol. 86, Pt. 2., p. 778, ASHRAE, Atlanta, GA.

Sherman, M.,1992. A Power-Law Formulation of Laminar Flow in Short Pipes". Journal of Fluids Engineering, Vol. 114, pp. 601-605. LBL-29414.

Sherman, M.H., 2006, Efficacy of Intermittent Ventilation for Providing Acceptable Indoor Air Quality, ASHRAE Trans. pp 93-101 Vol. 111 (I) 2006, LBL-

56292http://epb.lbl.gov/publications/lbnl-56292.pdf

Sherman, M.H. and Walker, I.S. 2008. Energy Impact of Residential Ventilation Standards in California. ASHRAE Transactions, June 2008. LBNL-61282. http://epb.lbl.gov/Publications/lbnl61282.pdf

Simmons, A. and Colbeck, I. 1990. Resistance of Various Building Materials to Ozone Deposition. Environmental Technology. Vol. 11, pp. 973-978.

Sippola, M.R. and Nazaroff, W.W. 2003. Modeling Particle Loss in Ventilation Ducts. Atmospheric Environment, Vol.37, Issues 39-40, December 2003, pp. 5597-5609. Elsevier. LBNL 52449.

Stock, T.H., Kotchmar, D.J., Contant, C.F., Bufflar, P.A., Holguin, A.H., Geham, B.M. et al. 2004. The estimation of personal exposures to air pollutants for a community-based study of health effects in asthmatics - design and results of air monitoring. J. of Air Pollution Control Association. 35(12):1266-1273.

Walker, I.S., Wilson, D.J., and Sherman, M.H., 1998, “A Comparison of the Power Law to Quadratic Formulations for Air Infiltration Calculations", Energy and Buildings, Vol. 27, No.3, pp. 293-299. Elsevier Science. LBNL 41447.

Walker, I.S. and Sherman, M.H. 2006. Evaluation of Existing Technologies for Meeting Residential Ventilation Requirements, LBNL 59998. Lawrence Berkeley National Laboratory, Berkeley, CA. and California Energy Commission, PIER Buildings End-Use Efficiency Program, CEC-500-2007-XXX.

Wang, H., Morrison, G.C., 2006. Ozone-initiated secondary emission rates of aldehydes from indoor surfaces in four homes, Environmental Science \& Technology 40, 5263-5268.

Weschler C.J., Wisthaler, A., Cowlin, S., Tamás, G., Strøm-Tejsen, P., Hodgson, A.T., Destaillats, H., Herrington, J., Zhang, J., Nazaroff, W.W., 2007. Ozone-initiated chemistry in an occupied simulated aircraft cabin, Environmental Science \& Technology 41, 6177-6184.

Weschler, C.J. 2000. Ozone in indoor environments: Concentration and Chemistry. Indoor Air, 10(4):269-288 
Weschler CJ, Shields HC, 2000. The influence of ventilation on reactions among indoor pollutants: Modeling and experimental observations. Indoor Air 10, 92-100.

Weschler, C.J., Shields, H.C., and Naik, 1989, Indoor Ozone Exposures, JAPLA, Vol. 39, pp. 1562-1568.

Zhao, P., Siegel, J. A. and Corsi, R. L. 2007. Ozone removal by HVAC filters. Atmospheric Environment, 41, 3151-3160. 


\subsection{Glossary}

\begin{tabular}{|l|l|}
\hline ACH & Air Changes per Hour \\
\hline ANSI & American National Standards Institute \\
\hline ASHRAE & American Society of Heating, Refrigerating and Airconditioning Engineers \\
\hline CARB & California Air Resources Board \\
\hline Cfm & cubic feet per minute \\
\hline CZ & Climate Zone \\
\hline HRV & Heat Recovery Ventilator \\
\hline HVAC & Heating, Ventilating and Air Conditioning \\
\hline I/O & Indoor/Outdoor \\
\hline ISDC & Interior Surface Deposition Coefficient \\
\hline LBNL & Lawrence Berkeley National Laboratory \\
\hline MERV & Minimum Efficiency Reporting Value \\
\hline Ppm & parts per million \\
\hline PVC & Poly Vinyl Chloride \\
\hline
\end{tabular}




\subsection{Ozone reactions with indoor materials: A bibliography}

1. Aoki T, Tanabe S, 2007. Generation of sub-micron particles and secondary pollutants from building materials by ozone reaction. Atmospheric Environment 41, 3139-3150.

2. Avol EL, Navidi WC, Colome SD, 1998. Modeling ozone levels in and around southern California homes, Environmental Science \& Technology 32, 463-468.

3. Cano-Ruiz JA, Kong D, Balas RB, Nazaroff WW, 1993, Removal of reactive gases at indoor surfaces: Combining mass-transport and surface kinetics. Atmospheric Environment 27A, 2039-2050.

4. Coleman BK, Destaillats H, Hodgson AT, Nazaroff WW, Ozone consumption and volatile byproduct formation from surface reactions with aircraft cabin materials and clothing fabrics. Atmospheric Environment (submitted).

5. Fick J, Nilsson C, Andersson B, 2004. Formation of oxidation products in a ventilation system. Atmospheric Environment 38, 5895-5899.

6. Grøntoft T, 2002. Dry deposition of ozone on building materials. Chamber measurements and modelling of the time-dependent deposition. Atmospheric Environment 36, 5661-5670.

7. Grøntoft T, 2004. Measurements and modelling of the ozone deposition velocity to concrete tiles, including the effect of diffusion. Atmospheric Environment 38, 49-58.

8. Grøntoft T, Henriksen JF, Seip HM, 2004. The humidity dependence of ozone deposition onto a variety of building surfaces. Atmospheric Environment 38, 59-68.

9. Grøntoft T, Raychaudhuri MR, 2004. Compilation of tables of surface deposition velocities for $\mathrm{O}_{3}, \mathrm{NO}_{2}$ and $\mathrm{SO}_{2}$ to a range of indoor surfaces, Atmospheric Environment 38, 533-544.

10. Hyttinen M, Pasanen N, Kalllokoski P, 2006. Removal of ozone on clean, dusty and sooty supply air filters. Atmospheric Environment 40, 315-325.

11. Hyttinen M, Pasanen P, Salo J, et al., 2003. Reactions of ozone on ventilation filters. Indoor + Built Environment 12, 151-158.

12. Klenø JG, Clausen PA, Weschler CJ, Wolkoff P, 2001. Determination of ozone removal rates by selected building products using the FLEC emission cell. Environmental Science \& Technology 35, 2548-2553.

13. Knudsen HN, Nielsen PA, Clausen PA, et al., 2003. Sensory evaluation of emissions from selected building products exposed to ozone. Indoor Air 13, 223-231.

14. Lee K, Vallarino J, Dumyahn T, et al., 1999. Ozone decay rates in residences. Journal of the Air \& Waste Management Association 49, 1238-1244.

15. Liu DL, Nazaroff WW, 2001. Modeling pollutant penetration across building envelopes. Atmospheric Environment 35, 4451-4462.

16. Moriske HJ, Ebert G, Konieczny L, et al., 1998. Concentrations and decay rates of ozone in indoor air in dependence on building and surface materials. Toxicology Letters 96-7, 319323.

17. Morrison GC, Nazaroff WW, 2000. The rate of ozone uptake on carpets: Experimental studies. Environmental Science \& Technology 34, 4963-4968.

18. Morrison GC, Nazaroff WW, 2002. The rate of ozone uptake on carpet: mathematical modeling. Atmospheric Environment 36, 1749-1756. 
19. Morrison GC, Nazaroff WW, Cano-Ruiz JA, Hodgson AT, Modera MP, 1998. Indoor air quality impacts of ventilation ducts: Ozone removal and emissions of volatile organic compounds. Journal of the Air and Waste Management Association 48, 941-952.

20. Mueller FX, Loeb L, Mapes WH, 1973. Decomposition rates of ozone in living areas. Environmental Science \& Technology 7, 342-346.

21. Nicolas M, Ramalho O, Maupetit F, 2007. Reactions between ozone and building products: Impact on primary and secondary emissions. Atmospheric Environment 41, 3129-3138.

22. Poppendieck D, Hubbard H, Ward M, et al., 2007. Ozone reactions with indoor materials during building disinfection. Atmospheric Environment 41, 3166-3176.

23. Reiss R, Ryan PB, Koutrakis P, 1994. Modeling ozone deposition onto indoor residential surfaces. Environmental Science \& Technology 28, 504-513, 1994.

24. Reiss R, Ryan PB, Koutrakis P, et al., 1995. Ozone reactive chemistry on interior latex paint. Environmental Science \& Technology 29, 1906-1912.

25. Sabersky RH, Sinema DA, Shair FH, 1973. Concentrations, decay rates, and removal of ozone and their relation to establishing clean indoor air. Environmental Science \& Technology 7, 347-353.

26. Shair FH, Heitner KL, 1974. Theoretical model for relating indoor pollutant concentrations to those outside. Environmental Science \& Technology 8, 444-451.

27. Simmons A, Colbeck I, 1990. Resistance of various building materials to ozone deposition. Environmental Technology 11, 973-978.

28. Stephens S, Rossi MJ, Golden DM, 1986. The heterogeneous reaction of ozone on carbonaceous surfaces. International Journal of Chemical Kinetics 18, 1133-1149.

29. Tamas G, Weschler CJ, Bako-Biro Z, et al., 2006. Factors affecting ozone removal rates in a simulated aircraft cabin environment. Atmospheric Environment 40, 6122-6133.

30. Wang H, Morrison GC, 2006. Ozone-initiated secondary emission rates of aldehydes from indoor surfaces in four homes. Environmental Science \& Technology 40, 5263-5268.

31. Weschler CJ, 1992. Indoor chemistry - Ozone, volatile organic compounds, and carpets. Environmental Science \& Technology 26, 2371-2377.

32. Weschler CJ, 2000. Ozone in indoor environments: Concentration and chemistry. Indoor Air 10, 269-288.

33. Weschler CJ, 2004. Chemical reactions among indoor pollutants: what we've learned in the new millennium. Indoor Air 14 (Suppl. 7), 184-194.

34. Weschler CJ, 2004. New directions: Ozone-initiated reaction products indoors may be more harmful than ozone itself. Atmospheric Environment 38, 5715-5716.

35. Weschler CJ, 2006. Ozone's impact on public health: Contributions from indoor exposures to ozone and products of ozone-initiated chemistry. Environmental Health Perspectives 114, 1489-1496.

36. Weschler CJ, Shields HC, 2000. The influence of ventilation on reactions among indoor pollutants: Modeling and experimental observations. Indoor Air 10, 92-100.

37. Zhang JF, Lioy PJ, 1994. Ozone in residential air - Concentrations, I/O ratios, indoor chemistry, and exposures. Indoor Air 4, 95-105.

38. Zhang JF, Wilson WE, Lioy PJ, 1994. Indoor air chemistry - Formation of organic acids and aldehydes. Environmental Science \& Technology 28, 1975-1982.

39. Zhao P, Siegel JA, Corsi RL, 2007. Ozone removal by HVAC filters. Atmospheric Environment 41, 3151-3160. 


\section{Appendix 1. Deposition Velocities from Grontoft (2004) - highlighted ext}

indicates material surfaces found in building envelopes.

Table 4

Air humidity-dependent surface deposition velocities of $\mathrm{O}_{3}$ to a range of material classes $\left(\mathrm{cm} \mathrm{s}^{-1}\right)$

\begin{tabular}{|c|c|c|c|c|c|c|}
\hline \multirow[t]{2}{*}{ No. } & \multirow[t]{2}{*}{ Material classes } & \multicolumn{5}{|c|}{ Air humidity $(\%)$} \\
\hline & & 0 & 30 & 50 & 70 & 90 \\
\hline 1 & Glass & $\sigma^{a}$ & $0.00010^{\mathrm{a}}$ & $0.00015^{\mathrm{a}}$ & $0.00020^{2}$ & $0.00025^{\mathrm{a}}$ \\
\hline 2 & Hard dense stone materiak-alkaline (marble) & $\sigma^{2}$ & $0.00010^{2}$ & $0.00015^{2}$ & $0.00020^{2}$ & $0.027^{a}$ \\
\hline 3 & $\begin{array}{l}\text { Hard dense stone materiak-acidic (e.g. } \\
\text { granite, slate) }\end{array}$ & $0^{-2}$ & $0.00010^{-2}$ & $0.00015^{-2}$ & $0.00020^{-2}$ & $0.027^{-2}$ \\
\hline 4 & $\begin{array}{l}\text { Softer less dense (porous) stone materials- } \\
\text { alkaline (e.g. limestone, calcareous sandstone) }\end{array}$ & $0.11^{2}$ & $0.076^{2}$ & $0.071^{2}$ & $0.068^{a}$ & $0.070^{2}$ \\
\hline 5 & $\begin{array}{l}\text { Softer less dense (porous) stone materials- } \\
\text { acidic (e.g. silicate sandstone) }\end{array}$ & $0.11^{-4}$ & $0.076^{-4}$ & $0.071^{-4}$ & $0.068^{-4}$ & $0.070^{-4}$ \\
\hline 6 & Course concrete & $0.10^{2}$ & $0.077^{2}$ & $0.080^{2}$ & $0.068^{2}$ & $0.063^{2}$ \\
\hline 7 & Fine concrete & $0.062^{a}$ & $0.043^{a}$ & $0.017^{2}$ & $0.019^{2}$ & $0.037^{2}$ \\
\hline 8 & Brick & $0.12^{\mathrm{A} \%}$ & $0.12^{\mathrm{A} \%}$ & $0.12^{2.5 \times 6,7}$ & $0.135^{\mathrm{A} \%}$ & $0.15^{\mathrm{A} \%}$ \\
\hline 9 & Untreated woodwork - fine, hard, aged & $0.0023^{\% 10}$ & $0.0026^{\% 10}$ & $0.0050^{b}$ & $0.0087^{\% 10}$ & $0.020 \% 10$ \\
\hline 10 & Untreated woodwork-course, soft, fresh & $0.010^{2}$ & $0.012^{2}$ & $0.022^{2}$ & $0.039^{2}$ & $0.089^{2}$ \\
\hline 11 & $\begin{array}{l}\text { Surface treated wood work and wall boards } \\
\text { (oiled, lacquered, varnished, painted etc.) }\end{array}$ & $0.0025^{\% 10}$ & $0.0028 \% 10$ & $0.0055^{\mathrm{cl}}$ & $0.010^{\% 10}$ & $0.022 \% 10$ \\
\hline 12 & $\begin{array}{l}\text { Gypsum wall board, surface treated (lacquered, } \\
\text { varnished, painted, etc.) }\end{array}$ & $0.017^{\% 10}$ & $0.019^{\% 10}$ & $0.036^{\mathrm{c} 3}$ & $0.063^{\% 10}$ & $0.14^{\% 10}$ \\
\hline 13 & Gypsum wall board, untreated & $0.12^{-15}$ & $0.12^{-15}$ & $0.12^{-15}$ & $0.135^{-15}$ & $0.15^{-15}$ \\
\hline 14 & Metal (with and without surface treatment) & $0.00063^{4}$ & $0.00070^{4}$ & $0.0014^{4}$ & $0.0024^{4}$ & $0.0054^{4}$ \\
\hline 15 & $\begin{array}{l}\text { Course composite panels (tree wool, stone wool } \\
\text { etc.-could be textile covered) }\end{array}$ & $0.12 \% \mathrm{~A}$ & $0.12 \% \mathrm{~A}$ & $0.12^{\mathrm{a}}$ & $0.14^{\% / A}$ & $0.15^{\% \mathrm{~A}}$ \\
\hline 16 & Wool carpet & $0.051^{\mathrm{a}}$ & $0.062^{a}$ & $0.073^{2}$ & $0.10^{a}$ & $0.13^{\mathrm{a}}$ \\
\hline 17 & Synthetic carpet & $0.057^{\% 17}$ & $0.069^{\% 17}$ & $0.081^{2 c c}$ & $0.113^{\% 17}$ & $0.145^{\% 17}$ \\
\hline 18 & Synthetic floor covering-medium worn & $0.0026 \% 10$ & $0.0029^{\% 10}$ & $0.0056^{\mathrm{c} 2}$ & $0.010^{\% 10}$ & $0.022 \% 10$ \\
\hline 19 & Wall paper & $0.051^{2, e}$ & $0.058^{a, e}$ & $0.068^{2 . e}$ & $0.080^{2, e}$ & $0.10^{2, e}$ \\
\hline 20 & Cloth $<1$ year old & $0.051^{\% 16}$ & $0.062^{\% 16}$ & $0.073^{\mathrm{b}}$ & $0.10^{\% 16}$ & $0.13^{\% 16}$ \\
\hline 21 & Cloth $>1$ year old & $0.0044^{\% 16}$ & $0.0054^{\% 16}$ & $0.0063^{b}$ & $0.0088^{\% 16}$ & $0.011^{\% 16}$ \\
\hline 22 & Plaster & $0.086^{4,7}$ & $0.060^{4,7}$ & $0.044^{4,7}$ & $0.044^{4,7}$ & $0.054^{4,7}$ \\
\hline 23 & Paintings & $0.055^{\% \mathrm{~A}}$ & $0.068^{2.2}$ & $0.086^{2.9}$ & $0.083^{2, a}$ & $0.090^{\% A}$ \\
\hline 24 & Activated carbon cloth & $0.155^{2}$ & $0.16^{\mathrm{a}}$ & $0.16^{\mathrm{a}}$ & $0.17^{2}$ & $0.17^{2}$ \\
\hline
\end{tabular}

${ }^{2}$ Experimental measurement values from this work.

${ }^{2, a}$ Mean of experimental measurement values from this work on oil painting on canvas and tempera painting on cardboard.

a,c Mean of experimental measurement values for polypropylene and polyamide carpets from this work and value for latex backed nylon fibre carpet from [10]Kleng et al. (2001).

${ }^{2,-e}$ Mean of experimental measurement values for wallpaper from this work and from Reiss et al. (1994).

${ }^{b}$ Value for aged plywood and mean of cloth values from Sabersky (1973).

${ }^{\mathrm{c}}$ Mean value for oiled woodwork from [10]Klenø et al. (2001)

${ }^{\mathrm{c} 2}$ Value for linoleum from [10]Kkne et al. (2001). Mean value of two samples one older than 12 months and the other older than 10 years.

${ }^{23}$ Mean value from two painted gypsum wallboards (Tabk 1a) from [10]Klena et al. (2001).

${ }^{4}$ Values for aluminium from Cox and Pankett (1972).

${ }^{4,7}$ Mean of values of material no. 4 and 7.

${ }^{2.5 * 6,7}$ Value set equal to 2.5 time the value of materials no. 6 and 7 . The $\mathrm{O}_{3}$ deposition velocity measured on bricks by Simons and Colbeck (1990) was 2.5 times higher than that measured on concrete. The actual values of Simons and Colbeck are however generally higher than those measured by other researchers.

" Set equal to material no. \#.

$\%$ Adjusted to humidity dependence of material no. \#.

\%A Assumed humidity dependence from general dependence of other materiak. 